\title{
Application of a reflective optical probe to measure solids fractions in a circulating fluidized bed
}

\author{
Steven M. Seachman \\ West Virginia University
}

Follow this and additional works at: https://researchrepository.wvu.edu/etd

\section{Recommended Citation}

Seachman, Steven M., "Application of a reflective optical probe to measure solids fractions in a circulating fluidized bed" (2007). Graduate Theses, Dissertations, and Problem Reports. 1809.

https://researchrepository.wvu.edu/etd/1809

This Thesis is protected by copyright and/or related rights. It has been brought to you by the The Research Repository @ WVU with permission from the rights-holder(s). You are free to use this Thesis in any way that is permitted by the copyright and related rights legislation that applies to your use. For other uses you must obtain permission from the rights-holder(s) directly, unless additional rights are indicated by a Creative Commons license in the record and/ or on the work itself. This Thesis has been accepted for inclusion in WVU Graduate Theses, Dissertations, and Problem Reports collection by an authorized administrator of The Research Repository @ WVU. For more information, please contact researchrepository@mail.wvu.edu. 


\title{
Application of A Reflective Optical Probe to Measure Solids Fractions in a Circulating Fluidized Bed
}

\author{
Steven M. Seachman \\ Thesis Submitted to the \\ College of Engineering and Mineral Resources \\ At West Virginia University \\ In partial fulfillment of the requirements \\ For the degree of \\ Master of Science \\ In \\ Mechanical Engineering
}

Dr. Gary Morris

Dr. Paul Yue

Dr. John Kuhlman

Department of Mechanical and Aerospace Engineering

Morgantown, WV

2007

Keywords: Fluidized Bed, Reflective Fiber Optic Probe, Solids Volume Fraction,

Beer-Lambert 


\title{
ABSTRACT \\ Application of A Reflective Optical Probe to Measure Solids Fractions in a Circulating Fluidized Bed
}

\author{
Steven M. Seachman
}

\begin{abstract}
A novel method of extracting localized solids volume fractions from reflective multi-fiber optical probes was developed. The fiber optic probes were originally designed by Vector Scientific, Inc. to measure local solids velocities. The probe measures reflected light from a particle medium which is converted into a voltage. Development of this new method yields two valuable solid flow parameters from a single probe system. The method involves a formulated model with empirical calibrations and three physical bases. The three physical bases are the Conservation Law, Beer-Lambert's Law, and the reflected light intensity from the particle medium. A novel bed depth calibration procedure is used to find the reflected light contribution from each layer of particles. This calibration is used to find the fixed fraction, $\mathrm{k}_{1}$, of scattered light detected by the probe, and the factor, $\mathrm{k}_{2}$, to convert number concentration into a solids volume fraction. The layer-by-layer analysis of the solids fraction avoids the need to directly address the effects of beam divergence and multiple scattering.

The probes were used to measure the solids volume fractions and velocities inside the riser of a cold-flow Circulating Fluidized Bed (CFB) operating under several different flow conditions. These experiments were performed with two different batches of glass spheres, with average particle diameters of $64 \mu \mathrm{m}$ and $180 \mu \mathrm{m}$, respectively. The solids fraction measurement method was compared with other solids fraction measurement methods. The fiber optic probe method compared well with other methods including solids sampling and pressure drop measurements, with the exception of near wall measurements using a solids sampling probe. The fiber optic probe gave solids fractions varying from $1.0 \%$ to $3.1 \%$ near the center and $7.7 \%$ and $21.1 \%$ at the wall of the riser of the CFB, which is consistent with other solids fraction measurement methods.

The fiber optic probe was used to make measurements at different angular positions near the solids inlet, in the fully developed region, and near the solids outlet of the CFB riser. The method developed allowed calculation of the solids fraction distribution at these locations. Statistical analyses were performed in order to determine if the velocities or solids fractions were azimuthally dependent. It was found that the angular dependency of solids velocity and solids fractions is functions of elevation and flow conditions.
\end{abstract}




\section{Table of Contents}

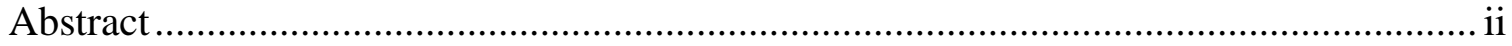

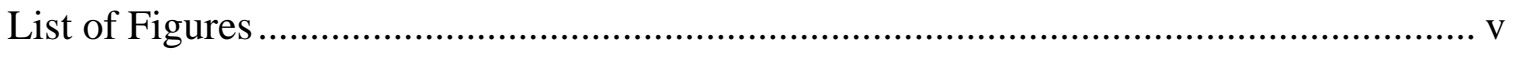

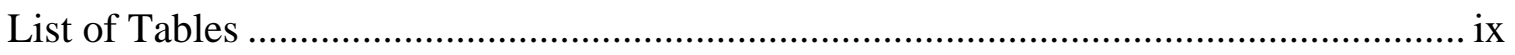

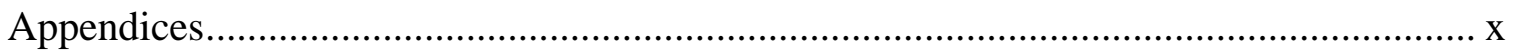

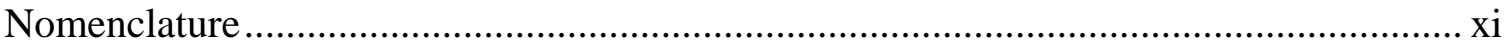

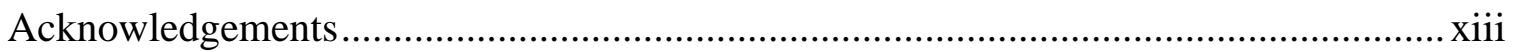

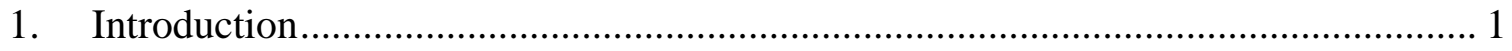

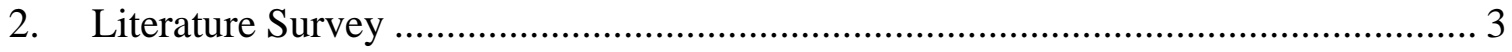

2.1 Solids Concentration Measurement Methods ................................................. 3

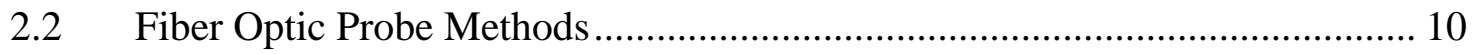

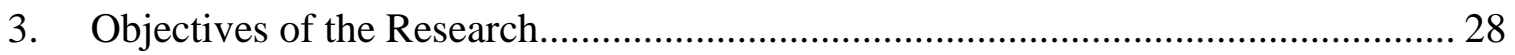

4. Components and Basic Operation of Reflective Fiber Optic Probe ....................... 29

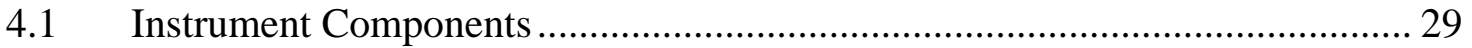

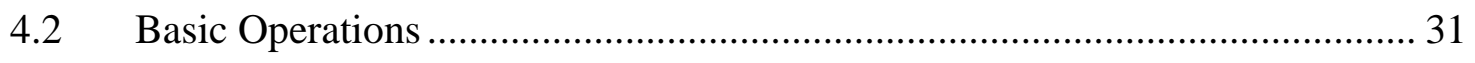

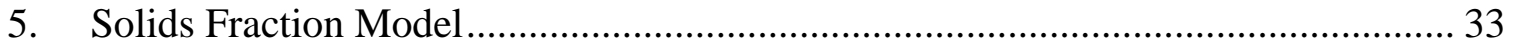

5.1 Light and Concentration Theory ............................................................ 33

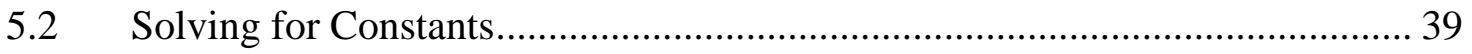

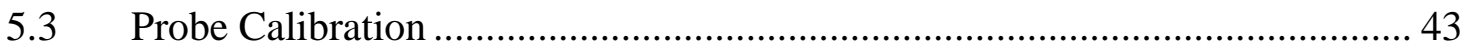

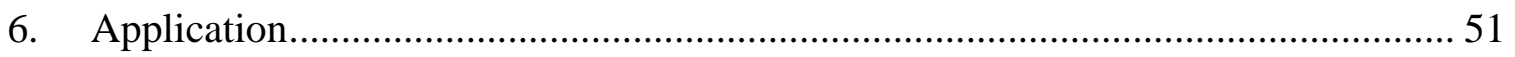

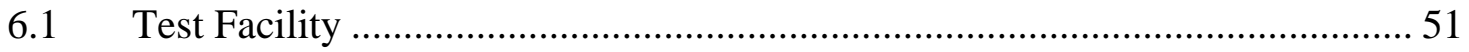

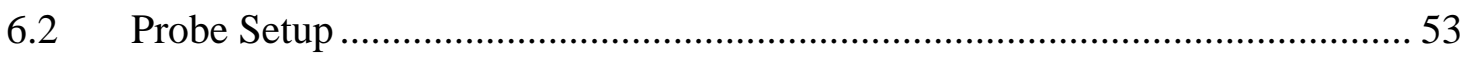




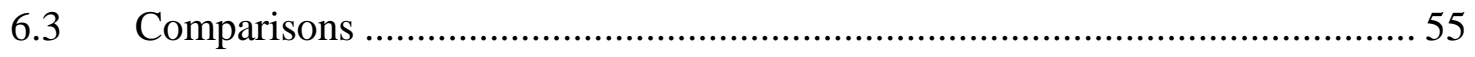

6.4 Azimuthal Dependency....................................................................... 56

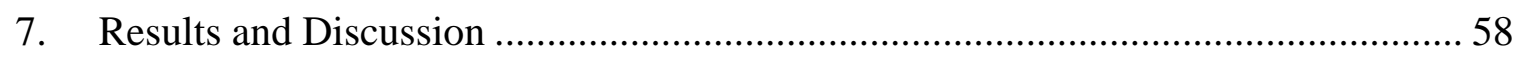

7.1 Fiber Optic Probe Calibration ................................................................ 58

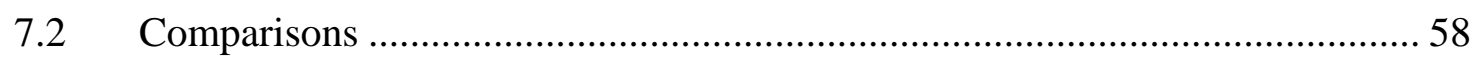

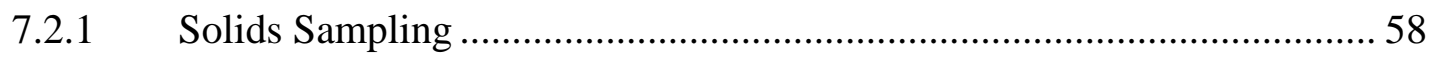

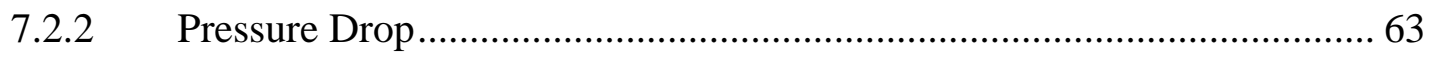

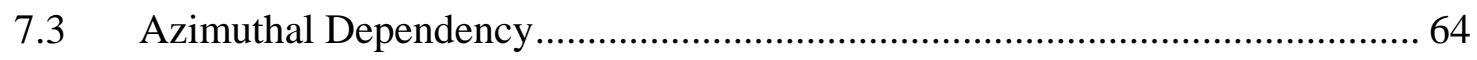

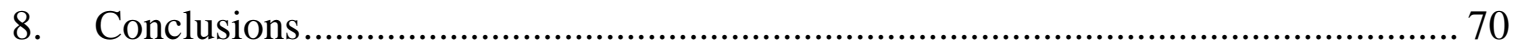

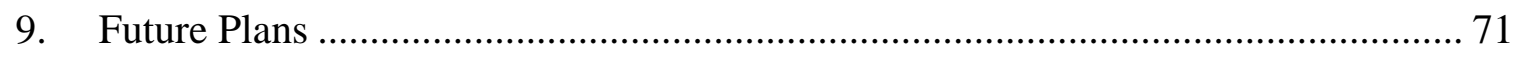

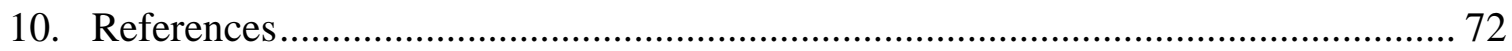




\section{List of Figures}

Figure 2.1 - Downer setup from Zhang et al. [5] (redrawn) .......................................... 4

Figure 2.2 - Diagram of ECT system by Du et al. [7] ................................................ 6

Figure 2.3 - Radial distribution of the time-averaged solids concentrations measured by the ECT and optical fiber probe from Du et al. [7] ................................... 7

Figure 2.4 - X-Ray Densitometer from Miller and Gidaspow [10] (redrawn) .................. 8

Figure 2.5 - Optical Probe Used by Morooka et al. [8] (redrawn)................................... 10

Figure 2.6 - Fiber optic Probe from Matsuno et al.; 1. Stainless Steel Pipe, 2. Clad, 3.

Core, 4. Silicone compound [16] (redrawn) .......................................... 12

Figure 2.7 - Fiber optic Probe Used by Hartge et al. (1. probe, 2. optical fibers, 3. photo diode, 4. beam splitter, 5. laser, 6. steel capillary) [17] (redrawn) .............. 12

Figure 2.8 - Solids Fraction Radial Profile from Horio et al. [19] (redrawn).................. 13

Figure 2.9 - Fiber optic probes used to measure A) Particle Velocities and B) Solids Concentrations by Horio et al. [19] (redrawn)...........................................14

Figure 2.10 -Optical Probe Design used by Nowak et al. [20] (redrawn) ........................ 15

Figure 2.11 - Different fiber bundles tested by Reh and Li [21] (redrawn)..................... 16

Figure 2.12 - Optical Probe used by Rensner and Werther [9] (1. Transmitting Fiber, 2. Probe Fiber, 3. Receiving Fiber).......................................................... 17

Figure 2.13 - Fiber optic Probe and Calibration setup used by Lischer and Louge [22].. 19

Figure 2.14 - Fiber optic probe used by Nieuwland et al. [12] (redrawn) ....................... 21

Figure 2.15 - Local solids concentrations as a function of dimensionless radial position at $1.8 \mathrm{~m}$ above the solids distributor for four solids mass fluxes; $\mathrm{u}^{0}=10 \mathrm{~m} / \mathrm{s}$

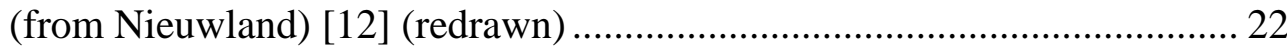

Figure 2.16 - Local solids concentrations as a function of dimensionless radial position at $1.8 \mathrm{~m}$ above the solids distributor for three superficial gas velocities; $\mathrm{G}_{\mathrm{s}}=$ $300 \mathrm{~kg} / \mathrm{m}^{2} \mathrm{~s}$ (from Nieuwland) [12] (redrawn)..... 
Figure 2.17 - High Temperature Fiber optic Probe used by Johnsson and Johnsson [23] (redrawn)

Figure 2.18 - Cross Fiber Probe Used by Rundqvist et al. [24]......................................... 25

Figure 2.19 - Basic Probe Setup used by Samuel et al. [25] (redrawn)............................. 26

Figure 2.20 - Comparison of radial solids holdup profile of the twin riser system at $\mathrm{Z}=$ $5.84 \mathrm{~m}$ (from Yan et al.) ([13]) ................................................................. 27

Figure 4.1 - Picture of Probe Tip ............................................................................... 29

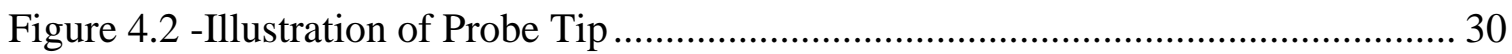

Figure 4.3 -Basic Fiber Optic Probe Setup [27] (redrawn)................................................ 31

Figure 5.1 - Interaction of Light with a Particle Medium.................................................... 33

Figure 5.2 - Model of Layer-by-Layer Light Intensity Measurement ............................... 36

Figure 5.3 - Particle Layer Contribution to Total Reflected Intensity............................... 39

Figure 5.4 - Particle Diameter Distribution for Smaller Glass Beads ................................. 40

Figure 5.5 - Particle Diameter Distribution for Larger Glass Beads.................................. 41

Figure 5.6 - Q values for different values of beta [31] (redrawn) ................................... 42

Figure 5.7 - Bed Depth Experimental Setup ....................................................................... 44

Figure 5.8 - Bed Depth Measurement for 64 m Glass Beads .......................................... 44

Figure 5.9 - Glass Bead Void Fractions, $180 \mu$ m Glass Beads............................................ 46

Figure 5.10 - Interpolated Values Compared with Calculated Values of the Probe signal from bed depth experiment, $64 \mu \mathrm{m}$ glass beads.............................................. 47

Figure 5.11 - Bed Depth Measurement for $180 \mu \mathrm{m}$ Glass Beads ....................................... 48

Figure 5.12 - Interpolated Values Compared with Calculated Values of the Probe's signal from bed depth experiment, $180 \mu \mathrm{m}$ glass beads (VSI2000). ...................... 49

Figure 5.13 - Interpolated Values Compared with Calculated Values of the Probe's signal from bed depth experiment, $180 \mu \mathrm{m}$ glass beads (Vector-S). ...................... 50

Figure 6.1 - CFB System and Probe Locations............................................................... 52 
Figure 6.2 - Riser Azimuthal Orientation

Figure 7.1 - Solids Fraction comparison at Low Ug, Low Ms Condition along the riser radius

Figure 7.2 - Solids Fraction Comparison at Low Ug, High Ms Condition along the riser radius

Figure 7.3 - Solids Fraction Comparison at "Centerpoint" Condition along the riser radius

Figure 7.4 - Solids Fraction Comparison at High Ug, Low Ms Condition along the riser radius

Figure 7.5 - Solids Fraction Comparison at High Ug, High Ms Condition along the riser radius

Figure 7.6 - Solids Fraction Comparisons at Different Load Ratios by three methods.... 64

Figure A3. 1 - Ug = 5.17 m/s, Ms = 5,400 kg/hr, 1.3 m elevation .............................. 86

Figure A3. 2 - Ug = 5.17 m/s, Ms = 33,500 kg/hr, $1.3 \mathrm{~m}$ elevation .......................... 87

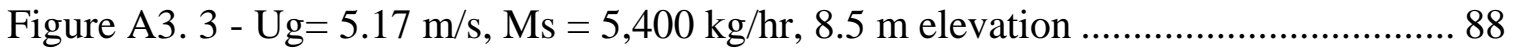

Figure A3. $4-\mathrm{Ug}=5.17 \mathrm{~m} / \mathrm{s}, \mathrm{Ms}=33,500 \mathrm{~kg} / \mathrm{hr}, 8.5 \mathrm{~m}$ elevation............................ 88

Figure A3. 5 - Ug = 5.5 m/s, Ms = 79,400 kg/hr, 0.7 m elevation ............................ 89

Figure A3. 6 - Ug = 7.6 m/s, Ms = 79,400 kg/hr, $0.7 \mathrm{~m}$ elevation ............................ 90

Figure A3. 7 - Ug = $6.4 \mathrm{~m} / \mathrm{s}, \mathrm{Ms}=51,000 \mathrm{~kg} / \mathrm{hr}, 0.7 \mathrm{~m}$ elevation ............................ 90

Figure A3. 8 - Ug $=5.5 \mathrm{~m} / \mathrm{s}, \mathrm{Ms}=22,700 \mathrm{~kg} / \mathrm{hr}, 0.7 \mathrm{~m}$ elevation ............................. 91

Figure A3. 9 - Ug = 7.6 m/s, Ms = 22,700 kg/hr, 0.7 m elevation ............................. 91

Figure A3. $10-\mathrm{Ug}=5.5 \mathrm{~m} / \mathrm{s}, \mathrm{Ms}=79,400 \mathrm{~kg} / \mathrm{hr}, 8.5 \mathrm{~m}$ elevation ............................ 92

Figure A3. 11 - Ug = 7.6 m/s, Ms = 79,400 kg/hr, 8.5 m elevation ........................... 92

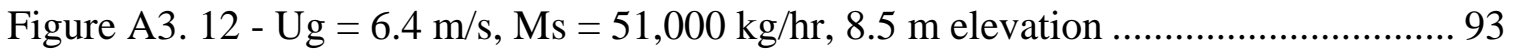

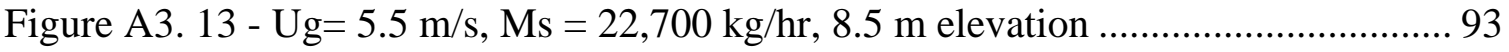


Figure A3. 14 - Ug = 7.6 m/s, Ms = 22,700 kg/hr, 8.5 m elevation ............................. 94

Figure A3. $15-\mathrm{Ug}=5.5 \mathrm{~m} / \mathrm{s}, \mathrm{Ms}=$ 79,400 kg/hr, $13 \mathrm{~m}$ elevation................................. 95

Figure A3. 16 -Ug = 7.6 m/s, Ms = 79,400 kg/hr, 13 m elevation .................................. 95

Figure A3. 17 - Ug = 6.4 m/s, Ms = 51,000 kg/hr, 13 m elevation ............................. 96

Figure A3. 18 - Ug = 7.6 m/s, Ms = 22,700 kg/hr, 13 m elevation ................................ 96

Figure A3. 19 - Ug = 7.6 m/s, Ms = 22,700 kg/hr, 13 m elevation ................................ 97 


\section{List of Tables}

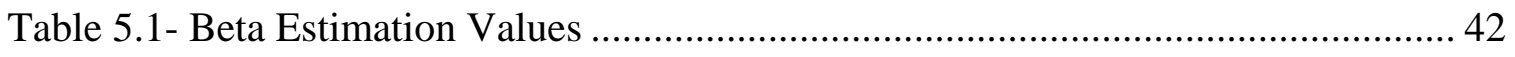

Table 6.1 - Sampling Rate Data for Fiber Optic Probe Systems .................................. 55

Table 7.1- ANOVA for 64-micron Particles, 1.3m level.............................................. 65

Table 7.2 - ANOVA for 64-micron Particles, 8.5 m level............................................. 66

Table 7.3 - ANOVA for 180-micron Particles, 0.7 m level........................................... 67

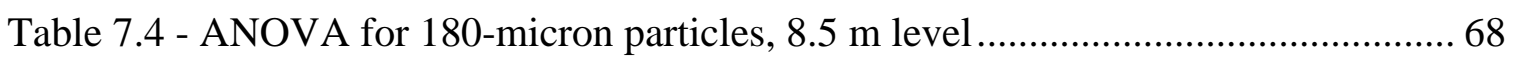

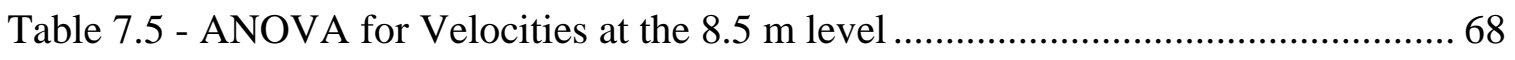

Table 7.6 - ANOVA for 180-micron Particles, 13 m level.......................................... 69

Table A1. 1- Solids Fraction Values From Centerpoint Condition, 8.5 m elevation, r/R =

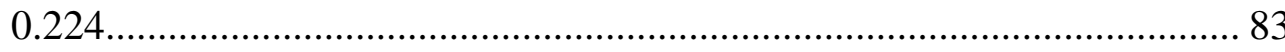

Table A1. 2 - Confidence Interval Values ................................................................. 83

Table A2. 1 - Solids Fraction Test Matrix for $64 \mu \mathrm{m}$ Glass Beads ................................. 84

Table A2. 2- Solids Fraction Test Matrix for $180 \mu \mathrm{m}$ Glass Beads ............................... 85 


\section{Appendices}

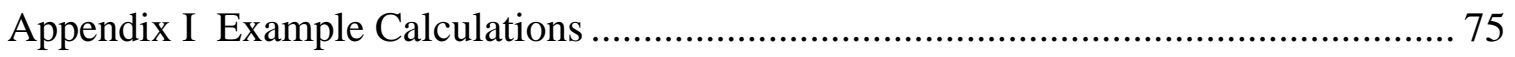

Appendix II Solids Fraction Test Matrices ............................................................. 84

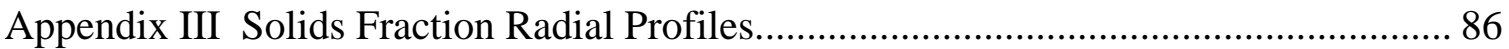




\section{Nomenclature}

\begin{tabular}{|c|c|}
\hline ANOVA & Analysis of Variance \\
\hline CFB & Circulating Fluidized Bed \\
\hline CI & Confidence Interval \\
\hline LED & Light-Emitting Diode \\
\hline SMA & Sub-Miniature version-A \\
\hline ST & Straight Tip \\
\hline VSI & Vector Scientific, Inc. \\
\hline$\alpha$ & size parameter \\
\hline$\beta$ & modified size parameter \\
\hline d & particle diameter, m \\
\hline$\Delta d$ & probe depth into packed bed, mm \\
\hline$\Delta \mathrm{L}$ & distance between pressure taps, m \\
\hline$\Delta \mathrm{P}$ & pressure drop across two taps, $\mathrm{Pa}$ \\
\hline $\mathrm{E}_{\max }$ & maximum allowed velocity error, m/s \\
\hline$\varepsilon$ & void fraction \\
\hline$(1-\varepsilon)$ & solids volume fraction \\
\hline$f$ & sampling frequency, $\mathrm{Hz}$ \\
\hline$i$ & one less the maximum particle layers summated \\
\hline $\mathrm{I}_{0}$ & maximum intensity measured by the photo cell, $\mathrm{V}$ \\
\hline
\end{tabular}




\begin{tabular}{|c|c|}
\hline $\mathrm{I}_{\mathrm{ext}}$ & light scattered, absorbed, or reflected, V \\
\hline $\mathrm{I}_{\mathrm{R}(1,2, \ldots .)}$ & light reflected from each particle layer, $\mathrm{V}$ \\
\hline $\mathrm{I}_{\mathrm{R}(\text { measured) }}$ & summation of light reflected back into the probe, $\mathrm{V}$ \\
\hline $\mathrm{I}_{\text {scatter }}$ & light scattered by particle, $\mathrm{V}$ \\
\hline $\mathrm{I}_{\mathrm{T}(1,2, \ldots)}$ & light transmitted through the particle, $\mathrm{V}$ \\
\hline $\mathrm{k}_{1}$ & fraction of $\mathrm{I}_{\text {ext }}$ that is detected by the probe \\
\hline $\mathrm{k}_{2}$ & conversion factor of number concentration to volume concentration \\
\hline$\ell$ & path length, mm \\
\hline$\lambda$ & wavelength of light, m \\
\hline $\mathrm{m}$ & index of refraction \\
\hline $\mathrm{M}_{\mathrm{s}}$ & solids circulation rate, $\mathrm{kg} / \mathrm{hr}$ \\
\hline $\mathrm{N}$ & number concentration, \#/cm ${ }^{3}$ \\
\hline Q & extinction coefficient \\
\hline $\mathrm{r} / \mathrm{R}$ & riser radial profile \\
\hline$\rho_{\text {glass }}$ & density of glass, $\mathrm{kg} / \mathrm{m}^{3}$ \\
\hline $\mathrm{Ug}_{\mathrm{g}}$ & superficial gas velocity, m/s \\
\hline $\mathrm{V}_{\mathrm{p}}$ & particle velocity, m/s \\
\hline
\end{tabular}




\section{Acknowledgements}

First and foremost, I must acknowledge the humble intelligence of my committee chair and lifelong friend, Dr. Gary Morris. His motivation, patience, intelligence, and teaching effectiveness throughout my academic endeavors are some of the many qualities that will be remembered always.

I would like to express my deepest gratitude to my mentor and committee member Dr. Paul Yue, who answered all questions and guided me down the right path. His wisdom and experience helped every step along the way. He was never too busy to answer questions, help out or keep me motivated. His patience and wisdom always made the process easier to handle. My thanks also go out to my other committee member Dr. John Kuhlman, for advising me through my undergraduate education.

I also want to convey my utmost appreciation to NETL employees that helped along the way. To Dr. J. Christopher Ludlow, Dr. Joseph Mei, Dr. Christopher Guenther, Dr. Ronald Breault, and Dr. James Spenik, whose ideas, assistance, and positive attitudes could never be forgotten.

My deepest thanks go out to my co-interns, David Casleton and Emily Taylor. Without David's computer programming knowledge, the large of amounts of acquired data would never have been processed. Without Emily's statistical knowledge, none of this data would have relevance, and I thank both of them sincerely.

Lastly, I wish to thank Dr. Larry Shadle for his financial support through my educational endeavors through the ORISE program, as well as his knowledge of Circulating Fluidized Beds. 


\section{Introduction}

Circulating Fluidized Beds (CFBs) have been used for many years in many applications such as coal power plants and metallurgy processes [1]. Different types of instrumentation have been used in order to attempt to characterize the different particle flow patterns and behaviors that occur within the CFB [5-26,28,32,35]. One of the common techniques for CFB particle flow characterization is the use of a reflective fiber optic probe [5,7-26].

Fiber optics can be traced back as early as 1790s when French inventor Claude Chappe created the semaphore telegraph [2]. In 1881, William Wheeler used the idea of piping light and optics to create a method to light multiple rooms of a building using a single light source [3].

Fiber optic probes have many advantageous qualities for measuring particle dynamics in CFBs. In comparison to other particle measuring devices, fiber optic probes are relatively inexpensive and easy to fabricate. Additionally, most of these probes use thin-walled stainless steel as their housing, making them lightweight, durable, and relatively unobtrusive to the flow of the particles. They can acquire data at high sampling rates and resolutions. Fiber optic probes can also be used in hot and cold flow situations. Lastly, Fiber optic probes are not affected by pressure, temperature, humidity, or electromagnetic interference [4].

Localized particle measurements, such as solids velocities and solids volume fractions, inside a CFB riser are important for characterizing particle distribution inside the riser. Solids velocities and solids fractions have been measured using fiber optic 
probes in previous studies [5,7-26]. This particle distribution can be characterized by knowing the azimuthal dependency at solids inlet, outlet, and in the fully developed region.

The present study focuses on the development of a new method to extract solids volume fractions from measurement with an existing probe that was originally developed to measure solids velocity. Development of this method will make it possible to determine two important solids flow characteristics simultaneously with the same probe. These potential benefits provided the incentive for the current study.

Following the development of this method, the fiber optic probe was applied to CFB riser studies. This involved comparisons with more obtrusive and global measurement methods, as well as statistical analysis in order to determine repeatability. 


\section{Literature Survey}

\subsection{Solids Concentration Measurement Methods}

Solids fraction (or concentration) is the measurement of solid particles within a sampling volume. This is a unitless value that can be characterized by weight, volume, or number concentration. Several different techniques have been used to measure solids fractions inside flow systems such as CFBs. Solids fractions inside pipes have been measured using several different techniques. The following are some of the methods that have been developed.

Quick closing “slingshot” valves have been used as early as 1986. Arena et al. [6] installed an eight valve system on a $41 \mathrm{~mm}$ diameter and $6.4 \mathrm{~m}$ high fast fluidized experimental column. They used glass beads with a Sauter mean diameter of $88 \mu \mathrm{m}$ as their testing material. These valves were essentially solenoid valves that were mounted $0.8 \mathrm{~m}$ apart. These valves would close simultaneously to stop the flow of particles and the solids would collect inside each of the $0.8 \mathrm{~m}$ sections. Since the total solids inventory and the fluxes inside the column were known, the solids concentration inside each divided section was determined. The valves would shut off the flow in less than $0.1 \mathrm{~s}$, which caused a weight uncertainty of less than 5\%. In 1998, Zhang et al. [5] installed slingshot valves in a downer setup to calibrate a fiber optic probe for solids fraction measurements. The valves closed after 3 milliseconds (ms) of actuation and closed within $1 \mathrm{~ms}$ of each other. Their setup is illustrated in Figure 2.1. 


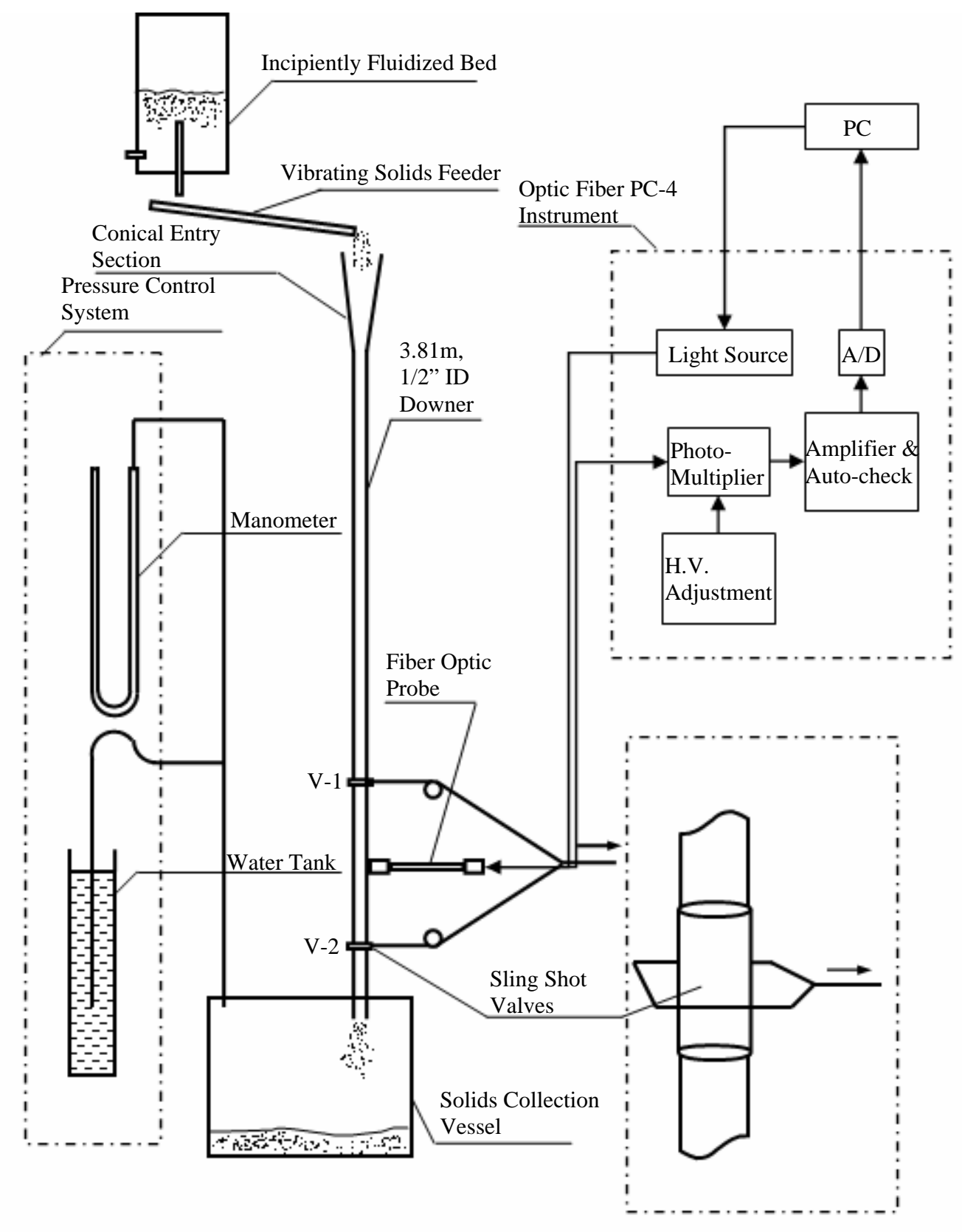

Figure 2.1 - Downer setup from Zhang et al. [5] (redrawn)

Given that these measurements are based on inventory, this method is very reliable. However, this method has to disrupt the flow of particles, in order to obtain the solids fraction. Additionally, the measurement can only determine the solids fraction for a fixed cross section, and does not measure local solids fractions. 
Solids fractions can also be determined by using a method known as electrical capacitance tomography (ECT). This method determines how an electric field is affected by dielectric media, such as concentration of particles. In 1980, Morooka [8] fabricated a capacitance probe to measure solids holdup $\left(\varepsilon_{\mathrm{s}}\right)$ in the freeboard of a $180 \mathrm{~cm}$ high and 12 cm i.d. fluidized bed using Fluid Cracking Catalyst (FCC) particles with a weight-mean diameter of 65-68 $\mu \mathrm{m}$ as their testing material. Their probe consisted of three $19 \mathrm{~mm}$ metal plates separated by $4 \mathrm{~mm}$. They concluded that the solids holdup changed with varying radial positions and gas velocities. This probe was limited to dilute particle flow conditions, and required a correction factor for solids holdup greater than 0.008 .

In 2005, Du et al. [7] used ECT to measure solids fractions inside fluidized beds of three different diameters and heights using FCC particles with a mean diameter of 60 $\mu \mathrm{m}$ as their test material. Their capacitance sensor consisted of a parallel plane sensor using 12 electrodes for each "plane". Guard sensors were placed above and below the measurement sensing planes to adjust the electrical field within the sensing area. An illustration of their system can be found in Figure 2.2. They used this method to determine if there was radial symmetry within the riser of their CFB and concluded that there was radial symmetry in the time averaged solids concentration located in the turbulent regime. Some solids concentration radial profiles from their study are shown in Figure 2.3. 


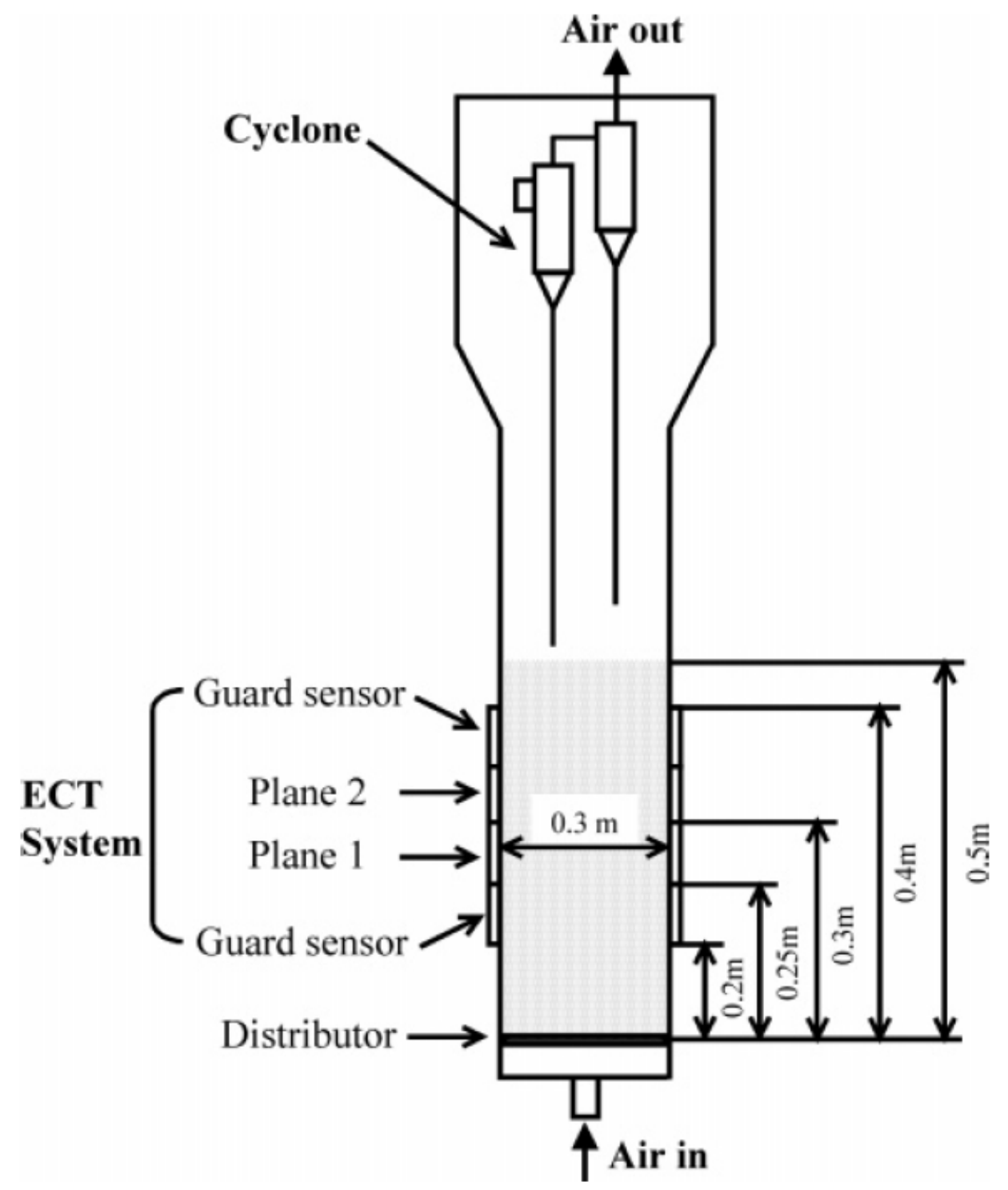

Figure 2.2 - Diagram of ECT system by Du et al. [7]

The resolution of a capacitance probe is dependent on the number of electrodes used in the system. Additionally, capacitance probes are highly sensitive to electrostatic charges on the particles, as well as high dependencies on humidity, as explained by Rensner and Werther [9] (1991). 


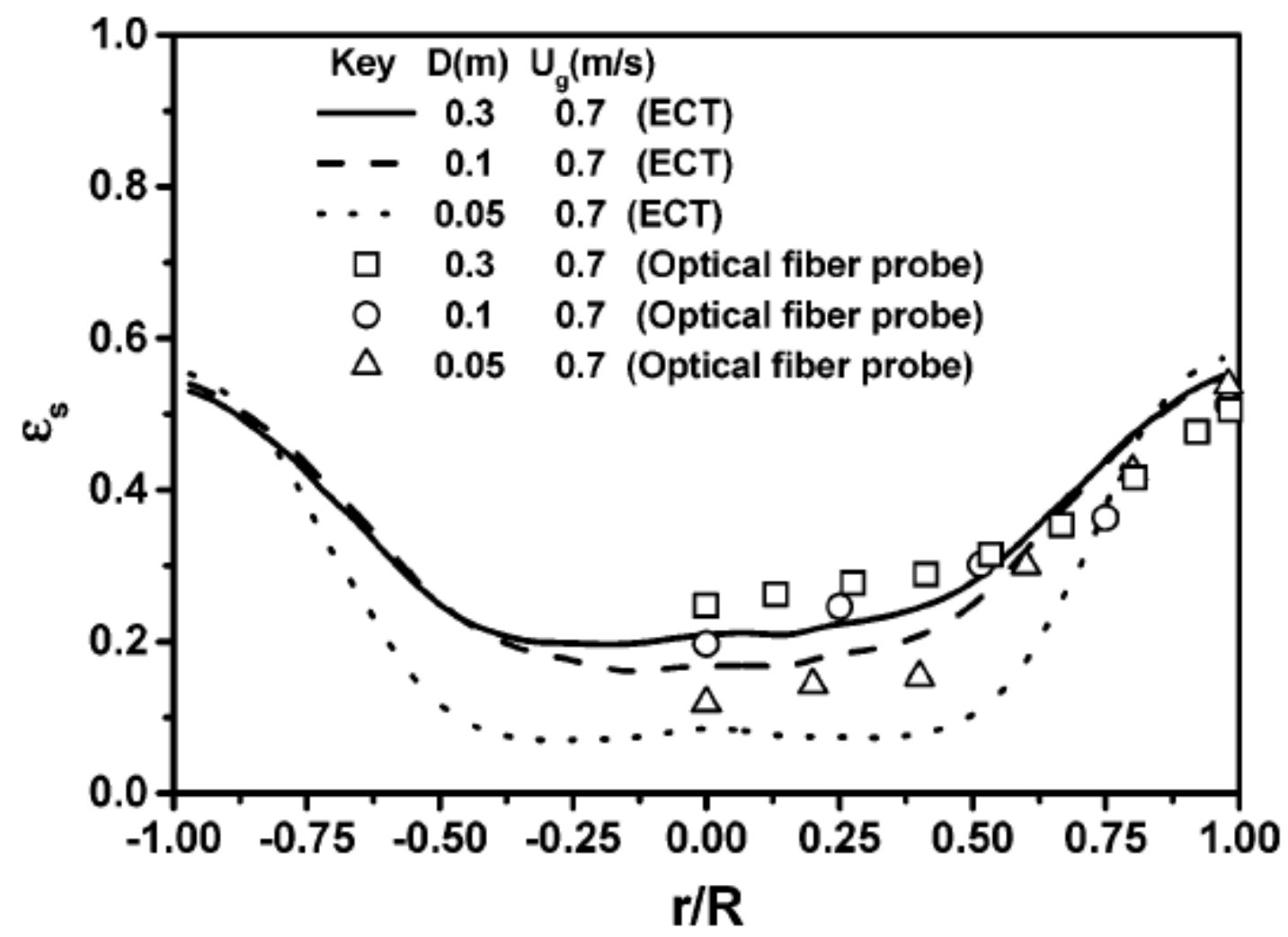

Figure 2.3 - Radial distribution of the time-averaged solids concentrations measured by the ECT and optical fiber probe from Du et al. [7]

In 1992, an X-ray Densitometer was developed by Miller and Gidaspow [10] to measure solids concentrations of FCC particles with a mean diameter of $75 \mu \mathrm{m}$ inside a $7.5 \mathrm{~cm}$ i.d. riser This measuring device used a 200-mCi Curium 244 as an X-ray source inside a 2.54-in diameter pipe. After the emitting photons travel through the volume of particles, the remaining radiation was absorbed by a thallium-activated sodium iodide scintillation detector. The problem involved with this method is that a receiver is required to be installed inside the pipe to detect the remaining radiation, which causes a significant amount of intrusion into the flow of particles. An illustration of this probe is found in Figure 2.4. 


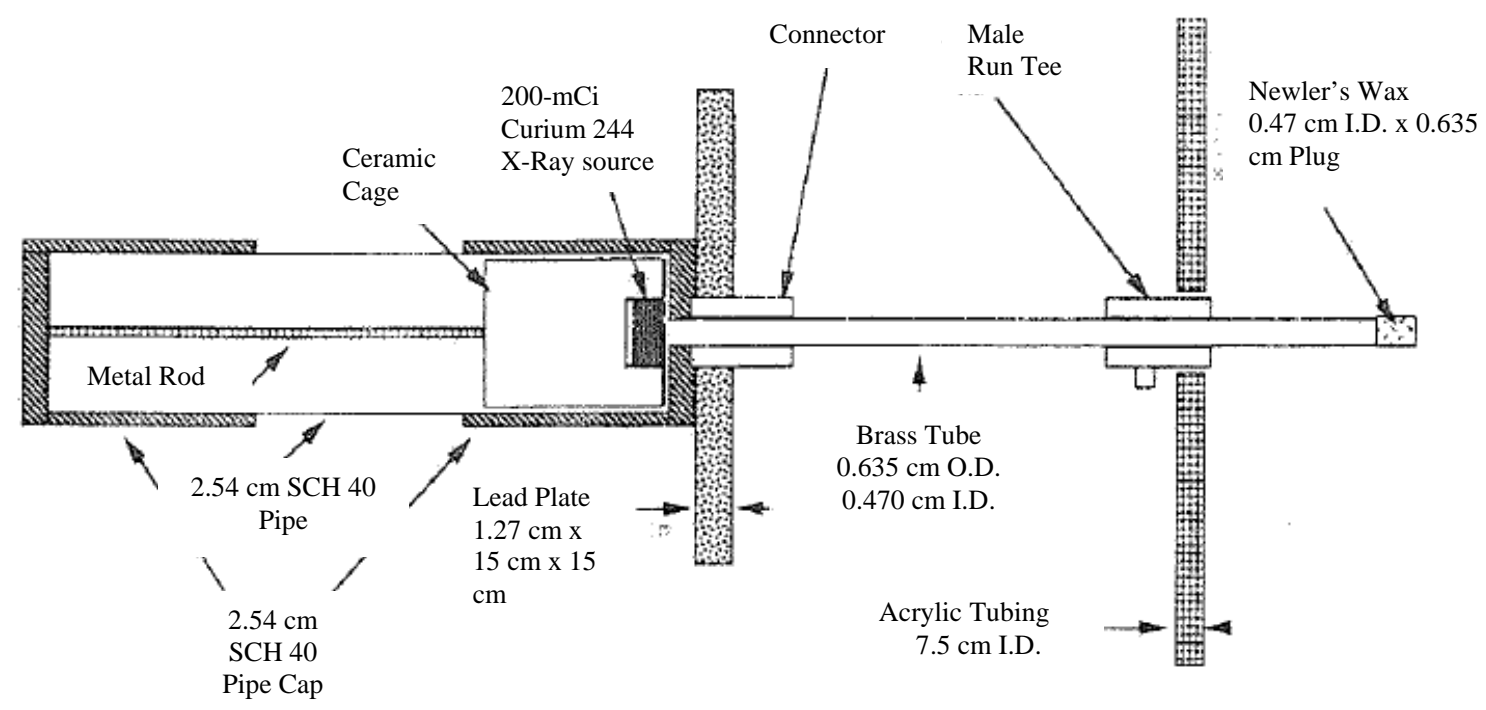

Figure 2.4 - X-Ray Densitometer from Miller and Gidaspow [10] (redrawn)

The use of pressure drops across the length of riser has been used by numerous researchers to measure solids volume fractions in CFB risers. It has also been used for calibrating other solids concentration methods. This method essentially uses the pressure drop across two pressure taps of known separation, and the Bernoulli equation neglecting wall friction, to solve for the solids fraction.

Nieuwland et al. [12] (1996) applied this method to calibrate a fiber optic probe for solids concentration measurements. Four experimentally determined pressure gradients were generated to correspond with four solids mass fluxes inside a CFB riser. This paper concluded that pressure drop measurements could both overestimate and underestimate the solids concentration. An underestimation of the solids concentration could occur when there is substantial particle downflow at the wall, resulting in large negative pressure drops. An overestimation could occur when the effects from wall friction dominate the acceleration of solids. 
Yan et al. [13] (2004) used eight pressure transducers in a pair of two $10 \mathrm{~m}$ high risers to measure and compare the axial solids holdup profile inside risers of different diameters. The paper concluded that axial solids holdup increases proportionally with riser diameter, but the shape of the profile does not change.

Magnusson et al. [11] (2005) used pressure drop measurements as a comparison to calculating solids fractions with a dual fiber optical probe. The pressure taps were positioned vertically above and below the fiber optic probe and measurements were taken at a rate of $5.12 \mathrm{kHz}$. The equation used to measure the solids concentration is given as:

$$
\Delta P=\alpha_{p}\left(\rho_{p}-\rho_{g}\right) g z+p_{a c c}
$$

where $\Delta P$ is the change in pressure across the two taps, $\alpha_{p}$ is the solids concentration, $\rho_{p}$ and $\rho_{g}$ are the solids and gas densities, $g$ is gravity, $z$ is the vertical distance between the two probes, and $p_{a c c}$ is the pressure due to acceleration which was neglected. The comparison between the values found with pressure drop measurements and the values found with their fiber optic probe measurements showed poor agreement. This could have been due to several factors such as the assuming $p_{a c c}$ was negligible. Moreover, solids fractions determined through pressure drops are averaged over a cross-section, whereas the fiber optic probe measure small, localized volumes.

In a previous attempt, solids fractions were determined through pressure drop measurements as a comparison for a reflective optical fiber probe used to measure solids fractions inside a cold flow CFB riser [14]. One conclusion in this paper was that the fiber optic probe followed the same trends as the solids fractions found by way of pressure drop measurements. However, the solids fractions obtained with the fiber optic probe were consistently higher than those found by way of pressure drops. This could 
have been due to friction at the wall of the CFB riser, as well as factors, such as multiple scattering and beam divergence, which were neglected.

\subsection{Fiber Optic Probe Methods}

Fiber optic probes and their methods for determining solids concentrations are the main focus of this study. There have been many types of probes and methods for extracting solids concentrations. The first method found for determining solids concentrations using a fiber optic probe was performed by Morooka et al. in 1980 [8]. They measured solids fractions in the freeboard of a $180 \mathrm{~cm}, 12 \mathrm{~cm}$ i.d. fluidized bed. They used fluid cracking catalyst (FCC) particles with a weight-mean diameter of 65-68 $\mu \mathrm{m}$ as their testing material. The probe developed, shown in Figure 2.5, was a three-fiber probe, where the central fiber projected light into the freeboard of a fluidized bed, and the fibers directly above and below received the reflected light. The probe was originally used for solids velocities, but was found to be a useful tool in finding the solids holdup. They used it primarily for "near wall” measurements. The frequency of the output pulses was used as a way to measure solids concentration.

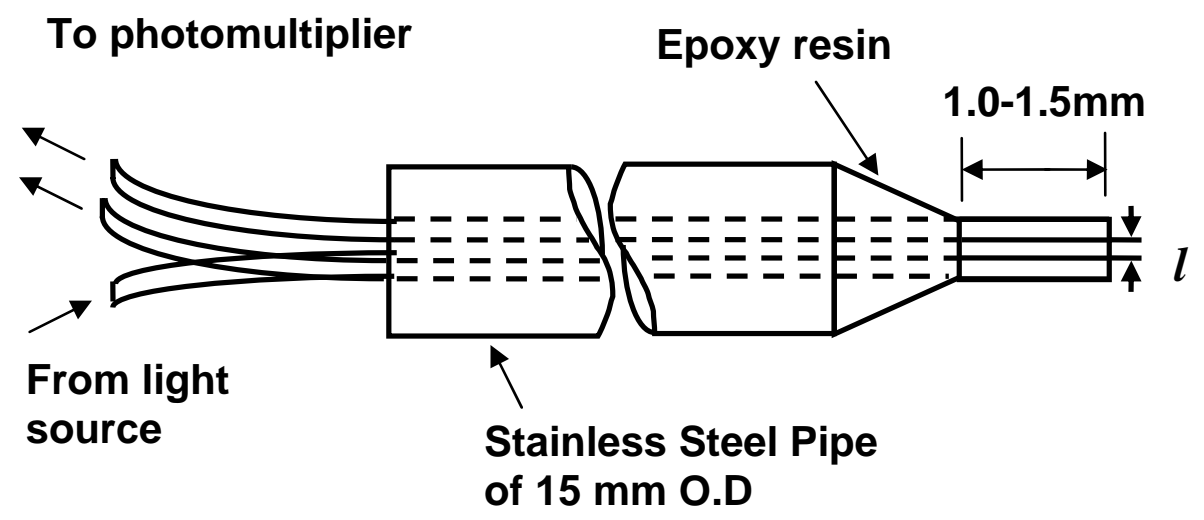

Figure 2.5 - Optical Probe Used by Morooka et al. [8] (redrawn) 
In 1982, Hatano and Ishida [15] used a fiber optic probe to measure solids concentrations by relating the light absorption to the medium concentration using the Beer-Lambert Law. Additionally, they measured the transmitted light through the medium. They verified the applicability of the Beer-Lambert law for measuring particle concentrations.

Matsuno et al. [16] (1983) used a four fiber optical probe to measure dilute particle concentrations in the $8.1 \mathrm{~cm}$ i.d. freeboard of a gas-fluidized bed. The freeboard varied in height. Glass beads with an average diameter of $56.5 \mu \mathrm{m}$ were the test material for these experiments. Plastic optical fibers were used in this probe, where two of the fibers emitted light and two collected the reflected light which was detected by the probe and converted to a voltage. The voltage measured with this circuit was compared against the particle concentrations found by using the following equation:

$$
c=\frac{\Delta w}{S u_{t} \Delta t}
$$

where $c$ is the particle concentration, $\Delta w$ is the weight of the particles sampled, $S$ is the cross sectional area of the sampling volume, $\Delta t$ is the sampling time, and $u_{t}$ is the terminal velocity of the particles. The relationship they found was a linear relationship between the particle concentration and the voltage. An illustration of their probe can be found in Figure 2.6. 


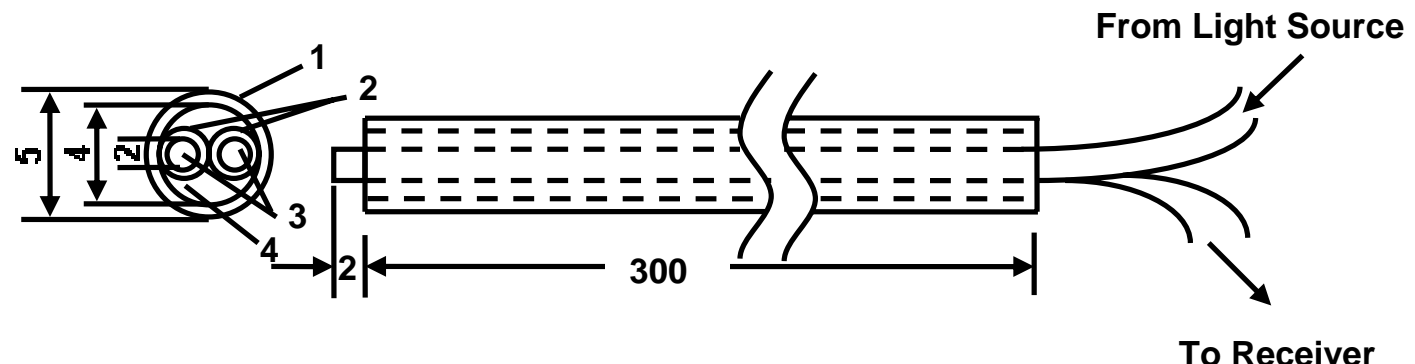

Figure 2.6 - Fiber optic Probe from Matsuno et al.; 1. Stainless Steel Pipe, 2. Clad, 3. Core, 4. Silicone compound [16] (redrawn)

In 1988, Hartge et al. [17] used an “opto-eletronical measuring system,” shown in Figure 2.7, to measure local solids concentrations inside the riser of a CFB. The riser of this system had an inner diameter of $0.4 \mathrm{~m}$ and a height of $8.4 \mathrm{~m}$. This probe contained a single optical fiber to transmit light from a laser into the bed containing FCC $\left(\mathrm{d}_{\mathrm{avg}}=85\right.$ $\mu \mathrm{m})$ and bed ash $\left(\mathrm{d}_{\mathrm{avg}}=120 \mu \mathrm{m}\right)$. The reflected light from the bed was then detected by a photo-diode. The solids concentration calibration technique was known as the "in-situ" method, which was described in a previous paper by Hartge and Werther (1986) [18].

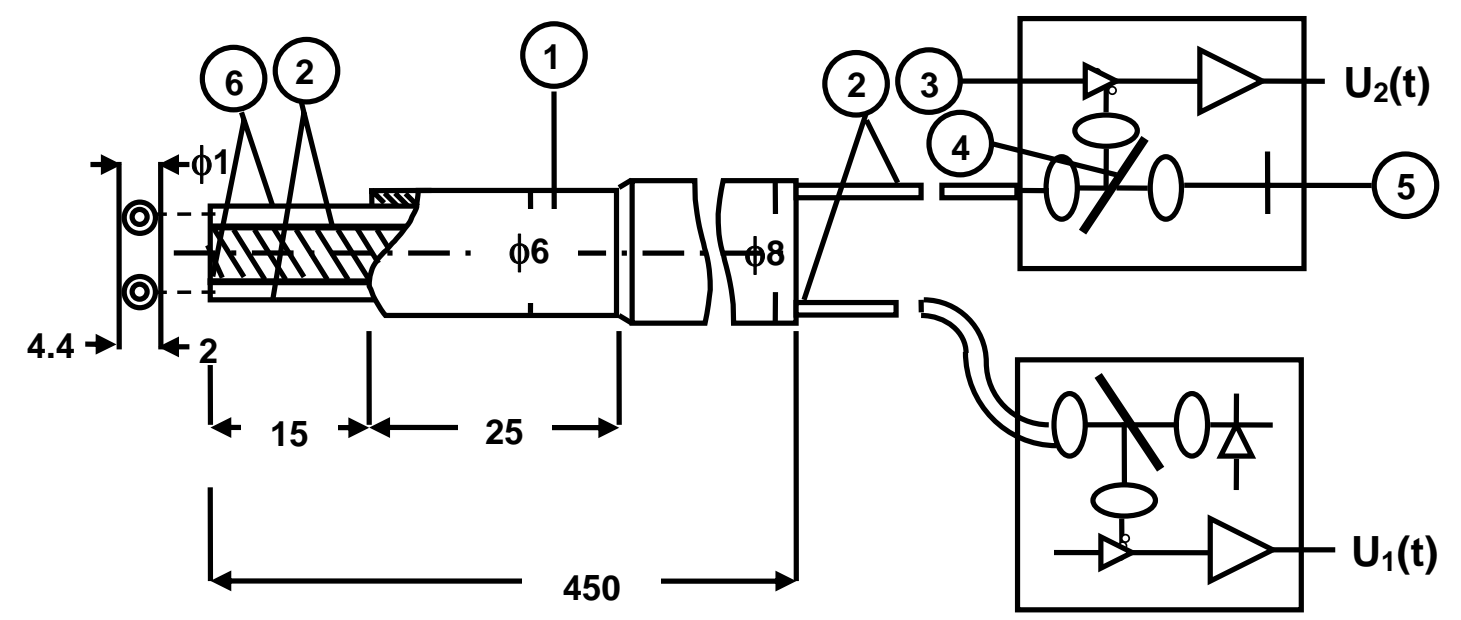

Figure 2.7 - Fiber optic Probe Used by Hartge et al. (1. probe, 2. optical fibers, 3. photo diode, 4. beam splitter, 5. laser, 6. steel capillary) [17] (redrawn)

An optical fiber probe was also used by Horio et al. [19] (1988) to measure solids concentrations of FCC particles with an average diameter of $60 \mu \mathrm{m}$ inside a CFB riser. 
They used a three fiber probe configuration and found a linear relationship between the solids concentration and the reflected light intensity. Some of the results from his study are shown in Figure 2.8. It shows the relative reflected light intensity detected by the probe as a function of radial distance from the center of the riser for various solids concentrations. Two separate probes were used in order to obtain solids concentrations and particle velocities, which are both shown in Figure 2.9.

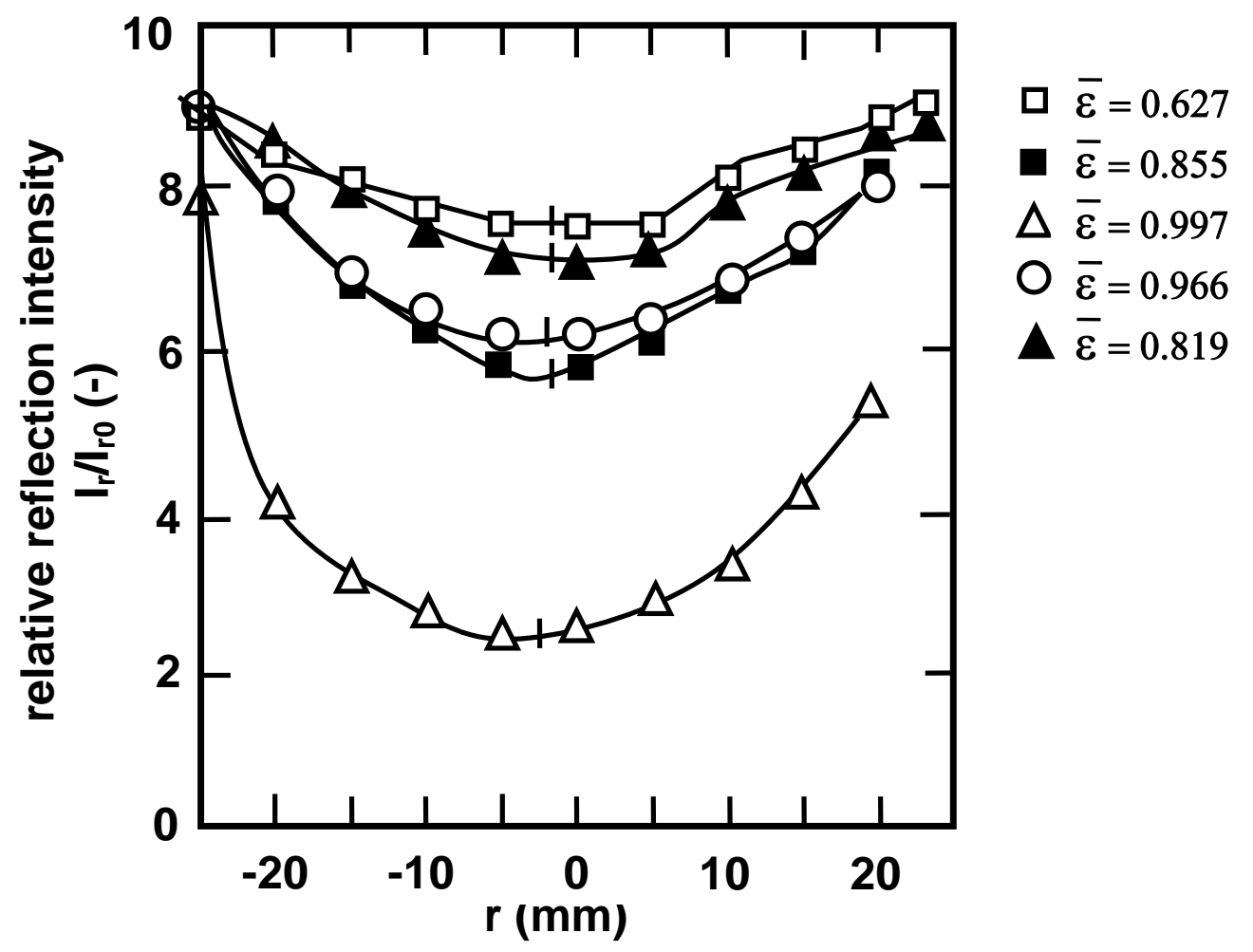

Figure 2.8 - Solids Fraction Radial Profile from Horio et al. [19] (redrawn) 


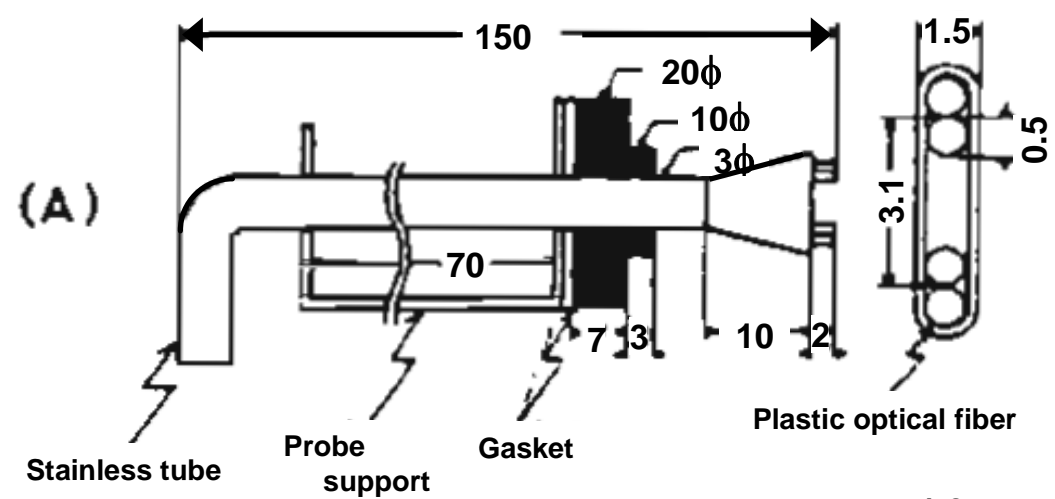

(B)
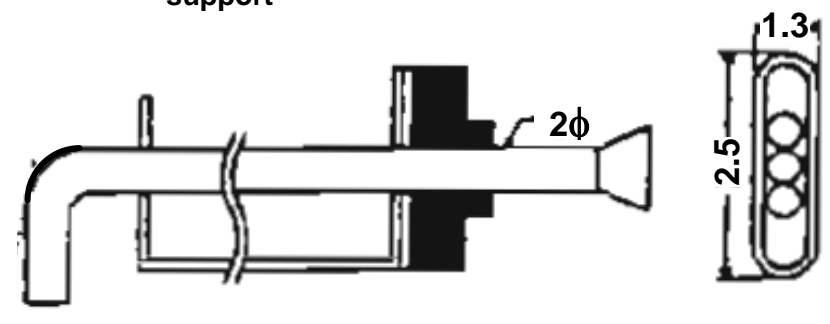

Figure 2.9 - Fiber optic probes used to measure A) Particle Velocities and B) Solids Concentrations by Horio et al. [19] (redrawn)

Nowak et al. [20] (1991) measured particle concentrations with a fiber optic probe in a CFB riser with an inner diameter of $0.205 \mathrm{~m}$ and a height of $6.65 \mathrm{~m}$. They used two different batches of particles: FCC with an average diameter of $46 \mu \mathrm{m}$ as their smaller particles and silica alumina particles with an average diameter of $3 \mathrm{~mm}$ as their large particles. A low pressure mercury lamp was the light source for this probe and several silica fibers were used to transmit the light into the bed. They measured the solids holdup in a CFB filled with FCC particles coated with a florescent dye. The fluorescent light from the particles travels back to a photomultiplier through plastic optical fibers. Their calibration method was not discussed in detail. Their setup is shown in Figure 2.10. 


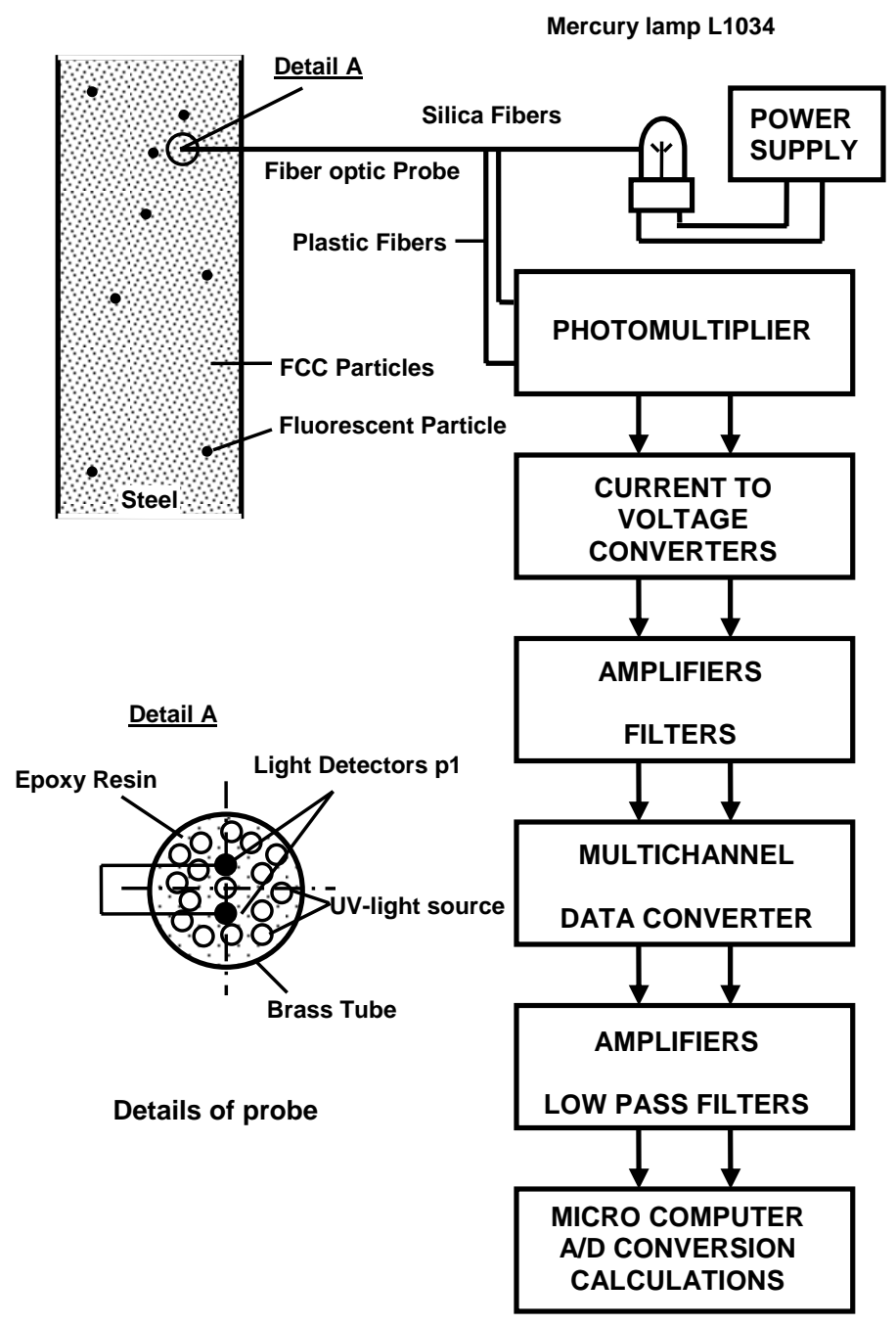

Figure 2.10 -Optical Probe Design used by Nowak et al. [20] (redrawn)

Reh and Li [21] (1991) performed a study that involved multiple types of fiber optic probes to measure solids concentrations in a bed of particles. The different fiber bundles used in this study are illustrated in Figure 2.11. They studied some of the previously ignored problems with solids fractions measurement methods, such as , particle size, material dependency, and power output from the probe. Glass beads with a wide range of diameters $(40-80 \mu \mathrm{m})$ and alumina particles with a diameter range from sub-micron to $100 \mu \mathrm{m}$ were used in this study. They concluded that probes with crossed 
fibers would be more beneficial for solids fraction measurements because of their more defined sampling volume and higher power output. Their probe calibration was based on the following equation:

$$
\varepsilon=1-Y\left(1-\varepsilon_{\text {dense }}\right) / Y_{\text {dense }}
$$

where $\varepsilon$ is the bed voidage, $\mathrm{Y}$ is the output signal, and "dense" represents the voidage and output signal in a dense bed condition.
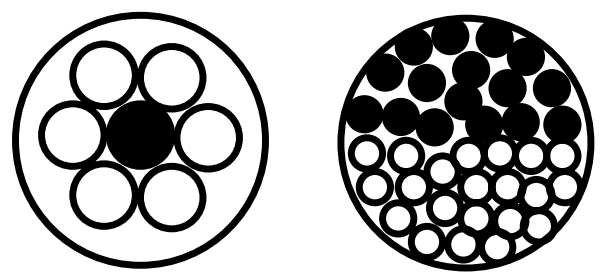

Coaxial Hemispherical

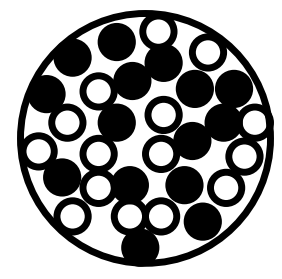

Random

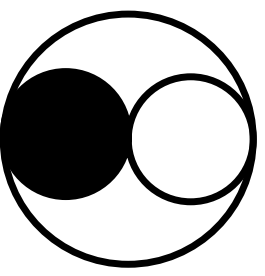

Fiber Pair

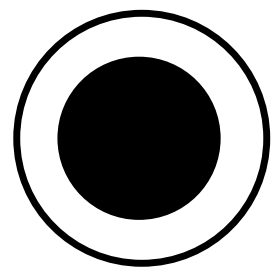

Single

Figure 2.11 - Different fiber bundles tested by Reh and Li [21] (redrawn)

In 1991, Rensner and Werther [9] developed the first probe designed specifically to measure local solids velocities and concentrations for dense cases inside a CFB riser. Their probe design is illustrated in Figure 2.12. This setup is a single fiber setup for transmitting the light into the particle flow and receiving the reflected light. The output signal from the probe was related to solids concentrations by using equation 2.2.3. 


$$
U-U_{o}=k \cdot c_{v}^{n}
$$

In this equation, $c_{v}$ is the volume concentration, $U$ is the signal level, $U_{o}$ is the signal at zero concentration, $k$ is a constant that depends on the solids properties, and the ratio of fiber diameter and particle size. $n$ is also a constant based on the same ratio. The focus of this study was to create a model to extract solids concentrations from this probe. They applied their probe a pilot scale CFB. This method provides a simple relationship between signal and particle concentration, however does not provide insight into light-toparticle interaction such as reflection, light attenuation, etc. This CFB riser had an inner diameter of $0.4 \mathrm{~m}$ and a height of $5 \mathrm{~m}$.

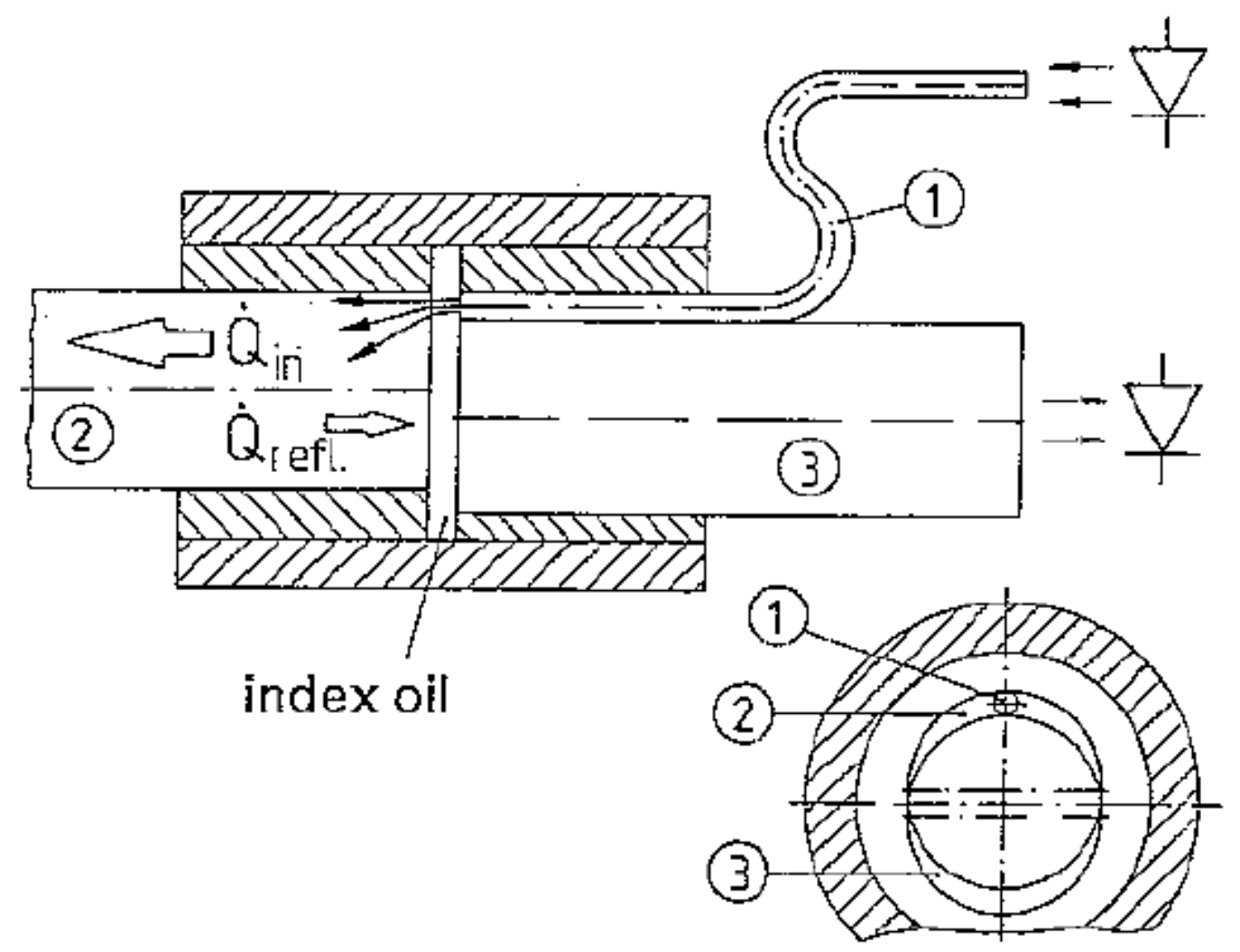

Figure 2.12 - Optical Probe used by Rensner and Werther [9] (1. Transmitting Fiber, 2. Probe Fiber, 3. Receiving Fiber) 
Lischer and Louge [22] (1992) developed a reflective fiber optic probe specifically for measuring solids concentration. Their method of extraction is called the Monte Carlo simulation. According to Lischer and Louge, this algorithm "predicts the fraction of the monochromatic radiant energy emitted by a multimode, step-index optical fiber that returns to the fiber's core from an isotropic, homogeneous, random suspension of smooth, transparent, monodisperse, spherical, dielectric particles.” This method attempted to account for the multiple scattering through a medium of different particles by using a theoretical block of particles. Their probe, illustrated in Figure 2.13, used a laser diode, a $200 \mu \mathrm{m}$ fiber, and a graded-index (GRIN) lens for transmitting light into the particle bed. The detected light traveled through a beam splitter to a photodiode. Glass spheres with diameters of $70 \pm 11 \mu \mathrm{m}$ and $210 \pm 32 \mu \mathrm{m}$ were the bed materials used. They used a capacitance probe for comparison; however the values from the two methods did not agree. 


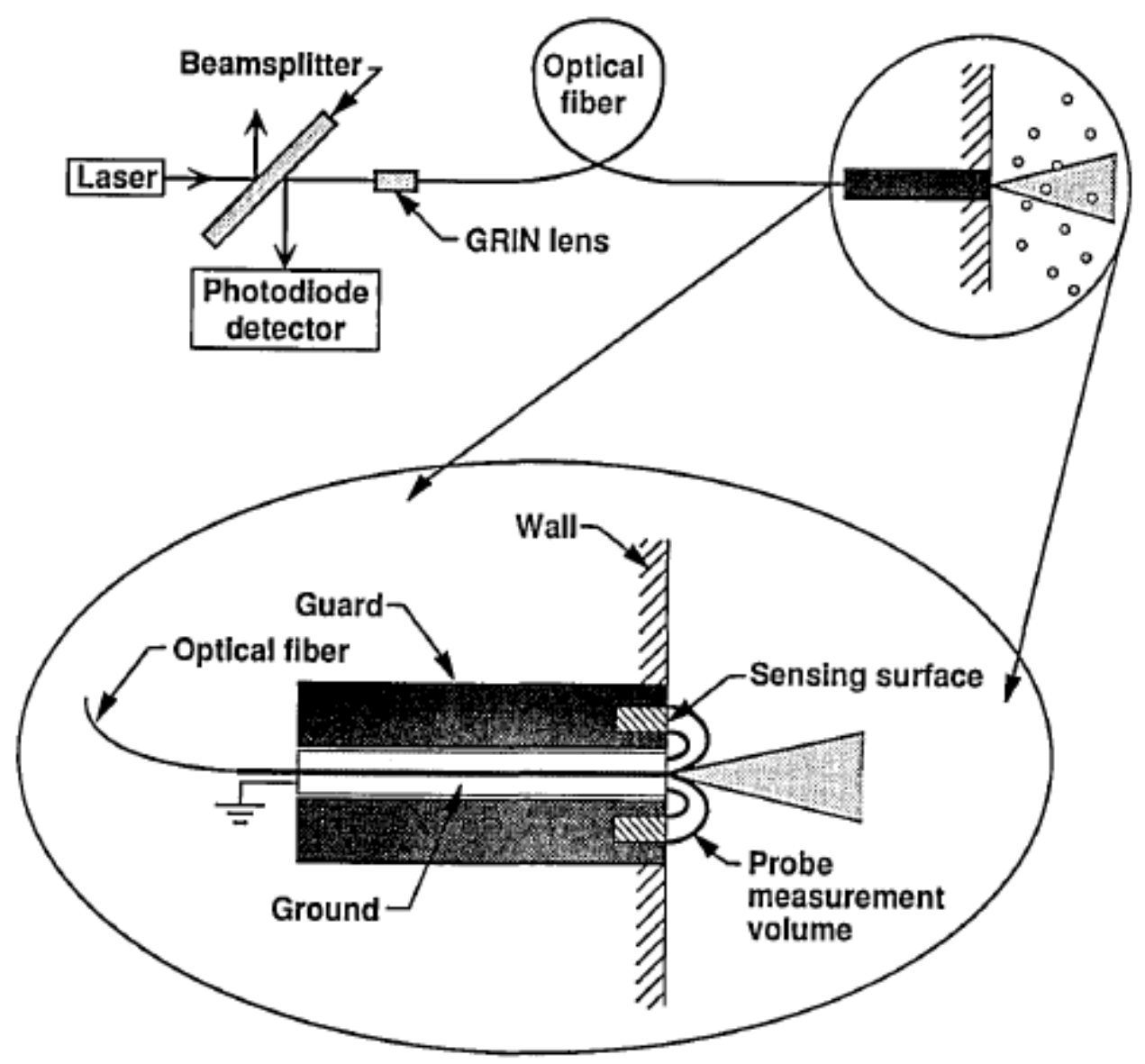

Figure 2.13 - Fiber optic Probe and Calibration setup used by Lischer and Louge [22]

Nieuwland et al. [12] (1996) used an optical measuring system to measure particle concentrations in two-phase flows. This probe was similar to the one used by Hartge et al., which was mentioned previously [17], but eliminated the use of a beam splitter by using a bifurcated multi-glass fiber instead of a monoglass fiber. Laser diodes were used as the light source and photodiodes as the receiver. They used sand particles with an average diameter of $129 \mu \mathrm{m}$ in their study. The riser used in their study was $8 \mathrm{~m}$ long with a diameter of $0.054 \mathrm{~m}$. This setup is depicted in Figure 2.14. They used the following equation to calculate the solids fractions from their voltage signals. 


$$
\varepsilon_{s}=\frac{1}{N} \sum_{i=1}^{N}\left(\frac{\Delta U_{i}}{a}\right)^{1 / b}
$$

In this equation, $N$ is the number of samples taken, $U_{i}$ are the voltage signals, $a$ is a constant found through a packed bed measurement, and $b$ is a constant that depends on the particulate phase. They used the method of using pressure drop measurements to determine solids fractions as a comparison for their fiber optic probe measurements. However, as mentioned earlier, pressure drop measurements could overestimate or underestimate the solid concentrations depending on the flow conditions. In this study, the effects on varying solids flux $\left(G_{s}\right)$ with a fixed superficial gas velocity $\left(u^{0}\right)$ and varying gas velocity with a fixed solids flux were studied. Some of these results are shown in Figures 2.15 and 2.16. 

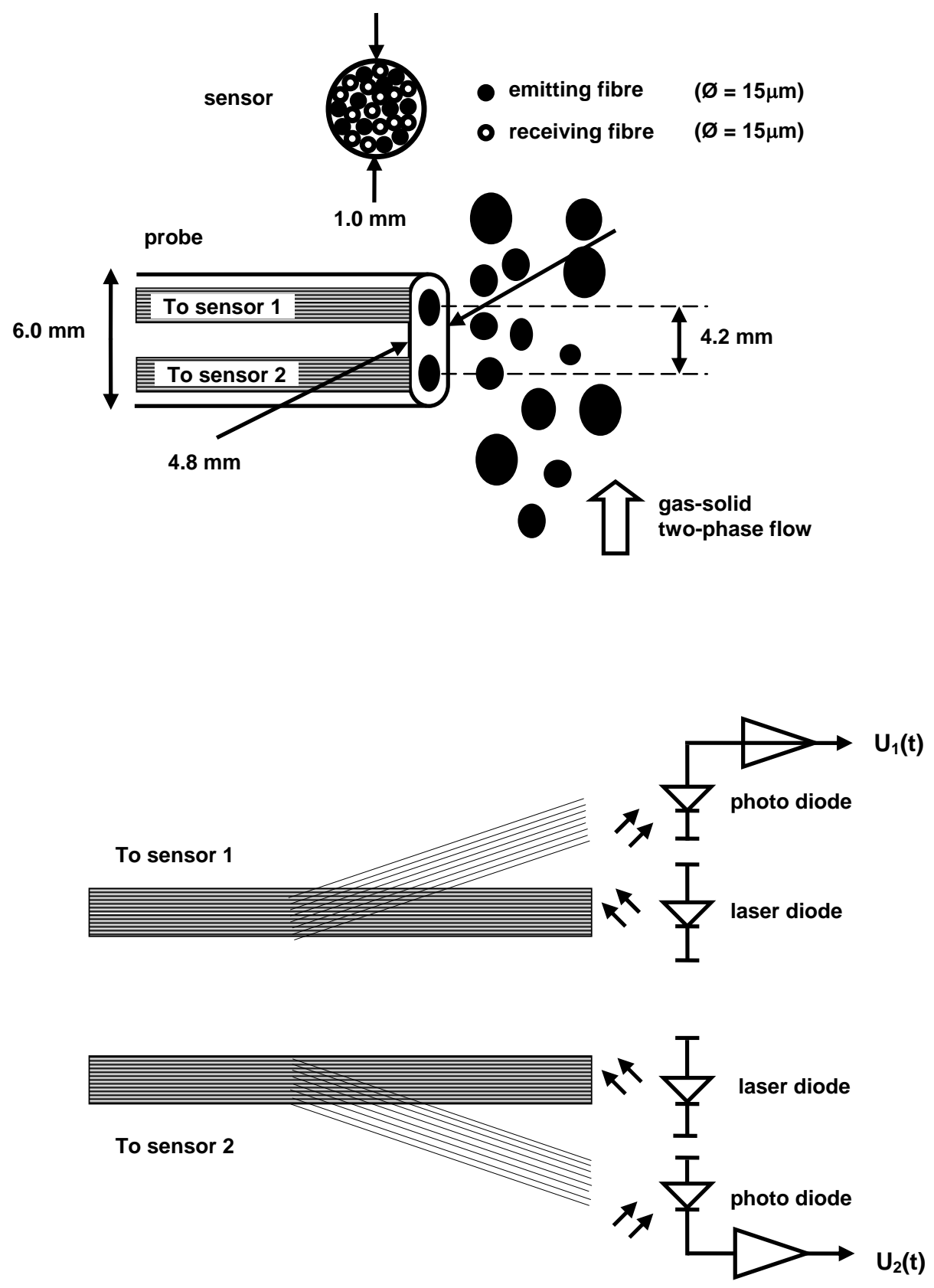

Figure 2.14 - Fiber optic probe used by Nieuwland et al. [12] (redrawn) 


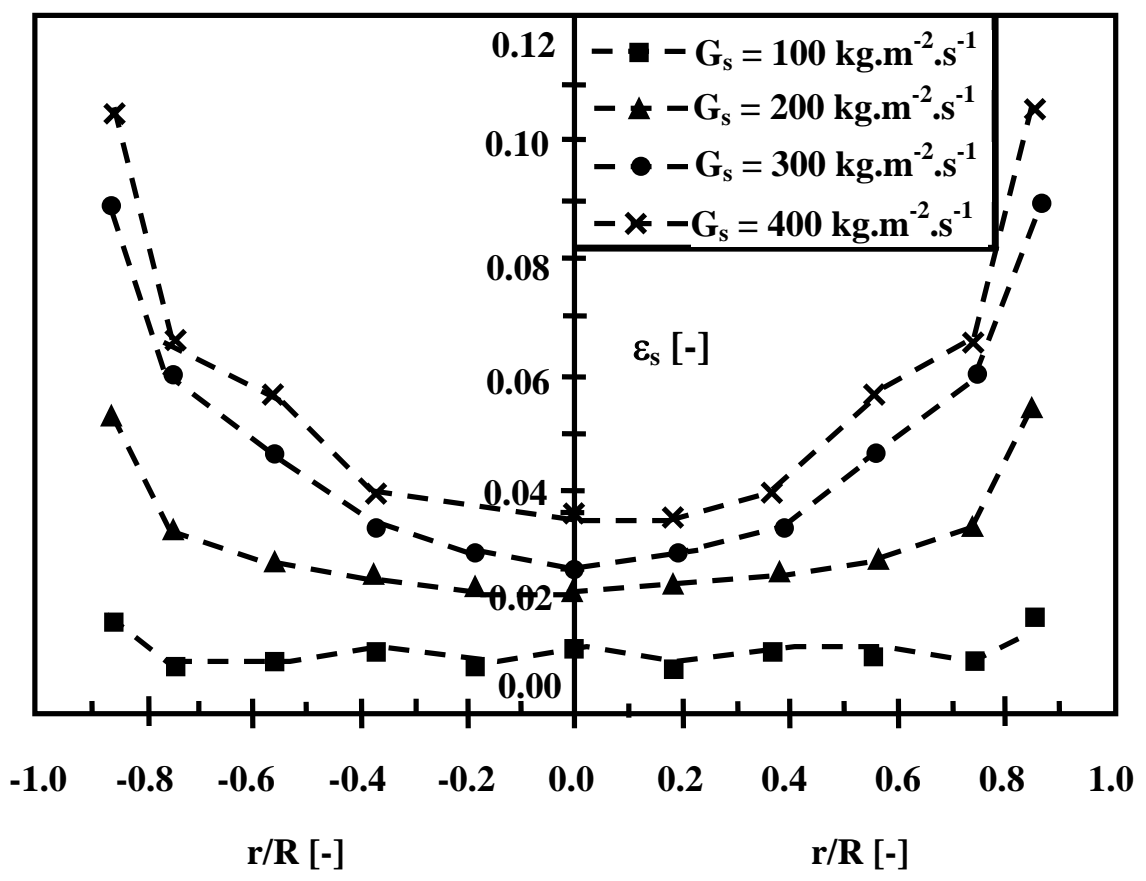

Figure 2.15 - Local solids concentrations as a function of dimensionless radial position at $1.8 \mathrm{~m}$ above the solids distributor for four solids mass fluxes; $\mathbf{u}^{0}=10 \mathrm{~m} / \mathrm{s}$ (from Nieuwland) [12] (redrawn)

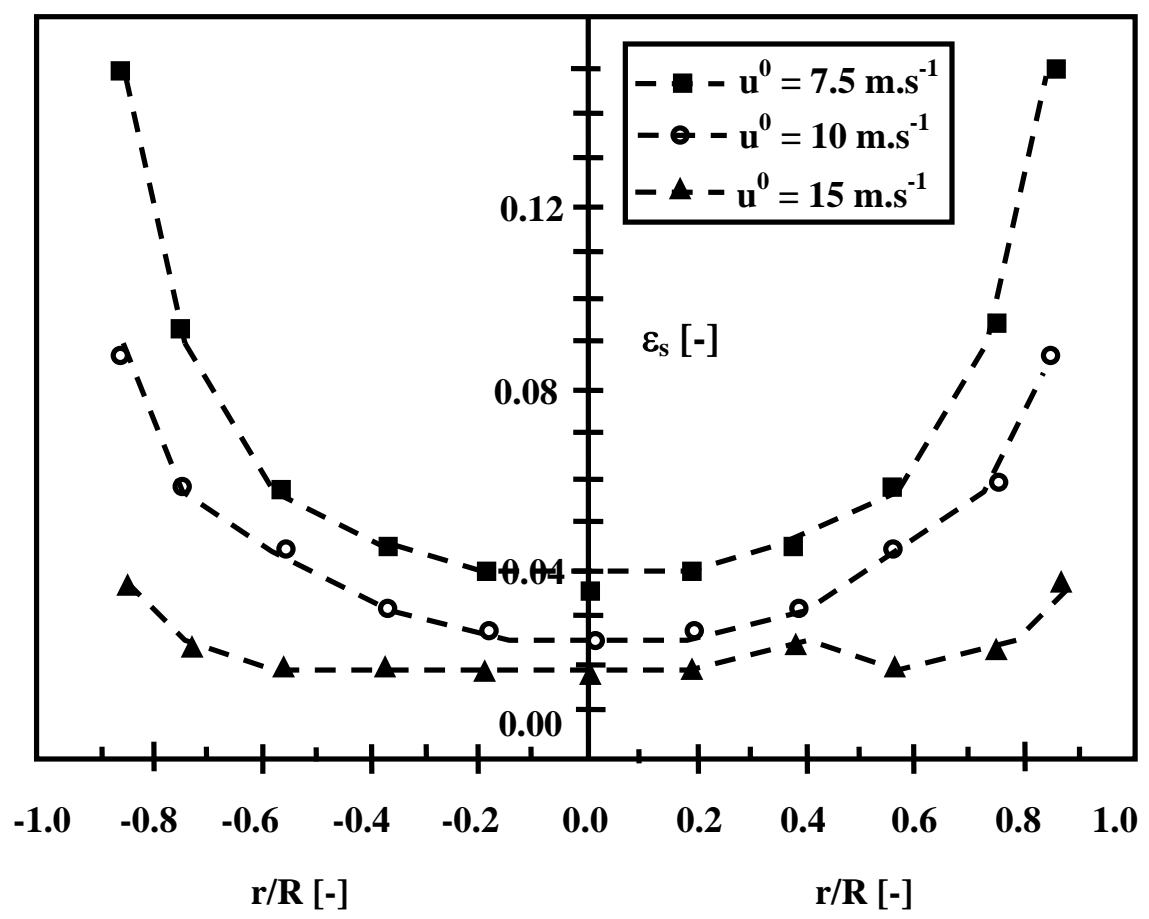

Figure 2.16 - Local solids concentrations as a function of dimensionless radial position at $1.8 \mathrm{~m}$ above the solids distributor for three superficial gas velocities; $G_{\mathrm{s}}=300 \mathrm{~kg} / \mathrm{m}^{2} \mathrm{~s}$ (from Nieuwland) [12] (redrawn) 
Zhang et al. [5] (1998) used a dual-bundle fiber optic probe to measure solids concentrations in a downer which was mentioned previously. This method made significant improvements over previous methods, because the calibration procedure was performed in a relatively stable environment. They used different sized FCC particles as their testing material, and a vibrator at the top of the downer to uniformly disperse the particles. The probe used had two bundles of evenly distributed transmitting and receiving fibers. The light source was an LED and the receiver was a photodiode. By using "slingshot valves" that were discussed earlier, they trapped the particles to determine various volume concentrations to compare with the voltages found with the fiber optic probe. This was a unique calibration procedure, but was still based on a global measurement. Additionally, the flow was not entirely uniform even though a vibrator was used to distribute the particles in the downer, which could cause error in the calibration. Furthermore, their probe design is very similar to the one used in the following study.

Fiber optic probes can be used in both hot and cold flow situations, as mentioned previously. Johnsson and Johnsson [23] (2000) fabricated a two-fiber, laser light, photodiode optical probe to measure solids concentrations of silica sand inside cold and hot flow CFBs. Their fibers, shown in Figure 2.17, were bent 13 degrees towards the center of the probe to create a well defined sampling volume. However, this probe was only used for solids concentrations and not for particle velocities. This test was to probe the simplicity of using an optical probe in both a cold flow simulation unit and a hot flow commercial unit. This probe was not compared against other fiber optic probes, but their 
probe did follow the same trends as other probe techniques. The probe detected a higher solids concentration near the wall of the CFB and more dilute towards the center.

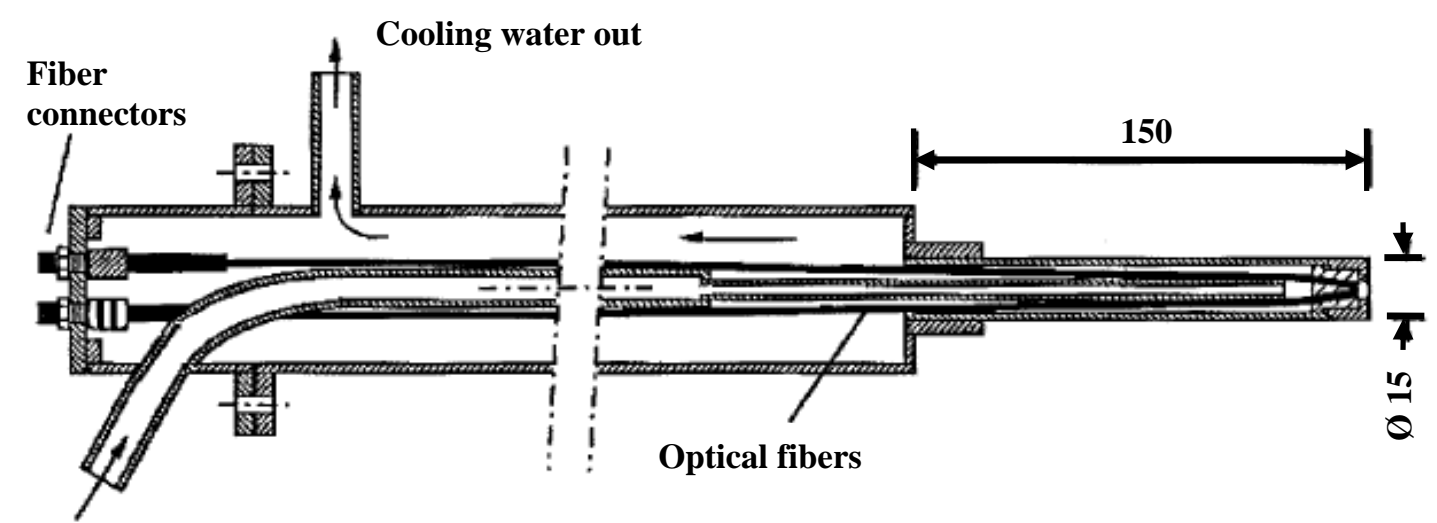

Cooling water in

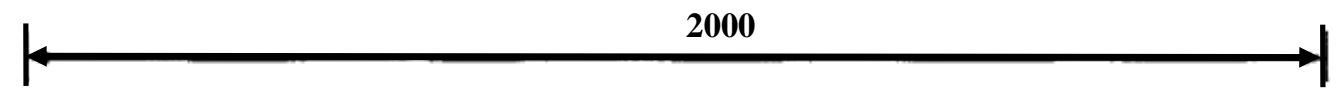

Figure 2.17 - High Temperature Fiber optic Probe used by Johnsson and Johnsson [23] (redrawn)

Rundqvist et al. [24] (2003) also used this crossbeam technique, shown in Figure 2.18, to measure solids volume concentrations in a gas/solids mixture. Scattered light is neglected and the method applied is the Monte Carlo simulation,. The probe in this test was the same probe used by Lischer and Louge, which was mentioned previously [22]. The results in this test were from calibration experiments, and no CFB results were shown in this paper. 

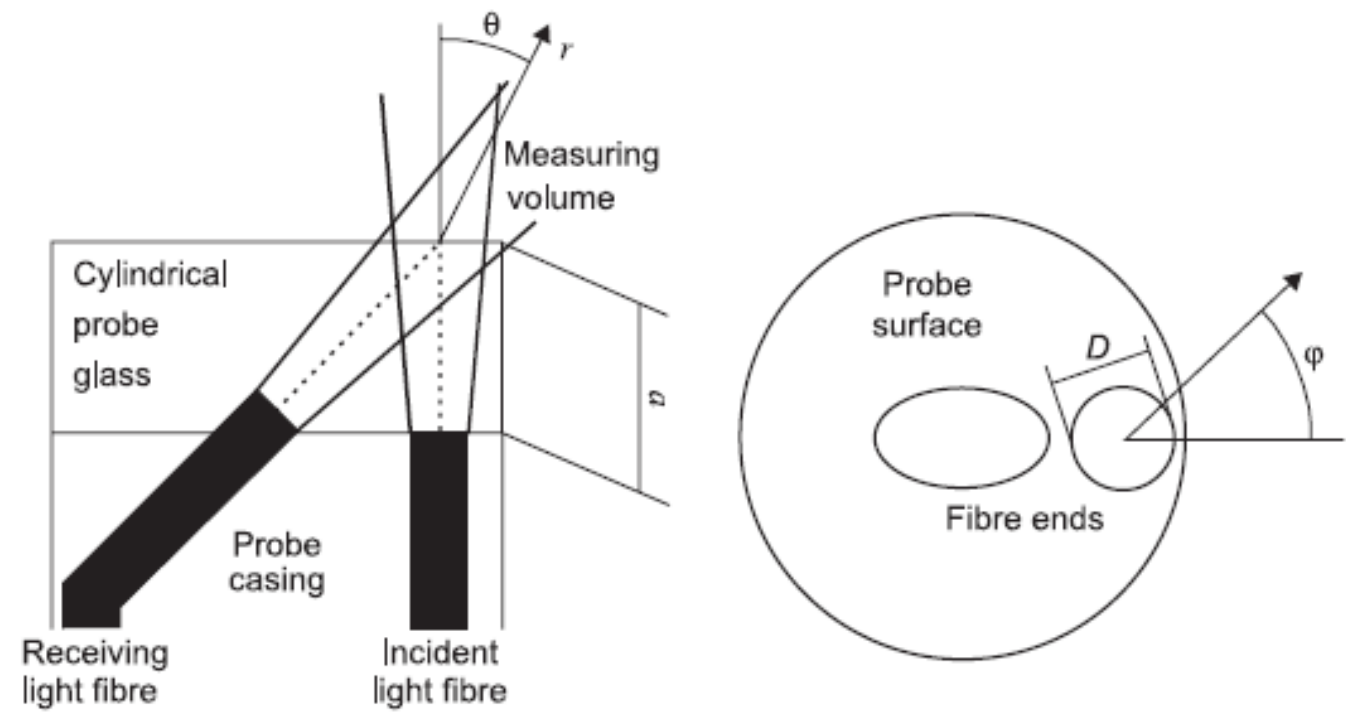

Figure 2.18 - Cross Fiber Probe Used by Rundqvist et al. [24]

In 2004 Samuel et al. [25] used a setup similar to the one used in Lischer and Louge [22]. Their setup was a downer-riser system with $76 \mu \mathrm{m}$ FCC particles. An illustration of their setup is shown in Figure 2.19. Yan et al. [13] (2004) used the same probe and techniques as Zhou et al. [26] in a twin riser system. They used their probe to measure the solids concentrations and particle velocities in a twin riser system with FCC particles as their test material. Their measurements were compared with values found through pressure drop measurements. The comparison of radial solids distributions in each riser is shown in Figure 2.20. According to Yan, the solids holdup near the wall of the larger diameter riser is much higher than the near wall solids holdup in the smaller riser. Magnusson et al. [11] used the same measuring principles and methods as Rundqvist et al. [24] used in his calibration. The probe was also the same as in Figure 2.18. Their measurements were also compared to solids fraction values calculated using the pressure drop method mentioned previously. 


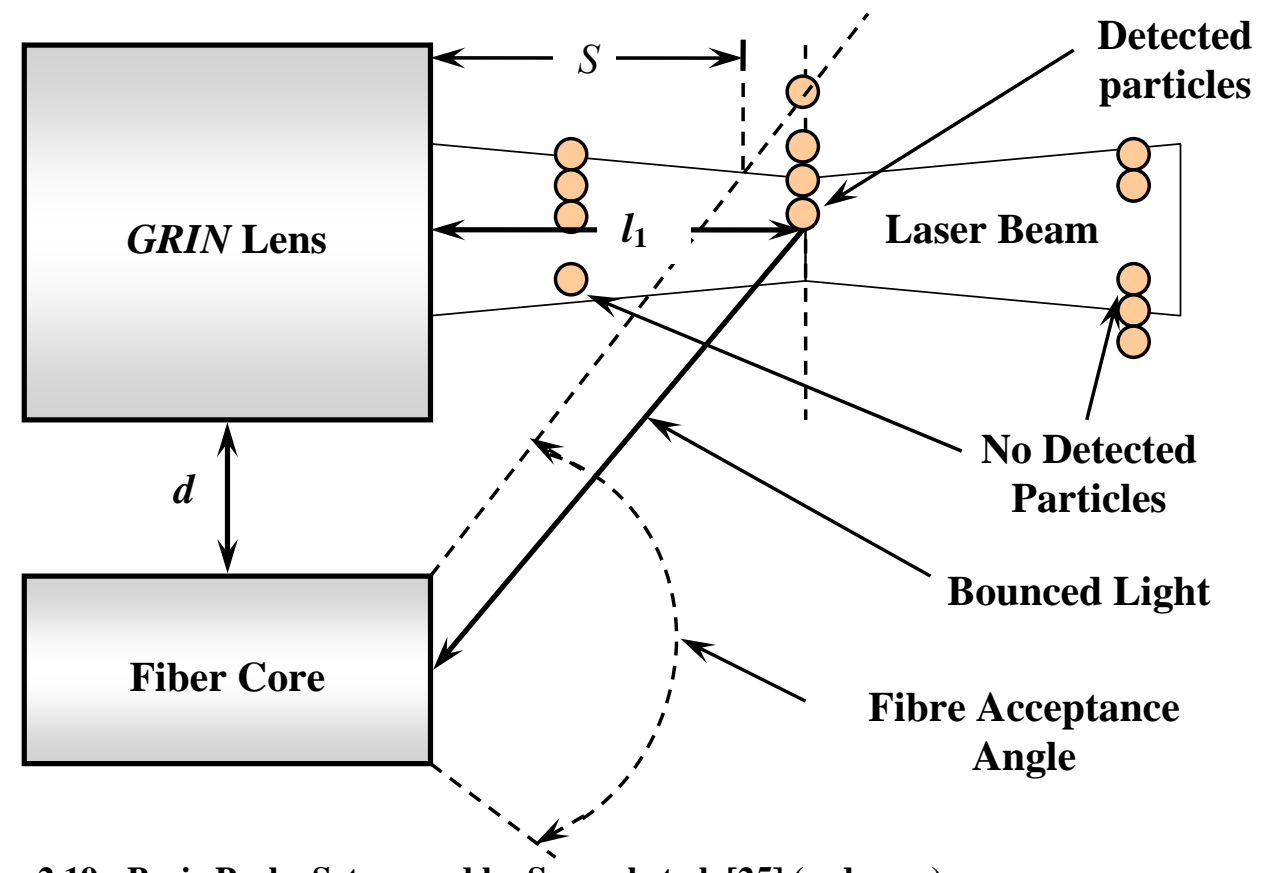

Figure 2.19 - Basic Probe Setup used by Samuel et al. [25] (redrawn) 


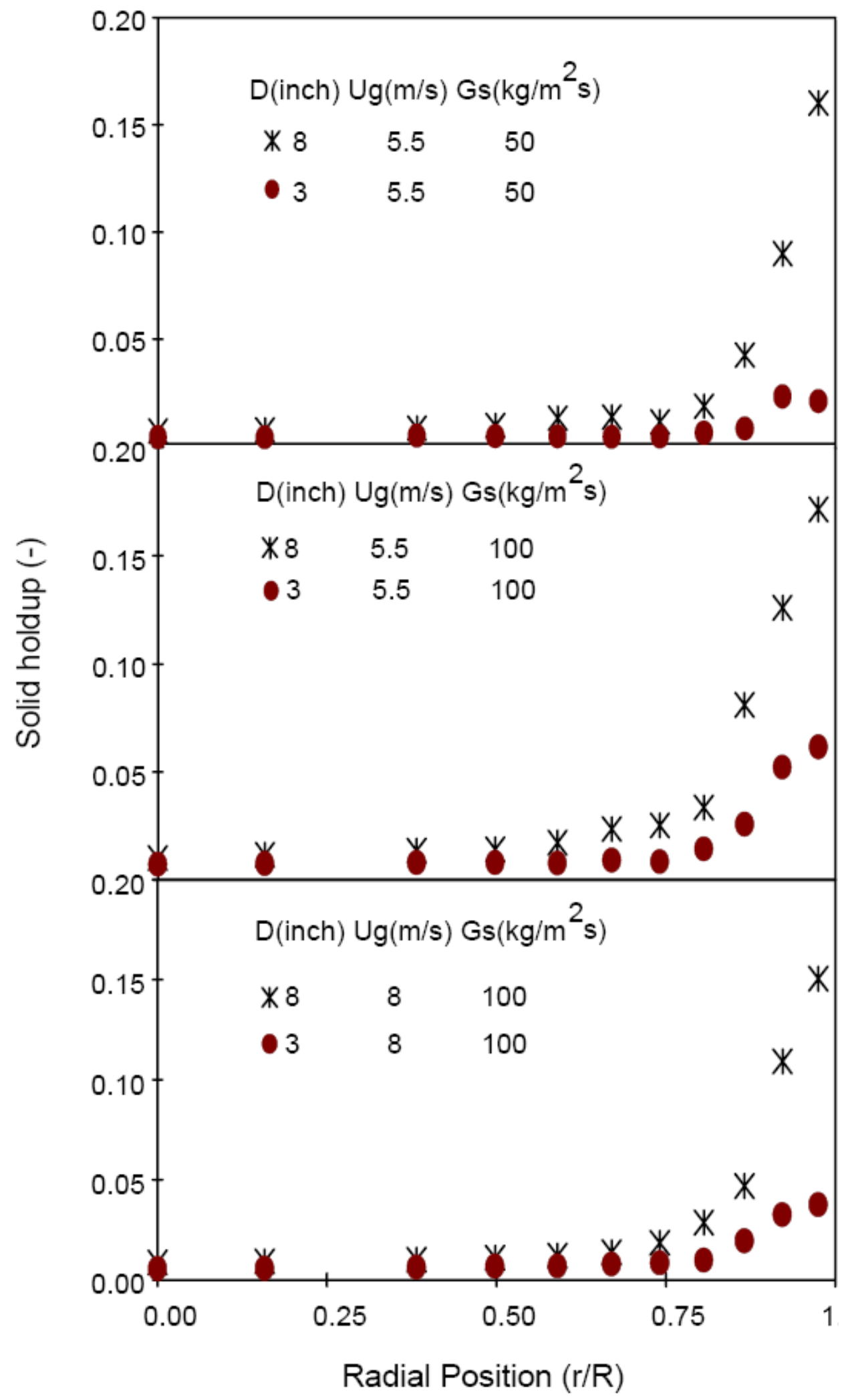

Figure 2.20 - Comparison of radial solids holdup profile of the twin riser system at $\mathrm{Z}=5.84 \mathrm{~m}$ (from Yan et al.) ([13]) 


\section{Objectives of the Research}

As can be seen from the literature review provided, many researchers have attempted to develop a reliable technique to measure the solids concentration or solids volume fractions inside the riser of a CFB. The present study provides a novel, empirical method of determining local solids volume fractions inside the riser of a CFB using the reflected light detected by a reflective fiber optic probe. This method was developed through equations accepted in literature and through novel bed depth calibrations. The commercially available probe was originally developed by others to find solids velocity [27]. Therefore, two important measurements to CFB studies can be obtained simultaneously with the same probe.

This study also provides two other solids fraction measurement devices currently used in a CFB unit to compare with the fiber optic probe method. Repeatability of this fiber optic probe method is also proven. The probe is applied to CFB operations testing to analyze the flow structure and azimuthal dependency inside the riser. This probe has the potential to replace other measuring devices currently used in the CFB. 


\section{Components and Basic Operation of Reflective Fiber Optic Probe}

\subsection{Instrument Components}

The optical probe used for the present study was a fiber optic probe commercially produced by Vector Scientific, Inc. in Halifax, Nova Scotia. The probe is constructed of stainless steel with an outer diameter of around $8 \mathrm{~mm}$. The probe tip, depicted in Figure 4.1 and illustrated in Figure 4.2, has two fiber bundles that are separated by a fixed distance of approximately $4 \mathrm{~mm}$. Each fiber bundle consists of 300 glass fibers that are split randomly and evenly between transmitting and receiving fibers. The basic setup of this probe is illustrated in Figure 4.3.

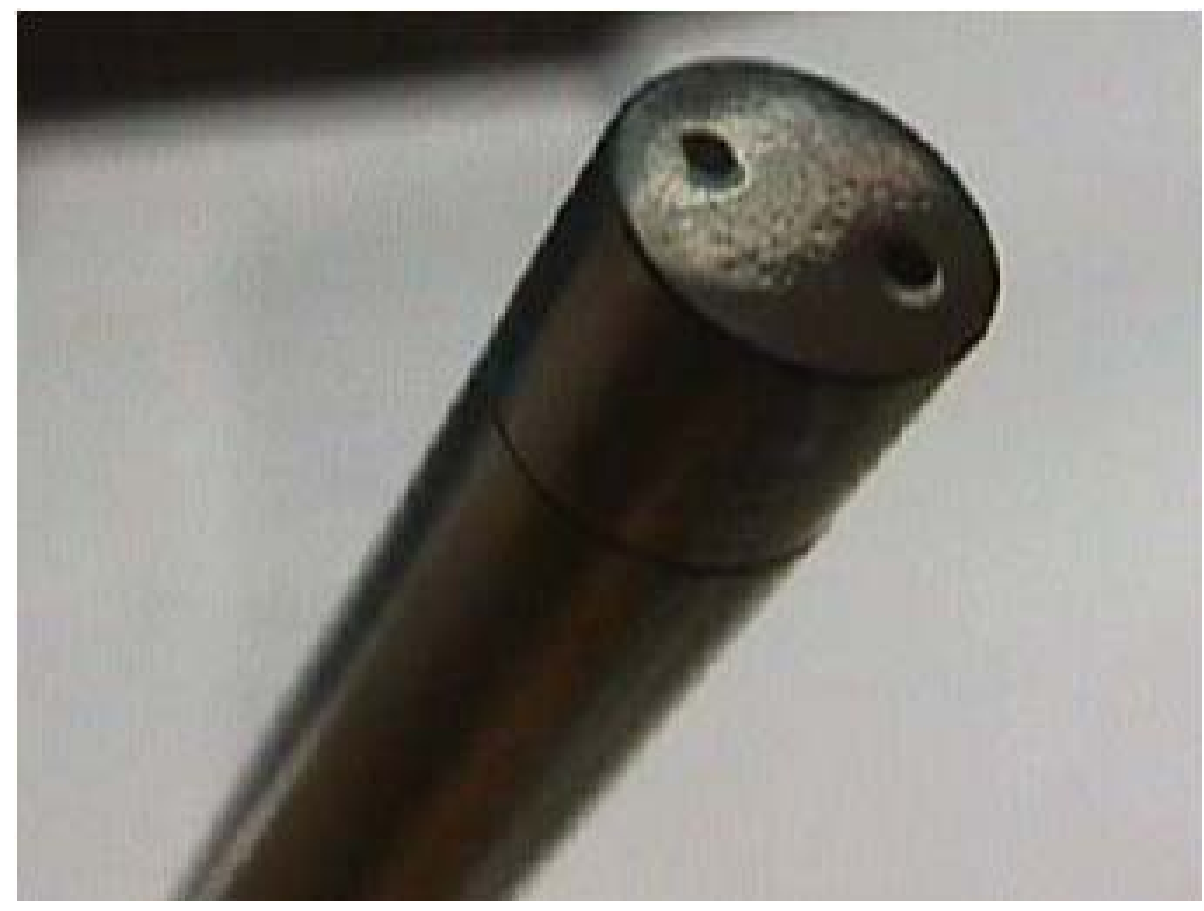

Figure 4.1 - Picture of Probe Tip 


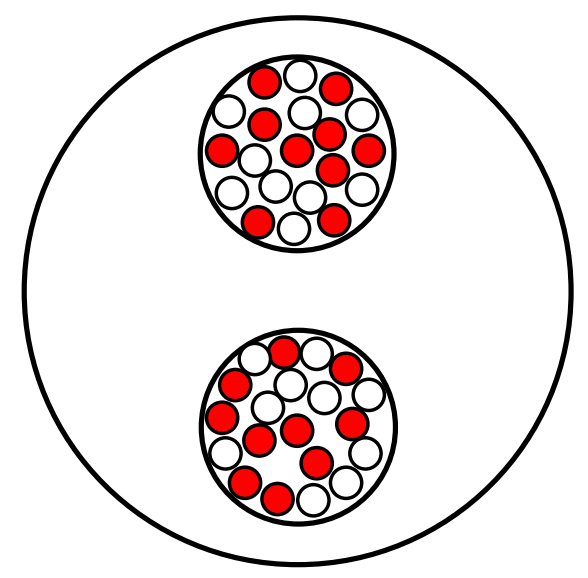

Figure 4.2 - Illustration of Probe Tip

The light source used in this probe is a red light emitting diode (LED) which is installed into the box labeled "vector" in the figure. The light source is pulsed at a user defined frequency ranging from $1-50,000 \mathrm{~Hz}$ in order to improve the signal to noise ratio and to minimize the effect of background lighting [27]. This light travels through the glass fibers into the particle media. After interacting with the particles, some of the light is reflected back into the receiving fibers. This lights travels back into the "vector" box to a photocell where the light intensity is converted into a voltage. These voltage signals are transferred to a PC that contains an analog/digital (A/D) card. The system records a sample at each pulse at the user defined frequency. These samples are grouped together in series ranging from 256 to 4096 samples per series. These series sizes double in range for each step change. 


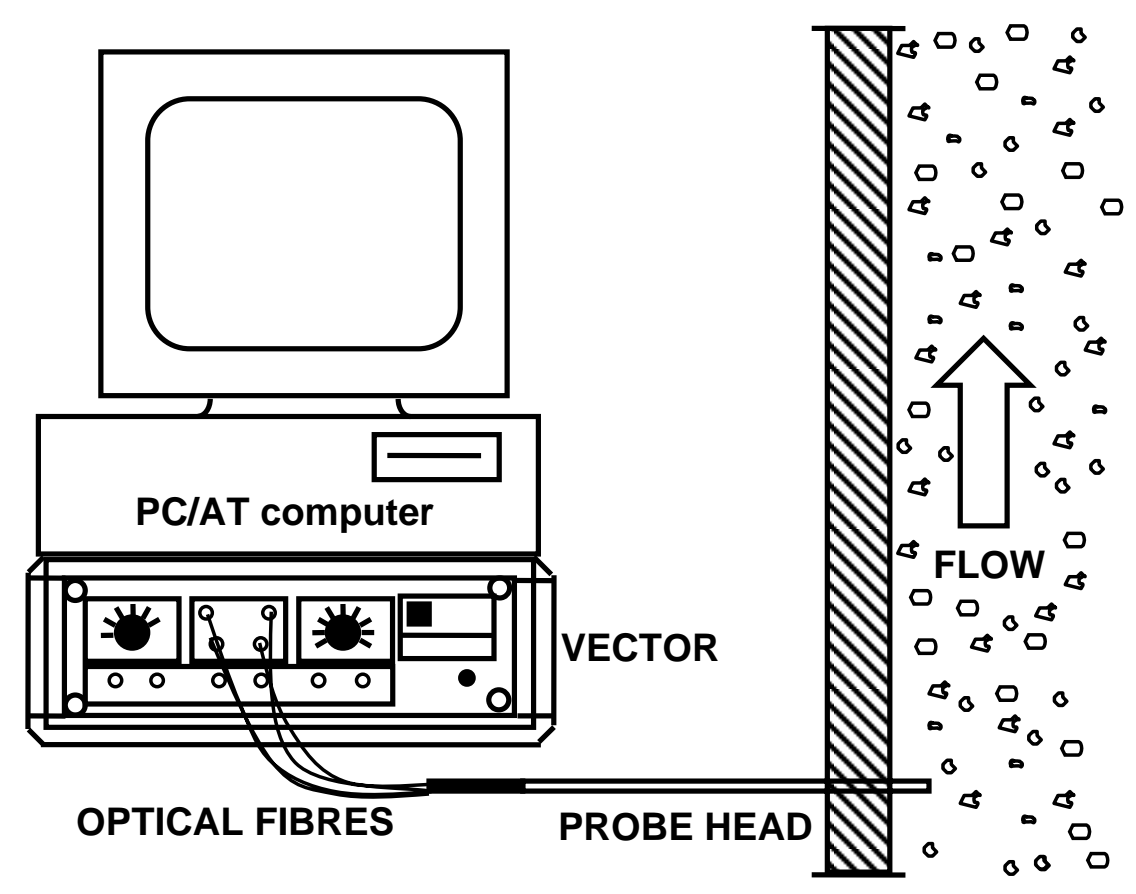

Figure 4.3 -Basic Fiber Optic Probe Setup [27] (redrawn)

\subsection{Basic Operations}

Both probe systems were originally developed to measure solids velocities. Fiber optic probes have been used to measure particle velocities in a number of studies $[8,12,14,19,20,25,26,28]$ and their methods have been widely accepted in finding particle velocities inside risers. As mentioned previously, the voltage samples recorded by the system are grouped into series. The voltages recorded by the probe are proportional to particle concentration. These data series from the two fiber bundles are time-shifted in order to obtain the best match. By knowing the "shift” needed in order to obtain the best match, the fixed distance between the two fiber bundles, and the sampling frequency of the probe, the average particle velocity for that series is calculated. More details of the 
setup of the sampling frequency and the velocity measurements inside the riser of the CFB will be discussed in the "Probe Setup" section. 


\section{Solids Fraction Model}

\subsection{Light and Concentration Theory}

Three physical bases were applied in this solids fraction model in order to create the foundation for the light-to-particle interaction. The first physical basis used in the proposed method is the conservation law illustrated in Figure 5.1. A light source interacts with the particle layer and is either transmitted, scattered, or absorbed. This relationship is shown in equation 5.1.1:

$$
I_{0}=I_{t}+I_{e x t}
$$

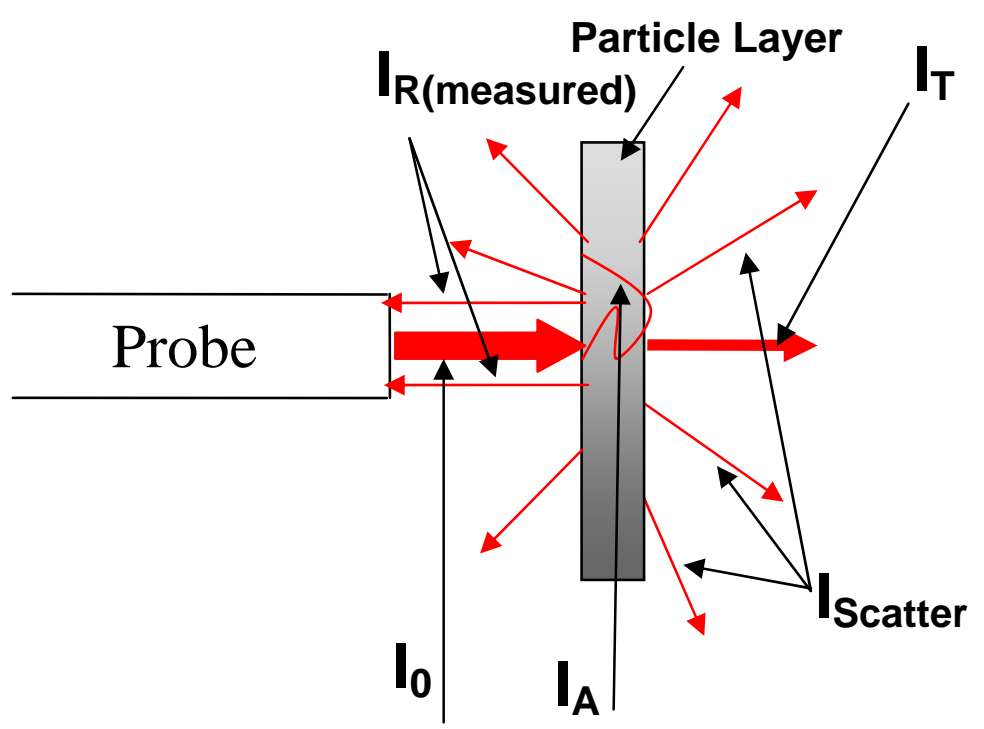

Figure 5.1 - Interaction of Light with a Particle Medium 
where $I_{0}$ represents the total light intensity emitted by the probe, $I_{t}$ is the transmitted light through the medium, and $\mathrm{I}_{\text {ext }}$ is the summation of light that has been scattered $\left(\mathrm{I}_{\text {scatter }}\right.$ and $I_{R}$ ) or absorbed $\left(I_{A}\right)$ by the medium.

The second physical basis used for this model is Beer-Lambert's law. According to van de Hulst, Beer-Lambert's law is “the strict proportionality between $\log \left(\mathrm{I}_{\mathrm{T}} / \mathrm{I}_{0}\right)$ and the concentration...[29].” The law states that a logarithmic relationship exists between the transmission of light and the concentration of particles in the medium. This relationship is also affect by the length of the optical path in the medium. The equation for the Beer-Lambert law states:

$$
I_{t}=I_{0} e^{-\left(\frac{\pi d^{2}}{4}\right) Q N \ell}
$$

where $\mathrm{Q}$ is the extinction coefficient, $\mathrm{N}$ is the number concentration of particles per unit volume, and $\boldsymbol{\ell}$ is the path length in which the light travels through [29]. The extinction coefficient $\mathrm{Q}$ is a material dependent parameter that quantifies how efficiently a material absorbs a certain wavelength of light or radiation. The area term, $\frac{\pi d^{2}}{4}$, is a coefficient of $\mathrm{Q}$, where $\mathrm{d}$ is the mean particle diameter.

The third physical basis implemented in this model is the reflected light intensity that is detected by the probe, $I_{R}$. This value was assumed as a fixed fraction of nontransmitted light that is detected by the probe. This fraction was represented by a constant, $\mathrm{k}_{1}$, as shown in the following equations:

$$
\begin{gathered}
I_{R}=k_{1} * I_{e x t} \\
I_{e x t}=I_{0}-I_{T}
\end{gathered}
$$

so, 


$$
I_{R}=k_{1}\left(I_{0}-I_{T}\right)
$$

In order to relate number concentration, $N$, in equation 5.1.2, to solids volume fraction traditionally by fluid bed researchers, a conversion constant, $\mathrm{k}_{2}$, was introduced so that:

$$
N=k_{2}(1-\varepsilon)
$$

$\varepsilon$ is the void fraction and $(1-\varepsilon)$ is the solids volume fraction.

In a previous study, equation 5.1.2 was used to extract solids fractions from fiber optic probe measurements [14]. However, multiple scattering and beam divergence were not accounted for, causing over-estimations in the solids fractions. The three physical bases and the model assumptions mentioned above were applied to a layer-by-layer model to better account for these issues. In order to find the light intensity contribution for each particle layer, the path length in equation 5.1.2 was taken to be the mean particle diameter of the bed material. The illustration of the light to particle interaction through each layer is shown in Figure 5.2.

In Figure 5.2 a three particle layer model is illustrated, but the number of layers contributing to the reflected light intensity measurement can vary. Light from the probe enters the particle flow, $\mathrm{I}_{0}$, and interacts with the first layer of solids. Through the physical bases mentioned earlier, the light is transmitted $\left(\mathrm{I}_{1}\right)$, scattered, and absorbed by the particle layer. A fraction of the scattered light from the first layer interaction is detected by the probe $\left(I_{R 1}\right)$ and $I_{1}$ travels to the second particle layer where the same phenomenon occurs. $I_{R 2}$ becomes the transmitted light source and interacts with the first layer of particles. The fraction of light that transmits through the first layer from the reaction with the second layer is detected by the probe. The light that is scattered between the two layer interaction, i.e. when $\mathrm{I}_{\mathrm{R} 2}$ interacts with the first particle layer, 
reflects off the first layer, then bounces back to the second layer, etc, is neglected in this model formulation $\left(\mathrm{I}_{\mathrm{R} 2(\mathrm{R} 1)}\right)$. Additionally, it is assumed that there are interstitial spaces between each layer of particles. This summation continues until the light contribution from the additional particle layers is no longer detected by the probe.

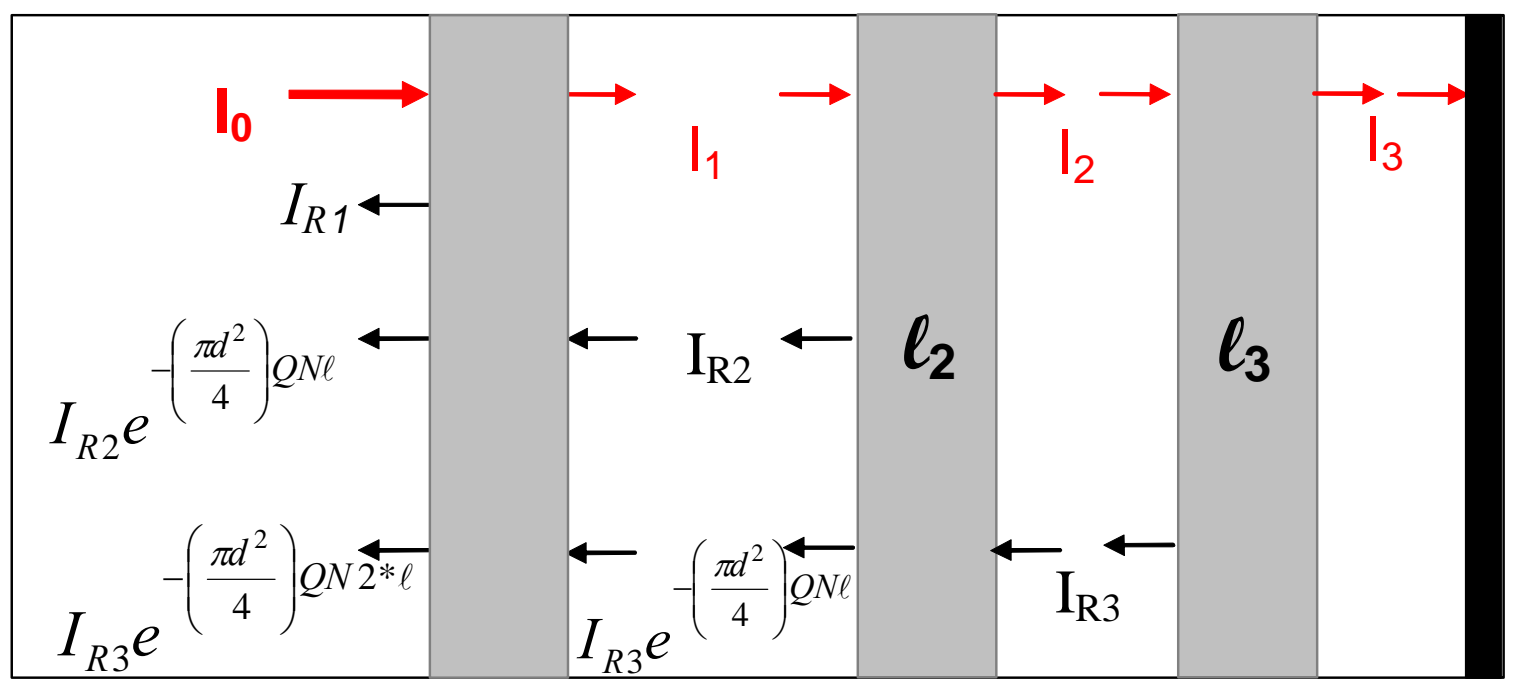

Figure 5.2 - Model of Layer-by-Layer Light Intensity Measurement

The total output voltage from the probe, $\mathrm{I}_{0}$, was measured by placing a surface reflecting mirror in front of the probe and recording a sample. Given that $\mathrm{I}_{0}$ is a known value, all calculations can be traced back to $\mathrm{I}_{0}$. For example:

for the second layer:

$$
I_{1}=I_{0} e^{-\frac{\pi d^{2}}{4} Q k_{2}(1-\varepsilon) \ell}
$$

$$
I_{2}=I_{1} e^{-\frac{\pi d^{2}}{4} Q k_{2}(1-\varepsilon) \ell}
$$

for the third layer:

$$
I_{3}=I_{2} e^{-\frac{\pi d^{2}}{4} Q k_{2}(1-\varepsilon) \ell}
$$

and so on for as many layers as needed for the calculation. Also, the equations for the reflected light intensities are as follows: 


$$
I_{R 1}=k_{1}\left(I_{0}-I_{1}\right)
$$

for the second layer:

$$
I_{R 2}=k_{1}\left(I_{1}-I_{2}\right)
$$

for the third layer:

$$
I_{R 3}=k_{1}\left(I_{2}-I_{3}\right)
$$

and so on for the number of particle layers necessary to account for the total reflected light detected by the probe. The equation that represents the summation of reflected light from each layer was formulated by substituting the light intensity values from equation 5.1.7 $\left(\mathrm{I}_{1}, \mathrm{I}_{2}, \ldots, \mathrm{I}_{\mathrm{i}}\right)$ into equation 5.1.8.

$$
\begin{gathered}
I_{R 1_{\text {Measured }}}=I_{R 1} e^{-\left(\frac{\pi d^{2}}{4}\right) Q k_{2}(1-\varepsilon) 0^{* \ell}}=k_{1}\left(I_{0}-I_{1}\right) e^{-\left(\frac{\pi d^{2}}{4}\right) Q k_{2}(1-\varepsilon) 0 * \ell} \\
I_{R 1_{\text {Messured }}}=k_{1}\left(I_{0}-I_{0} e^{-\frac{\pi d^{2}}{4} Q k_{2}(1-\varepsilon) \ell}\right) e^{-\left(\frac{\pi d^{2}}{4}\right) Q k_{2}(1-\varepsilon) 0^{* \ell}}=k_{1} I_{0}\left(1-e^{-\frac{\pi d^{2}}{4} Q k_{2}(1-\varepsilon) \ell}\right)
\end{gathered}
$$

for the second layer:

$$
\begin{gathered}
I_{R 2_{\text {Measured }}}=I_{R 1} e^{-\left(\frac{\pi d^{2}}{4}\right) Q k_{2}(1-\varepsilon) 0^{*} \ell}+I_{R 2} e^{-\left(\frac{\pi d^{2}}{4}\right) Q k_{2}(1-\varepsilon) * \ell} \\
I_{R 2_{\text {Measwed }}}=k_{1}\left(I_{0}-I_{1}\right) e^{-\left(\frac{\pi d^{2}}{4}\right) Q k_{2}(1-\varepsilon) 0^{*} \ell}+k_{1}\left(I_{1}-I_{2}\right) e^{\left.-\left(\frac{\pi d^{2}}{4}\right) Q k_{2}(1-\varepsilon)\right)^{* \ell}} \\
I_{R 2_{\text {Meassured }}}=I_{R 1_{\text {Meassred }}}+k_{1}\left(I_{0} e^{-\frac{\pi d^{2}}{4} Q k_{2}(1-\varepsilon) \ell}-I_{0} e^{-\frac{\pi d^{2}}{4} Q k_{2}(1-\varepsilon) 2 \ell}\right) e^{\left.-\left(\frac{\pi d^{2}}{4}\right) Q k_{2}(1-\varepsilon)\right)^{* \ell}} \\
I_{R 2_{\text {Measured }}}=k_{1} I_{0}\left(1-e^{-\frac{\pi d^{2}}{4} Q k_{2}(1-\varepsilon) \ell}+e^{-\frac{\pi d^{2}}{4} Q k_{2}(1-\varepsilon) 2 \ell}-e^{-\frac{\pi d^{2}}{4} Q k_{2}(1-\varepsilon) 3 \ell}\right)
\end{gathered}
$$

for the third layer: 


$$
\begin{gathered}
I_{R 3_{\text {Measured }}}=I_{R 1} e^{-\left(\frac{\pi d^{2}}{4}\right) Q k_{2}(1-\varepsilon) 0^{* \ell}}+I_{R 2} e^{\left.-\left(\frac{\pi d^{2}}{4}\right) Q k_{2}(1-\varepsilon)\right)^{* \ell}} I_{R 3} e^{-\left(\frac{\pi d^{2}}{4}\right) Q k_{2}(1-\varepsilon) 1^{* \ell}} \\
I_{R 3_{\text {Measured }}}=k_{1}\left(I_{0}-I_{1}\right) e^{-\left(\frac{\pi d^{2}}{4}\right) Q k_{2}(1-\varepsilon) 0^{*} \ell}+k_{1}\left(I_{1}-I_{2}\right) e^{-\left(\frac{\pi d^{2}}{4}\right) Q k_{2}(1-\varepsilon) 1^{*} \ell}+k_{1}\left(I_{2}-I_{3}\right) e^{-\left(\frac{\pi d^{2}}{4}\right) Q k_{2}(1-\varepsilon) 1^{* \ell}} \\
I_{R 3_{\text {Measured }}}=I_{R 1_{\text {Measured }}}+I_{R 2_{\text {Measured }}}+k_{1}\left(I_{0} e^{-\frac{\pi d^{2}}{4} Q k_{2}(1-\varepsilon) 3 \ell}-I_{0} e^{-\frac{\pi d^{2}}{4} Q k_{2}(1-\varepsilon) 4 \ell}\right) e^{-\left(\frac{\pi d^{2}}{4}\right) Q k_{2}(1-\varepsilon) 1^{* \ell}} \\
I_{R 3_{\text {Measured }}}=k_{1} I_{0}\left(1-e^{-\frac{\pi d^{2}}{4} Q k_{2}(1-\varepsilon) \ell}+e^{-\frac{\pi d^{2}}{4} Q k_{2}(1-\varepsilon) 2 \ell}-e^{-\frac{\pi d^{2}}{4} Q k_{2}(1-\varepsilon) 3 \ell}+e^{-\frac{\pi d^{2}}{4} Q k_{2}(1-\varepsilon) 4 \ell}-e^{-\frac{\pi d^{2}}{4} Q k_{2}(1-\varepsilon) 5 \ell}\right)
\end{gathered}
$$

and so on for each additional layer.

From the above, a generalized form can be derived.:

$$
I_{R_{\text {Measured }}}=\sum_{n=0}^{i} I_{R_{n+1}} e^{-n\left(\frac{\pi d^{2}}{4}\right) Q k_{2}(1-\varepsilon) \ell}=k_{1} I_{0}\left[\sum_{n=0}^{i}\left(e^{-2 n\left(\frac{\pi d^{2}}{4}\right) Q k_{2}(1-\varepsilon) \ell}-e^{-(2 n+1)\left(\frac{\pi d^{2}}{4}\right) Q k_{2}(1-\varepsilon) \ell}\right)\right]
$$

An initial calculation was conducted to determine the amount of particle layers necessary to represent the reflected light detected by the probe using equation 5.1.12. All values were held to arbitrary constants for this initial calculation. Figure 5.3 illustrates the layer-by-layer summation of the reflected light intensities and demonstrates the reflected light detected by the probe as the amount of particle layers increase. The light is being scattered by each particle layer, and a fraction of the light from each layer is reflected back into the probe, as demonstrated in Figure 5.2. Figure 5.3 illustrates that the light intensity reaches a constant value at four particle layers, meaning that reflected from 
the fourth particle layer is not detected by the probe. Therefore, the light-to-particle interaction after the fourth layer is no longer contributing to the measurement.

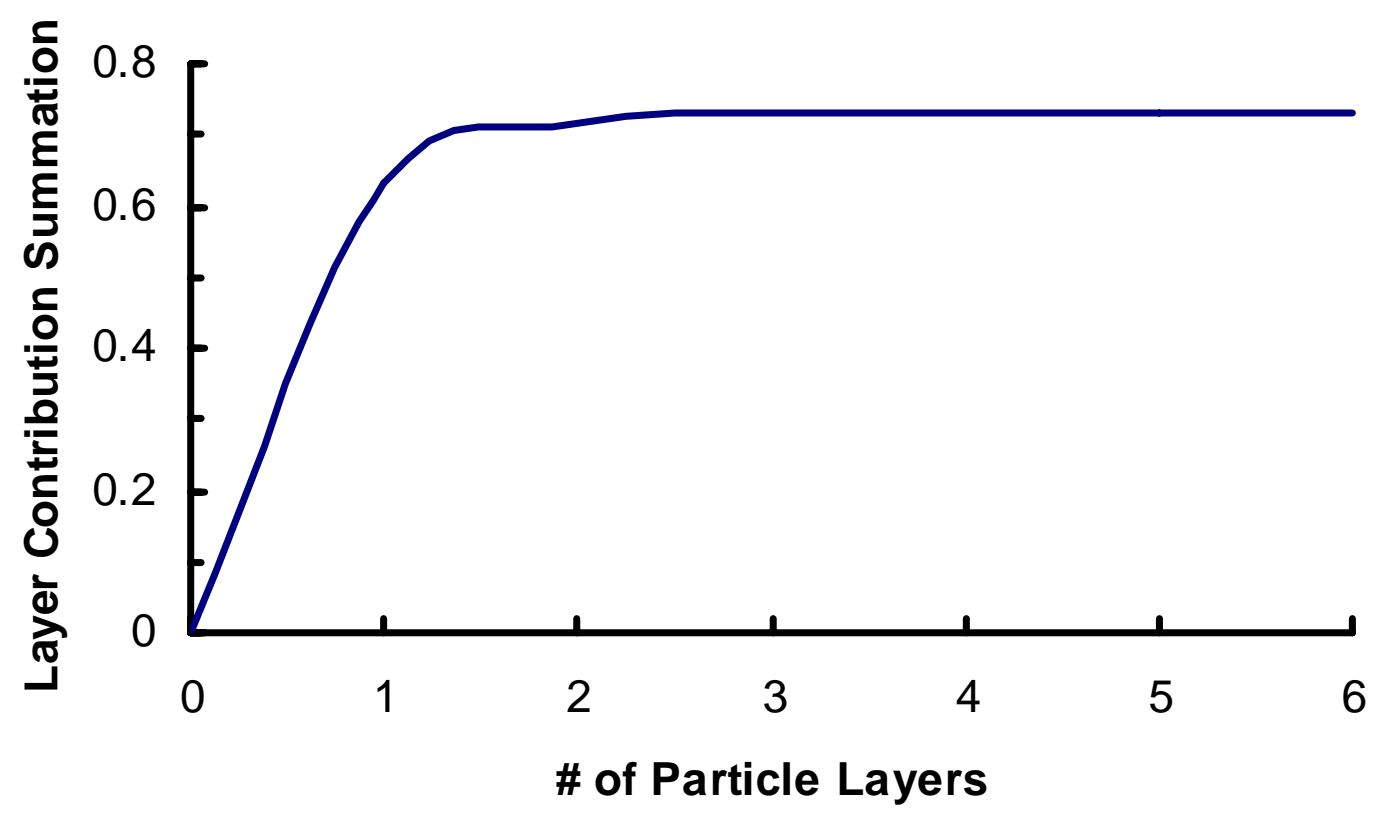

Figure 5.3 - Particle Layer Contribution to Total Reflected Intensity

\subsection{Solving for Constants}

The constants in equation 5.1.12 were solved for using empirical calibration techniques and equations from literature. The constants from these equations are material dependent, therefore a calibration is necessary for each batch of particles. Two groups of glass beads were used in this study: one with an average particle diameter of 64 $\mu \mathrm{m}$ and the other with an average diameter of $180 \mu \mathrm{m}$. The materials used for calibration were non-virgin material, meaning that they had been used in the CFB that will be discussed in the "Test Facility" section. The size distributions of each group of beads are 
shown in Figures 5.4 and 5.5, respectively. The distribution of the smaller batch was found using a system called a multisizer, and the distribution of the larger batch was determined using different sized sieves. Direct percent, from Figure 5.5, is the weight for each particle size measured from the total weight of the particles in the given sample. For the proposed model, the mean particle diameter was the value assigned for the particle diameter, $\mathrm{d}$, and the path length, $\boldsymbol{\ell}$.

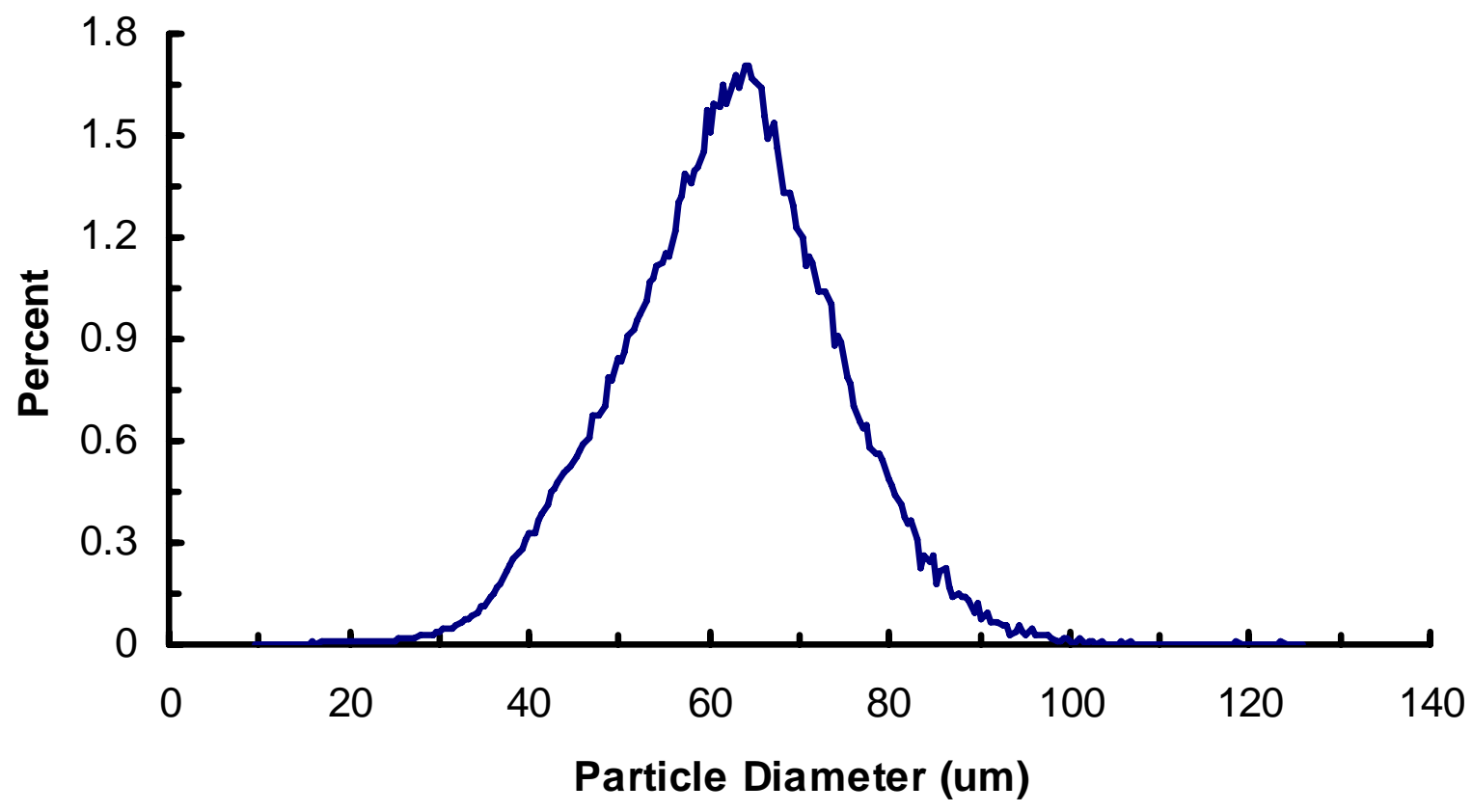

Figure 5.4 - Particle Diameter Distribution for Smaller Glass Beads 


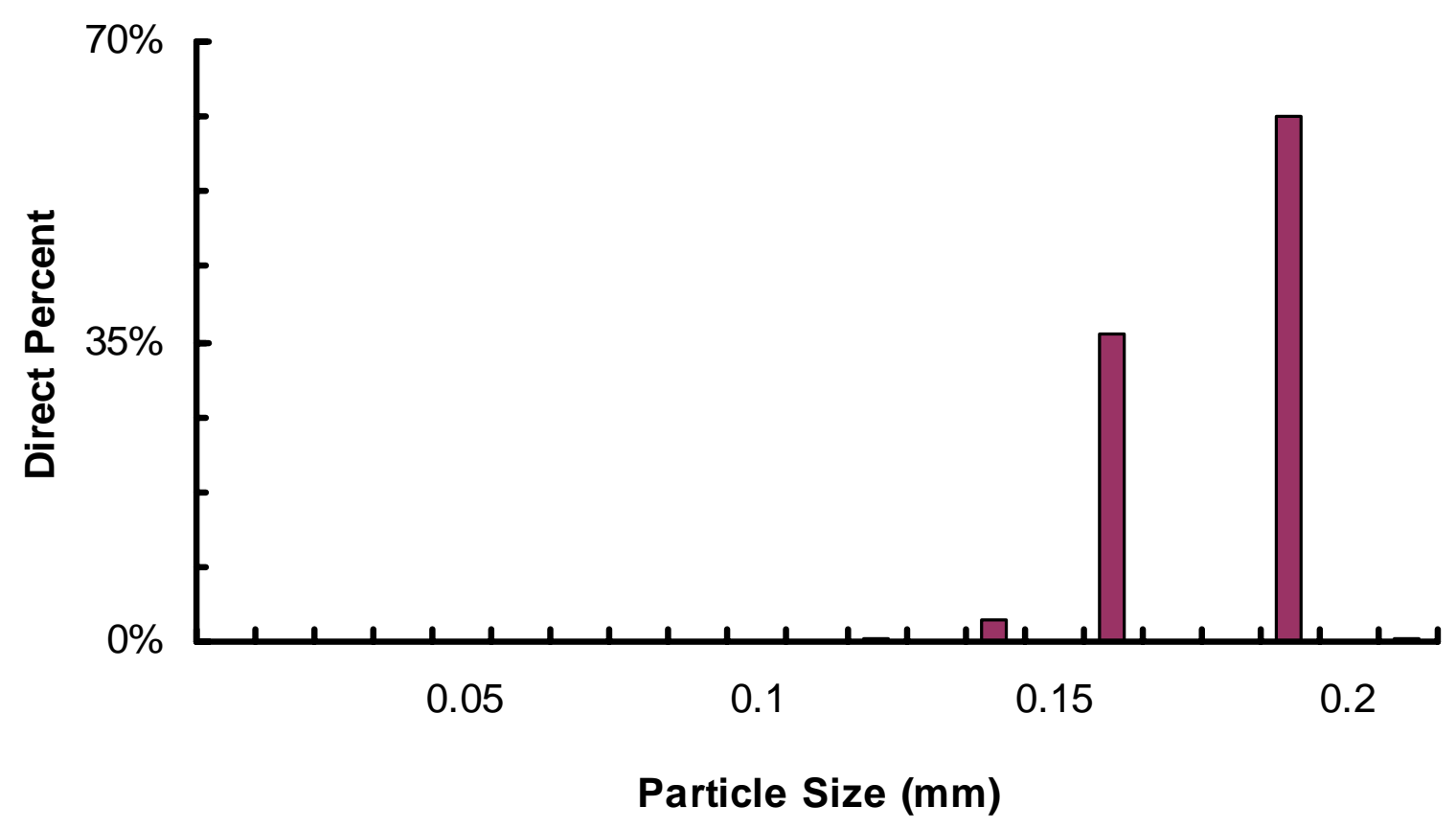

Figure 5.5 - Particle Diameter Distribution for Larger Glass Beads

The next constant, the extinction coefficient $\mathrm{Q}$, was determined by calculating the size parameter, $\alpha$, the modified size parameter, $\beta$, and then using the graph from Vincent [31] illustrated in Figure 5.6. The particle size parameter $\alpha$ is an aerosol value that is a function of the material size and the wavelength of the light source. $\beta$ is also an aerosol constant that relates the particle diameter and index of refraction of the material to the wavelength of the light source. These two values were calculated with the following equations:

$$
\alpha=\frac{\pi d}{\lambda}
$$

and

$$
\beta=4 \alpha(m-1)
$$


where $\mathrm{d}$ is the mean particle diameter, $\lambda$ is the wavelength of the light source, and $\mathrm{m}$ is the index of refraction of the material. Table 5.1 shows the range of values used to find $\beta$ for each group of particles. For this study $m$ is the refractive index for glass, and the range of $\lambda$ is the range found for red LEDs. Figure 5.6 illustrates that as the value of Q approaches 2 as $\beta$ approaches a value of 20 [31]. Since the $\beta$ values both bed materials used are significantly above 20, a value of 2 was used for Q in the given model. Sample calculations for these values can be found in Appendix I.

Table 5.1- Beta Estimation Values

\begin{tabular}{|l|c|c|c|c|}
\cline { 2 - 5 } \multicolumn{1}{c|}{} & \multicolumn{2}{c|}{$64 \mu \mathrm{m}$ glass spheres } & \multicolumn{2}{c|}{$180 \mu \mathrm{m}$ glass spheres } \\
\hline Lambda $(\mathrm{m})$ & $6.25 \mathrm{E}-07$ & $6.6 \mathrm{E}-07$ & $6.25 \mathrm{E}-07$ & $6.6 \mathrm{E}-07$ \\
\hline $\mathrm{d}(\mathrm{m})$ & \multicolumn{2}{|c|}{$6.40 \mathrm{E}-05$} & \multicolumn{2}{c|}{0.00018} \\
\hline$\alpha$ & $3.22 \mathrm{E}+02$ & $3.05 \mathrm{E}+02$ & $9.05 \mathrm{E}+02$ & $8.57 \mathrm{E}+02$ \\
\hline$m$ & \multicolumn{2}{|c|}{1.5} & \multicolumn{2}{|c|}{1.5} \\
\hline$\beta$ & $\mathbf{6 4 3}$ & $\mathbf{6 0 9}$ & $\mathbf{1 8 1 0}$ & $\mathbf{1 7 1 4}$ \\
\hline
\end{tabular}

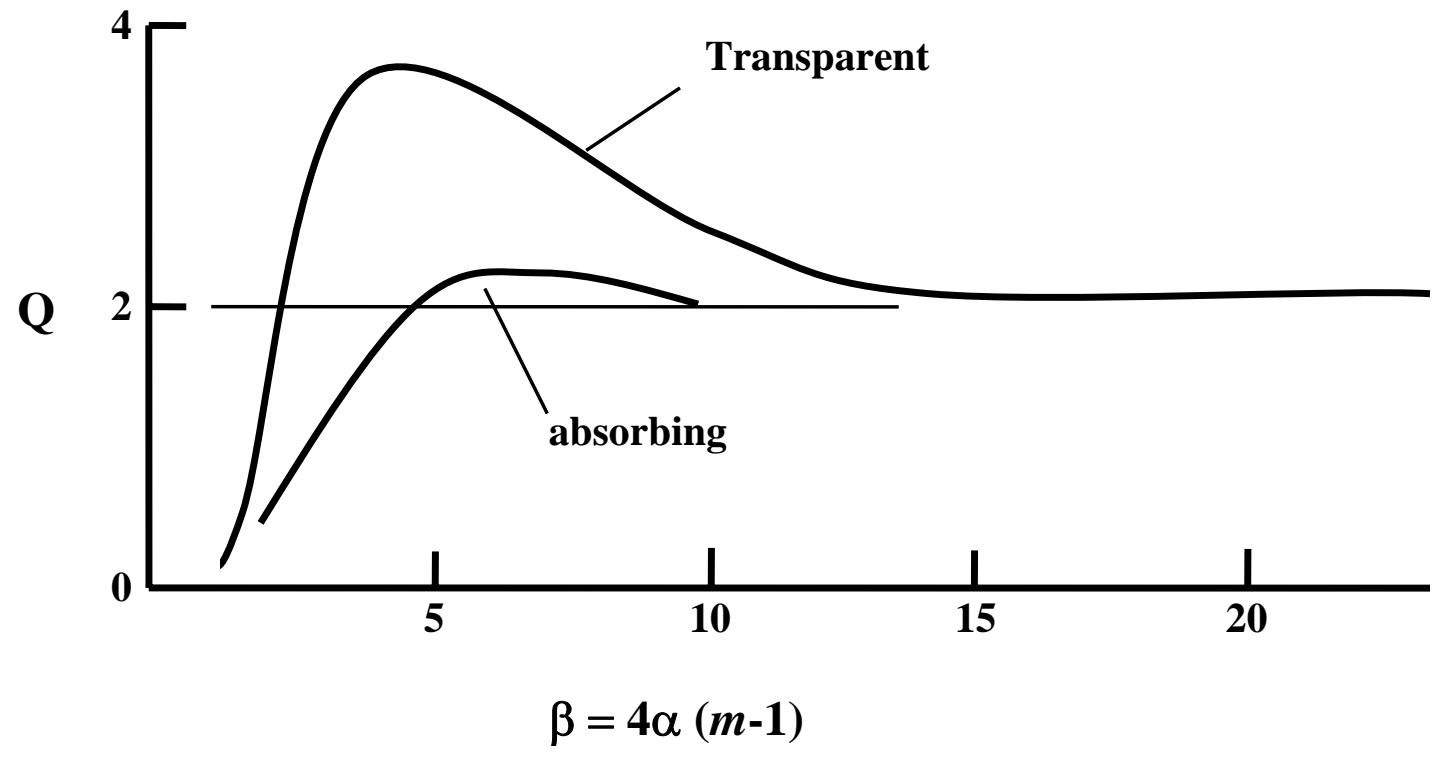

Figure 5.6 - Q values for different values of beta [31] (redrawn) 


\subsection{Probe Calibration}

The final two constants necessary for solving for solids fractions using equation 5.1.12 were the fraction, $\mathrm{k}_{1}$, of non-transmitted light detected by the probe from equation 5.1.5 and the number concentration to volume concentration conversion factor, $\mathrm{k}_{2}$, from equation 5.1.6. These two constant were determined by performing a novel bed depth calibration procedure. The probe was mounted pointing upwards inside a packed bed of particles, as shown in Figure 5.7. The probe was moved into the packed bed at $0.1 \mathrm{~mm}$ increments. Particles were added to the bed after each change in position and leveled off by scraping the top of the funnel. A sample was taken with the probe at each incremental measurement. This measurement was repeated four times in order to obtain duplicate samples to determine the $95 \%$ confidence interval. This process was repeated until the probe reached a maximum bed depth of $5 \mathrm{~mm}$.

The vernier used in the calibration had a step change of $0.1 \mathrm{~mm}$, so higher resolution could not be obtained. In order to estimate the light contribution from each layer, the measurements were plotted and a cubic equation was fit to the data, which is shown in Figure 5.8. The interpolated curve fit the measured data well, with an $\mathrm{R}^{2}$ value of over 99\%. The y-error bars represent the 95\% confidence interval of the test over four samples taken. The x-error bars represent the precision of the vernier. The voltage variations can be attributed to the accuracy of the vernier as well as the possible changes in the bed conditions. It was determined that the voltage reached a constant value at a bed depth of $0.4 \mathrm{~mm}$, so it was unnecessary to plot the maximum of $5 \mathrm{~mm}$ into the bed of particles. 


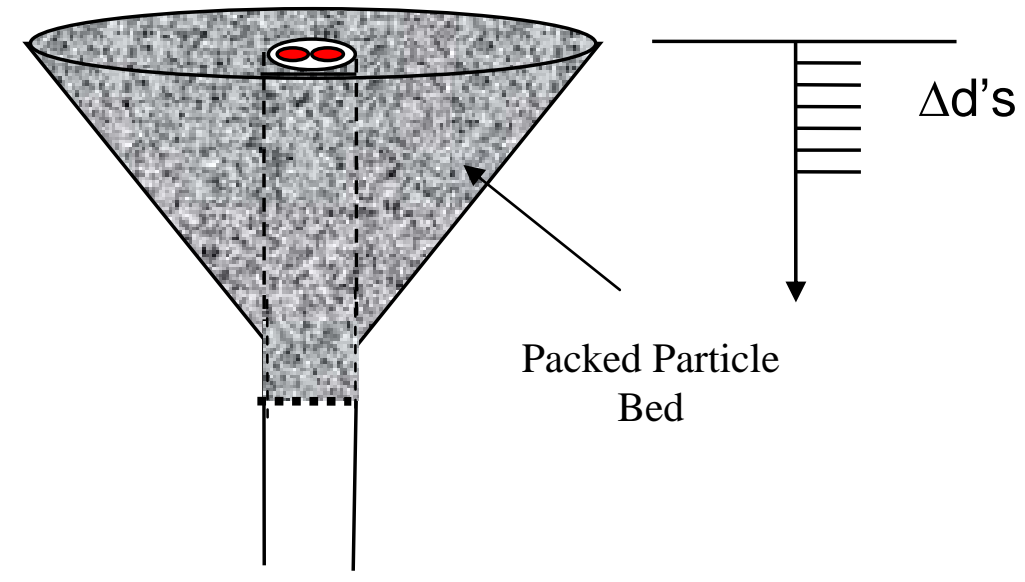

Figure 5.7 - Bed Depth Experimental Setup

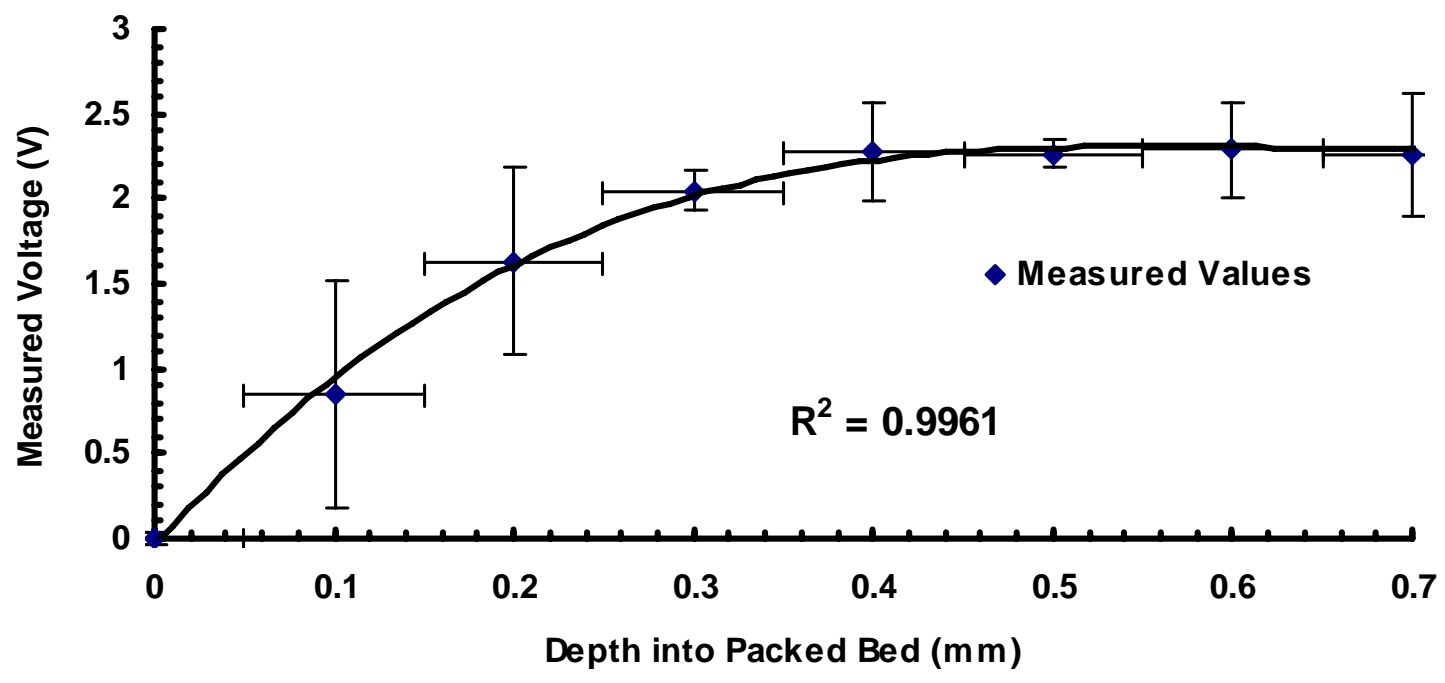

Figure 5.8 - Bed Depth Measurement for $64 \mu \mathrm{m}$ Glass Beads

The fitted curve in Figure 5.8 was used to interpolate the data for the layer-by-layer analysis mentioned above.

Two bed conditions exist. The "packed" bed condition is when the particles are forced to settle within the interstitial spaces of the bed by tapping or shaking the bed. The "fluffed" bed condition is when the particles are not forced to settle within the interstitial spaces. Since the particles were not forced to settle into interstitial spaces, the 
dense beds in all calibration procedures were assumed to be at a "fluffed" bed condition. Solids fractions of the material both packed and fluffed were determined using a pycnometer. The pycnometer was weighed dry, and then a sample of the particles was placed into the pycnometer and weighed again. With the weight and bulk density of the material known, the volume of the sample was determined. Next, the remainder of the space inside the pycnometer was filled with water and the pycnometer was weighed again. The apparent volume of the solids and total volume of water were calculated and the water volume above the solids was then determined by knowing the difference between the volume of the pycnometer and the volume of the solids. The water in between the solids was determined by taking the difference between the total volume of water and the volume of water above the solids. The void fraction was calculated by taking the ratio of the interstitial volume of water determined above and the total volume of the pycnometer. The solids fraction is one minus the void fraction. Both glass beads batches had packed bed solids fraction values within $\pm 2 \%$ of each particle batch. The results from the larger particle batch are shown Figure 5.9. 


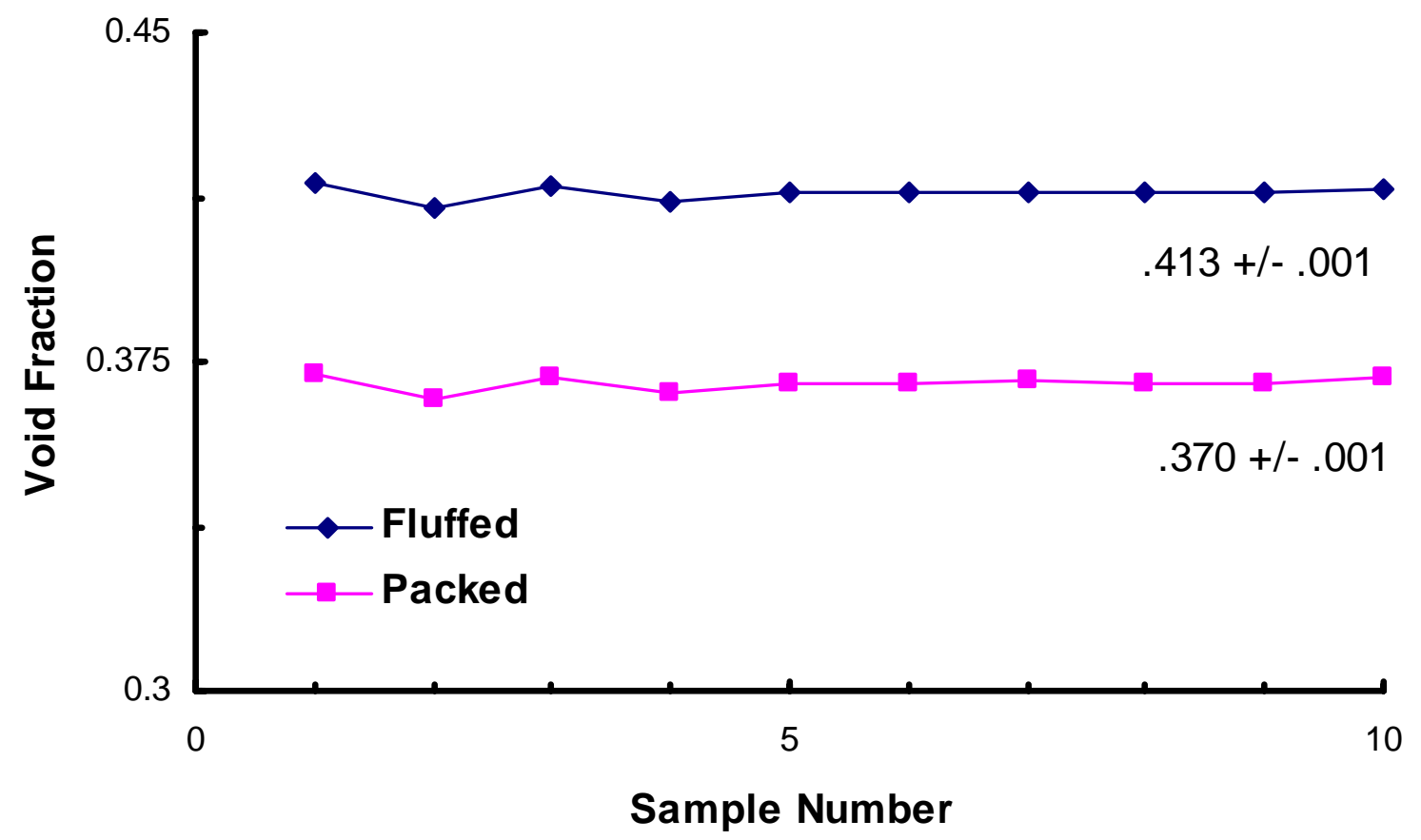

Figure 5.9 - Glass Bead Void Fractions, $180 \mu \mathrm{m}$ Glass Beads

Since there were two unknowns, two equations had to be used in order to find $\mathrm{k}_{1}$ and $\mathrm{k}_{2}$. However, which two equations was an uncertainty. The first equation used was the equation for one particle layer $(\mathrm{i}=0)$, which is the straightforward approach to solve for $k_{1}$ in terms of $k_{2}$ :

$$
k_{1}=\frac{I_{R 1_{\text {Messured }}}}{I_{0}\left(1-e^{-\left(\frac{\pi d^{2}}{4}\right) Q k_{2}(1-\varepsilon) \ell}\right)}
$$

Equation 5.2.3 was substituted into all equations from two particle layers (i=1) to seven particle layers (i=6), which is where the signal was assumed to be constant as shown in 
Figure 5.8, and the constants that had the best fit with the interpolated values were used. Example calculations of the $\mathrm{k}$ values can be found in Appendix I.

As seen in Figure 5.10, the $\mathrm{k}$ values for 4 particle layers ( $\mathrm{i}=3$ ) deviated the least from the interpolated values. The calculated $\mathrm{k}$ values for four particle layers had a maximum difference of $\pm 4 \%$ of the interpolated layer-by-layer values. Therefore, the $\mathrm{k}$ constants using equation 5.2.3 and equation 5.1.12 with four particle layers (i=3) were used for the $64 \mu \mathrm{m}$ particle batch. Figure 5.3 shows that the contribution to the reflected light was minimal after 4 particle layers (i=3), so these values were expected. For the 64 $\mu \mathrm{m}$ particles, the fraction of light reflected back into the probe, $\mathrm{k}_{1}$, was approximately $54 \%$ of the non-transmitted light.

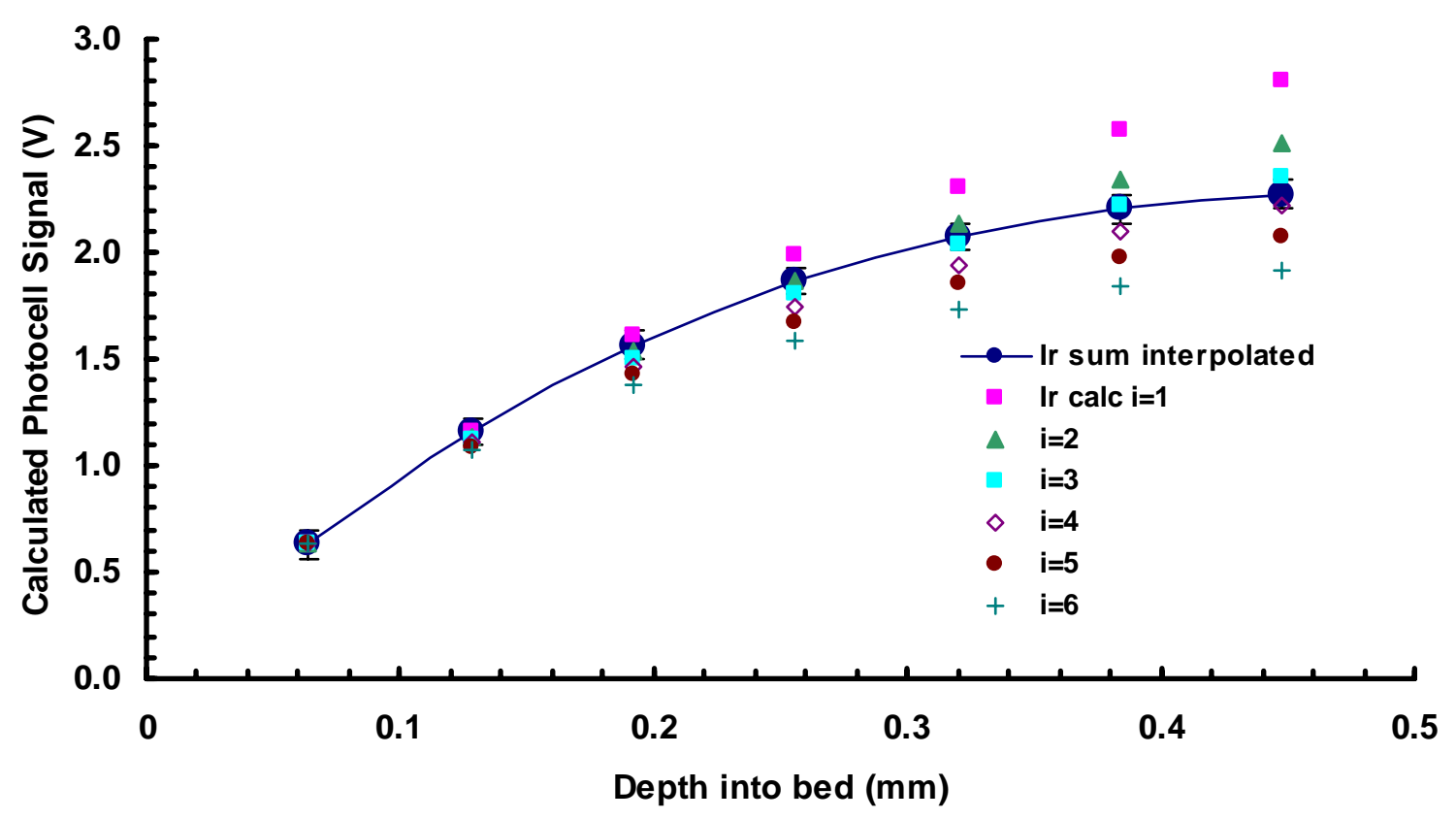

Figure 5.10 - Interpolated Values Compared with Calculated Values of the Probe signal from bed depth experiment, $64 \mu \mathrm{m}$ glass beads.

Lastly, the solids fraction values were solved for using equation 5.1.12, the number of particle layers necessary to represent a packed bed of particles from Figure 
$5.8, \boldsymbol{\ell}$ as the average diameter of one particle, $\mathrm{Q}$ as 2 , and the $\mathrm{k}$ constants which were solved above. The signal from the probe is the only input value, as all other values are known. The solids fraction, (1-ع), is the only independent variable in equation 5.1.12.

The constants were solved for with the $180 \mu \mathrm{m}$ glass beads using the same process. This was necessary because the calibration must be performed for different particle types and sizes. Two different probes both manufactured by Vector Scientific were calibrated for the larger particle batch due to small differences in the probes. The newer probe system was called the "VSI2000" and the older probe was labeled "VectorS.” . The bed depth calibration method mentioned above was performed for both probe systems and the results are shown in Figure 5.11. Cubic equations were fit to both sets of data. $\mathrm{R}^{2}$ for both interpolated curves were above $98 \%$.

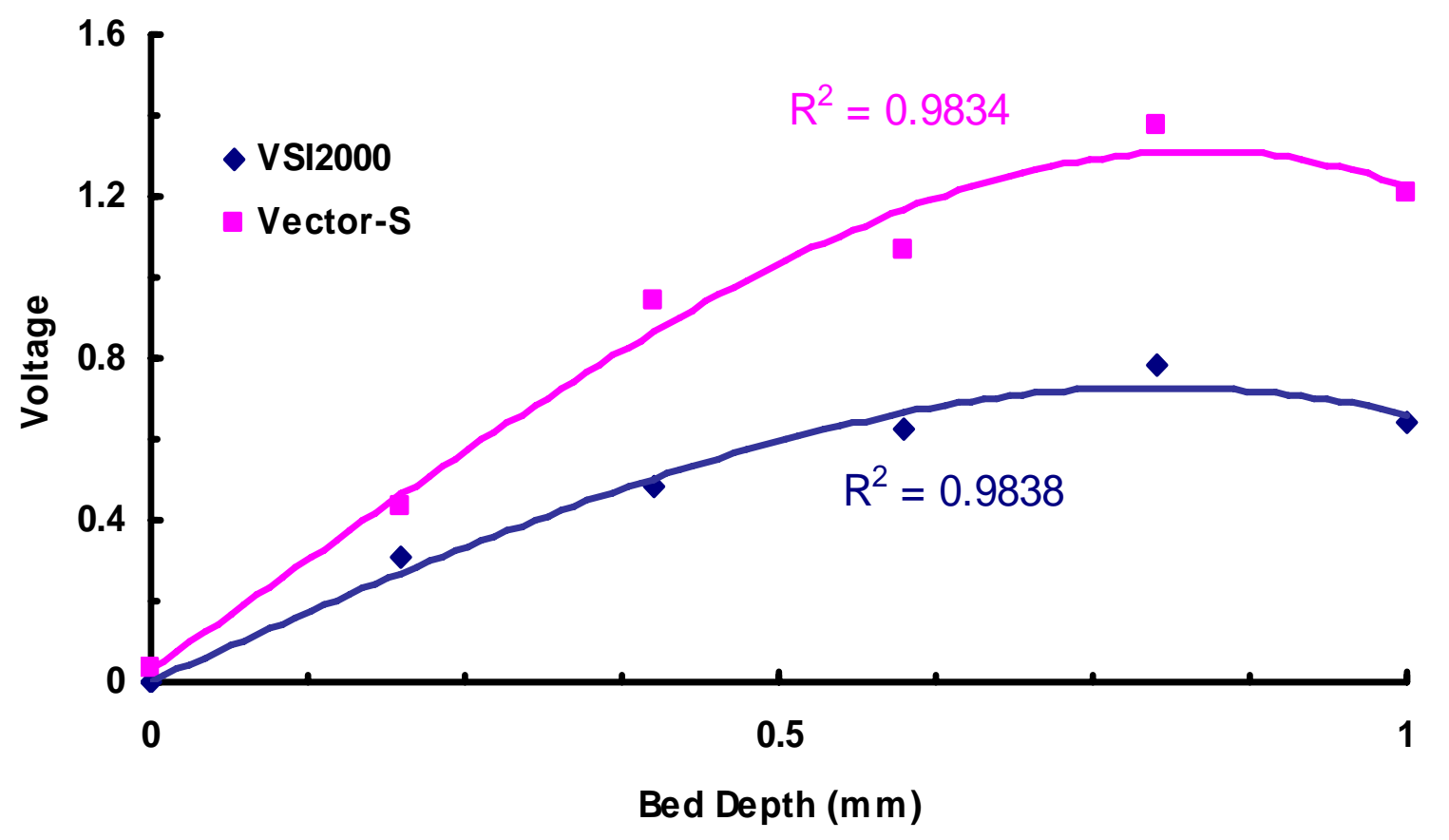

Figure 5.11 - Bed Depth Measurement for $180 \mu \mathrm{m}$ Glass Beads 
Equations 5.1.12 and 5.2.3 were used once again to determine the " $\mathrm{k}$ " constants for both probes. Since the signal became constant at 4 particle layers, $i=3$ was the maximum value used in equation 5.1.12 and these results are plotted in figures 5.12 and 5.13. The fraction of light, $\mathrm{k}_{1}$, detected by the probe for the VSI2000 and the Vector-S systems were approximately $24 \%$ and $44 \%$, respectively.

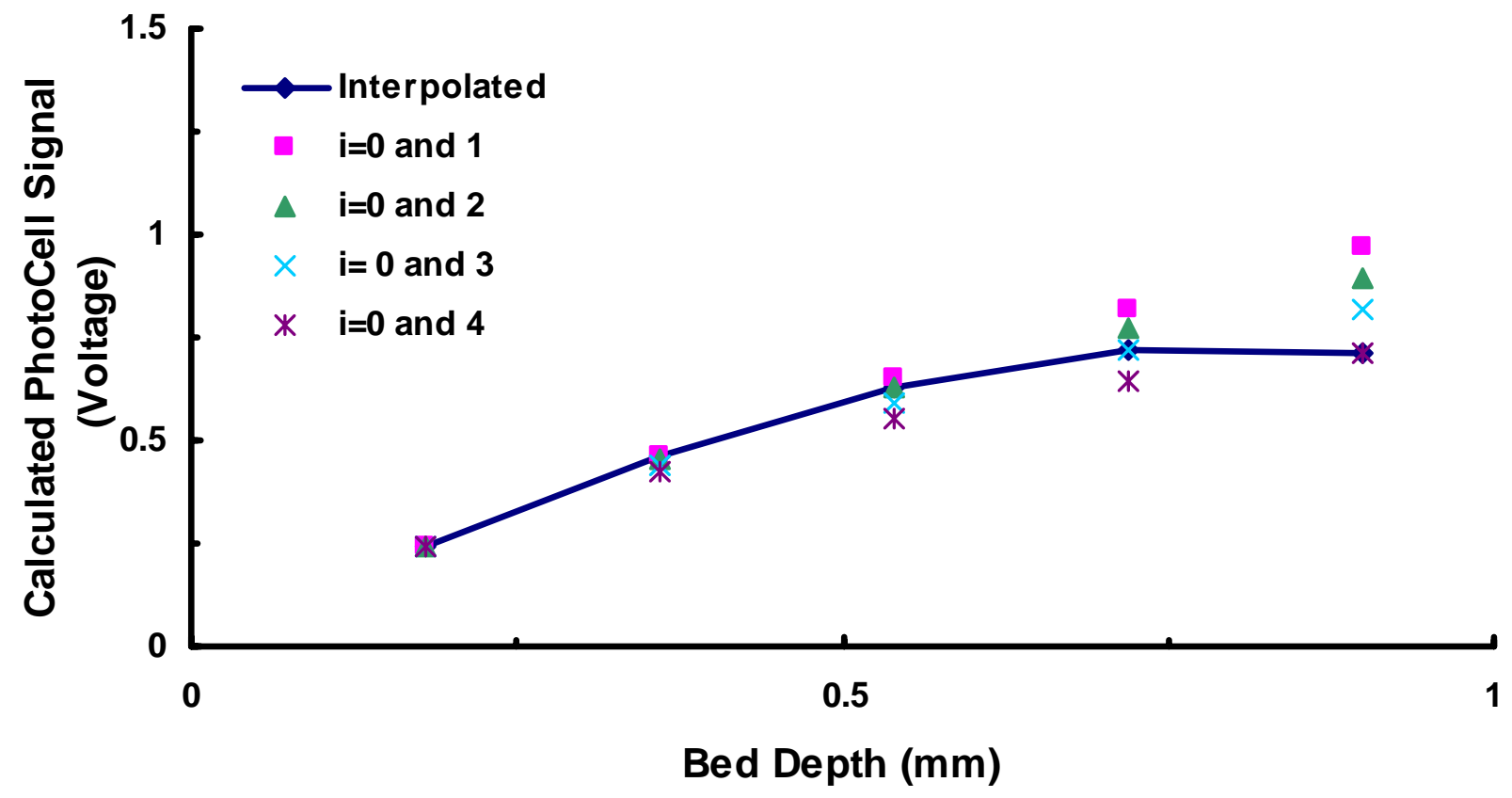

Figure 5.12 - Interpolated Values Compared with Calculated Values of the Probe's signal from bed depth experiment, $180 \mu \mathrm{m}$ glass beads (VSI2000). 


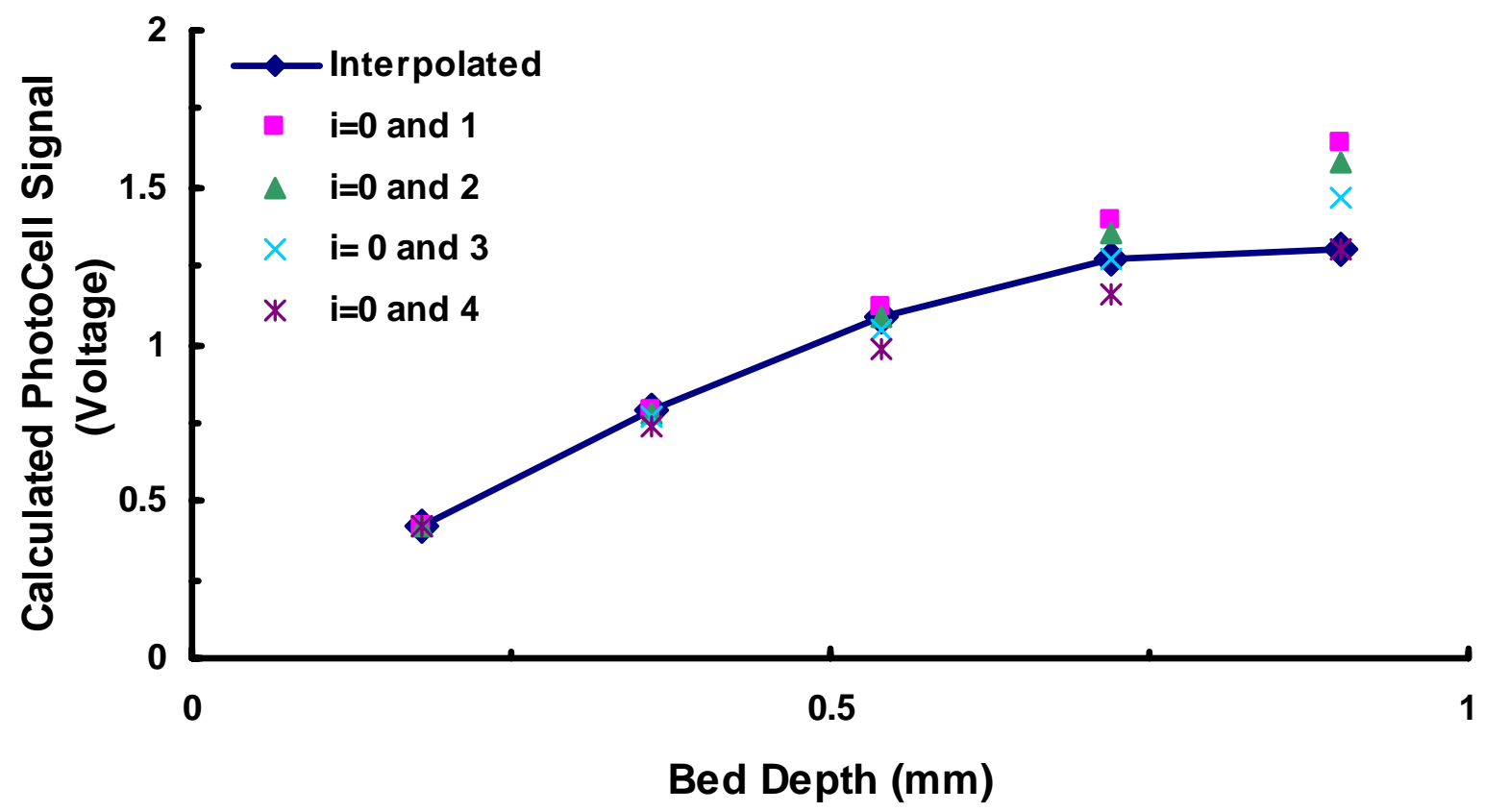

Figure 5.13 - Interpolated Values Compared with Calculated Values of the Probe's signal from bed depth experiment, $180 \mu \mathrm{m}$ glass beads (Vector-S). 


\section{Application}

\subsection{Test Facility}

The model described in Chapter 5 has been used to extract solids fractions from fiber optic probe data taken inside the riser of a Circulating Fluidized Bed (CFB) located at the National Energy Technology Laboratory (NETL) in Morgantown, West Virginia in order to determine if the model could be used in a practical system to yield consistent results. This cold-flow CFB unit was described in Monazam et al. [32] (2001) with glass beads as the bed material. Time constraints and administrative decisions limited the tests performed with the $64 \mu \mathrm{m}$ glass spheres. The dimensions and configuration of the CFB system are shown in Figure 6.1. 


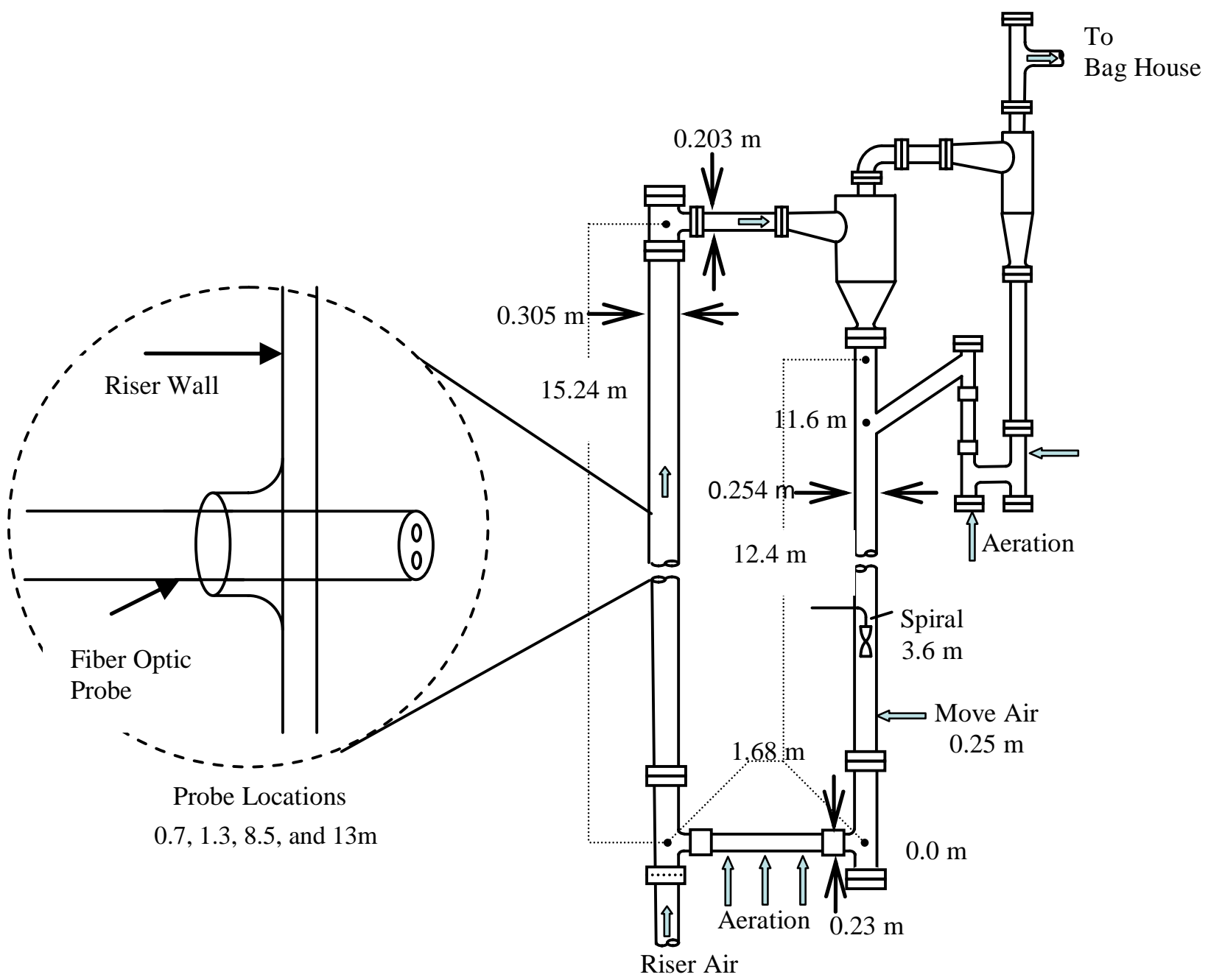

Figure 6.1 - CFB System and Probe Locations

The $64 \mu \mathrm{m}$ particle batch was used in the bed under two conditions, where the superficial gas velocity $\left(U_{g}\right)$ was fixed at $5.17 \mathrm{~m} / \mathrm{s}$ and the solids circulation rate $\left(M_{s}\right)$ was varied between $5,400 \mathrm{~kg} / \mathrm{hr}$ for the dilute flow condition and 33,500 kg/hr for the core annular flow condition. Both conditions were in the transport flow regime above the second transport velocity as defined by Monazam et al. [32].

The $180 \mu \mathrm{m}$ particle batch was tested under five different conditions. Four of the conditions involved alternating between 5.5 and $7.6 \mathrm{~m} / \mathrm{s}$ for $\mathrm{U}_{\mathrm{g}}$ and 22,700 and 79,400 $\mathrm{kg} / \mathrm{hr}$ for $\mathrm{M}_{\mathrm{s}}$. The other flow condition was a $U_{\mathrm{g}}$ value of $6.4 \mathrm{~m} / \mathrm{s}$ and an $\mathrm{M}_{\mathrm{s}}$ value of 
$51,000 \mathrm{~kg} / \mathrm{hr}$. This condition was defined as the "centerpoint" flow condition. All tests were performed in the transport flow regime, as described by Monazam et al [34] (2006).

\subsection{Probe Setup}

The fiber optic probe was positioned into the riser for the CFB studies conducted with the $64 \mu \mathrm{m}$ glass beads. Fiber optic probe data were acquired in a random sequence in all three dimensions in order to characterize particle mixing inside the riser. Midpoints of five equal area positions were used to obtain a radial profile of solids fractions and particle velocities, as well as an integral average of that radial profile. The behavior of the solids within these five equal area positions was assumed to be represented by the midpoint of each equal area "ring." This radial profile was obtained azimuthal locations of 90 and 180 degrees at the 1.3 meters above the centerline of the solids inlet and 0, 90, and 270 degrees at 8.5 meters above the centerline of the solids inlet. The orientations of the azimuthal locations to the CFB unit are illustrated in Figure 6.2.

Riser profile data were also obtained in the CFB studies conducted with the 180 $\mu \mathrm{m}$ glass beads. Once again, fiber optic data were acquired in a random sequence in three dimensions for these tests. Data at six radial positions were taken in these tests to represent the radial profile. These six positions contained the same midpoints of five equal area positions of the riser, with the sixth point being at the wall of the CFB. The sixth point was added to determine if there was a dramatic change of solids mixing at the wall of the CFB. These radial profiles were acquired at 0,90 , and 180 degrees for the 0.7 meter and 8.5 meter elevations and at 45, 135, 225, and 315 degrees at the 13 meter elevation. The 45 degree shift in azimuthal locations was due to available port locations in the riser. The test matrix for both CFB studies can be found in Appendix II. 


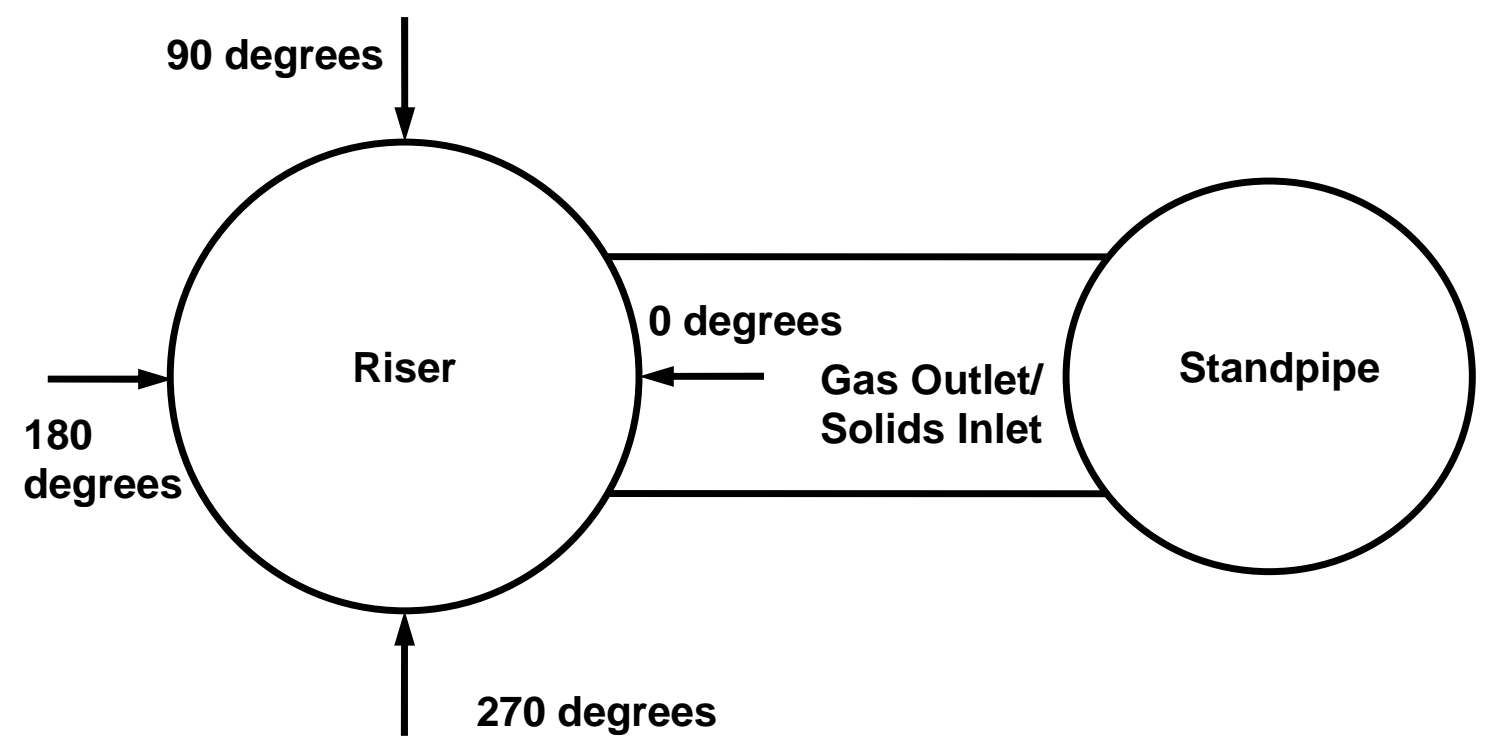

Figure 6.2 - Riser Azimuthal Orientation

The sampling frequency required to obtain accurate particle velocities inside the CFB riser were calculated using the following equation:

$$
f=\frac{V_{p}}{d}\left(\frac{V_{p}}{E_{\max }}-1\right)
$$

where $f$ is the sampling frequency in hertz, $V_{p}$ is the maximum measured particle velocity in meters per second, $d$ is the distance between the fiber bundles in meters, and $E_{\max }$ is the user-defined maximum allowable error in the velocity measurement in meters per second [27]. The sampling frequencies and sample times from each probe are shown in Table 6.1. The sampling time for the CFB tests with the $180 \mu \mathrm{m}$ particle batch were increased to obtain more duplicates within each riser flow condition. A sample calculation in determining the sampling frequency can be found in Appendix II. 
Table 6.1 - Sampling Rate Data for Fiber Optic Probe Systems

\begin{tabular}{|c|c|c|c|}
\hline $\begin{array}{c}\text { Average Particle } \\
\text { Diameter }\end{array}$ & $64 \mu \mathrm{m}$ & \multicolumn{2}{|c|}{$180 \mu \mathrm{m}$} \\
\hline Probe System & Vector-S & Vector-S & VSI2000 \\
\hline Sampling Rate (kHz) & 12.5 & 12.5 & 15.58 \\
\hline Series Size & 200 & 1700 & 670 \\
\hline Samples Per Series & 1024 & 1024 & 4096 \\
\hline Sampling Time (s) & 16.38 & 139.26 & 176.14 \\
\hline
\end{tabular}

\subsection{Comparisons}

The first analysis involved comparing the solids fractions extracted from the data taken with the fiber optic probe with two other solids fraction measurement methods currently implemented in the CFB riser. One of these methods involved extracting samples of solids from the riser through a $9.525 \mathrm{~mm}$ O.D. stainless steel tube at five equal area locations that are equivalent to those used with the fiber optic probe. The solids fraction is calculated by weighing the sample of solids and recording the time in which the sample was taken.

The second method involved using the change in pressure inside the riser to determine solids fractions. The methods using the fiber optic probe and solids sampling probe were averaged over the five equal area positions in order to compare with the global pressure drop method. The solids fractions were calculated with the pressure drop measurements with the following equation:

$$
(1-\varepsilon)=\left(\frac{\Delta P}{\Delta L}\right) / g * \rho_{\text {glass }}
$$

where (1- $\varepsilon$ ) is the solids fraction, $\Delta \mathrm{P}$ is the pressure drop across the two pressure taps located above and below the fiber optic probe, $\Delta \mathrm{L}$ is the distance between the two taps, $\mathrm{g}$ is the acceleration due to gravity, and $\rho_{\text {glass }}$ is the density of the glass spheres. The data 
used in these comparisons were from measurements taken at the $8.5 \mathrm{~m}$ elevation with the larger diameter glass spheres as the bed material. Many measurements involving the three methods were taken at this elevation and the location was assumed to be the fullydeveloped region of the riser.

\subsection{Azimuthal Dependency}

The second data analysis was to determine azimuthal dependency in the riser at the elevations described above. This was determined through a statistical analysis that determines the amount of variability that independent variables have on a dependent variable. This analysis of variance (ANOVA) was used to determine the number of azimuthal locations necessary to represent the particle3 mixing in an entire cross section of the riser at a given elevation. ANOVAs were performed for the solids velocity and solids fraction data provided by the fiber optic probe.

In an ANOVA, degrees of freedom indicate the effective number of observations which contribute to the sum of squares. It is quantified by to the total number of observations minus the number of linear constraints in the data. The sum of squares (SS) is a quantitative measure of how much the group average of the dependent variables deviates from the overall average of independent variables. The p-value is the probability that the result found is as extreme as or more extreme than what was observed; i.e. it is essentially the same as the confidence interval.

These ANOVAs were executed through a statistics analysis program called "JMP” [34]. The two dependent parameters involved were the solids volume fractions and the local average velocities, which were considered normally distributed and the significance was determined at the $95 \%$ confidence interval. An example calculation of 
the 95\% confidence interval can be found in Appendix I and all solids fraction radial profiles determined with these experiments can be found in Appendix III. 


\section{Results and Discussion}

\subsection{Fiber Optic Probe Calibration}

The solids fractions values extracted from the data obtained using the fiber optic probe were determined to be favorable with the values recorded during the bed depth calibrations. As previously discussed, for the $64 \mu \mathrm{m}$ particle batch, calculated values using equation 5.1 .12 were within $\pm 4 \%$ of the interpolated values during the bed depth calibration and approximately 54\% of the non-transmitted light was detected by the probe, which was determined by solving for $\mathrm{k}_{1}$. For the $180 \mu \mathrm{m}$ particle batch, the calculated values had a maximum deviation of $\pm 5 \%$ from the interpolated curve and the fraction of non-transmitted light detected by the VSI2000 and the Vector-S probes were approximately $24 \%$ and $44 \%$, respectively. This difference in detected light could be due to the random fiber bundle configuration which was mentioned previously in Chapter 4. It is important to note that it is necessary for the calibration material to be identical to that of the bed material to obtain accurate results when using this method. Refer to Chapter 5 for all calibration curves, figures, and equations.

\subsection{Comparisons}

\subsubsection{Solids Sampling}

The local solids volume fractions results obtained using the present fiber optic probe and data reduction method have been compared with the local solids sampling probe results at the $8.5 \mathrm{~m}$ elevation of the CFB riser at all five flow conditions mentioned 
for the $180 \mu \mathrm{m}$ particles. The comparison of results are presented in figures 7.1-7.5, with error bars representing the $95 \%$ confidence interval for the data obtained with the fiber optic probe. The amount of data taken with the solids sampling probe were insufficient to find the 95\% CI, so standard deviation bars were presented. The number of duplicates taken for each flow condition can be found in the "Solids Fraction Test Matrix" in Appendix II.

For the (low $\mathrm{U}_{\mathrm{g}}$, low $\mathrm{M}_{\mathrm{s}}$ ) condition depicted in Figure 7.1, the two probes agree reasonably well, with both data sets showing the trend of very low concentration of solids towards the center of the riser, and a rapid increase in concentration as $\mathrm{r} / \mathrm{R}$ increases. This is due to the shape of the gas velocity profile with lower gas velocities at the wall and higher velocities towards the center, causing the particles to become more concentrated near the wall.

The (low $\mathrm{U}_{\mathrm{g}}$, high $\mathrm{M}_{\mathrm{s}}$ ) condition is illustrated in Figure 7.2. There is some discrepancy in the measurements between the fiber optic probe and the solids sampling probe, especially as the wall is approached, at this condition, which could be attributed to the fact that this was a high solids loading in the riser, which may have caused the solids sampling probe to obtain a non-isokinetic sample. Isokinetic sampling requires the probe to obtain solids from the riser at the same localized particle velocity as in the riser, therefore obtaining isokinetic particle flux samples. The sampling probe used solids velocities, not gas velocities, in order to obtain a flow rate of gas to attempt isokinetic sampling, which can also cause under sampling. Moreover, The sampling probe uses an average velocity to acquire samples, where the flow behavior inside the riser is turbulent, causing fluctuating velocities, especially near the wall, which could also cause 
discrepancies in the measurements. However, the fiber optic probe records much higher solids concentrations at this higher loading condition, which is the trend that was expected.

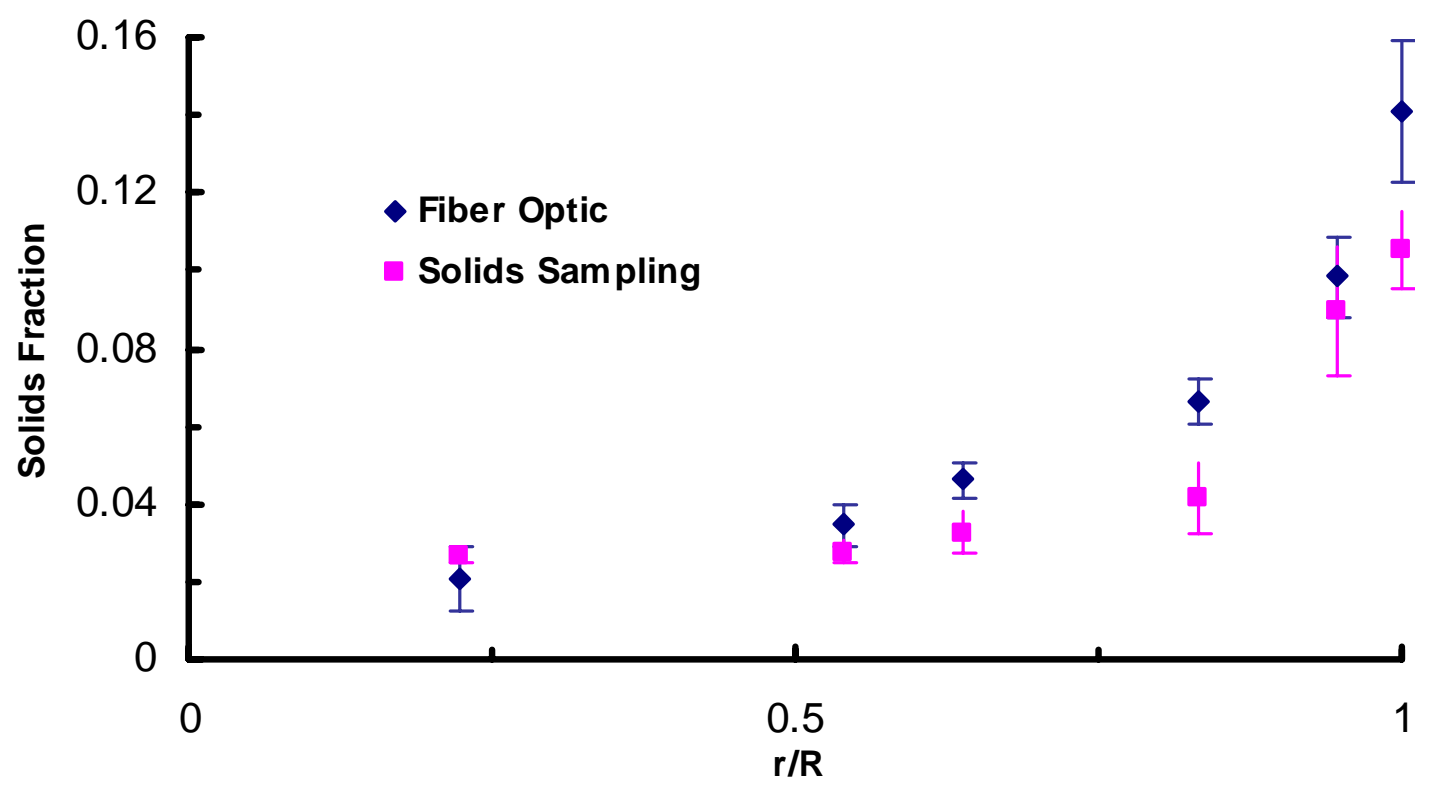

Figure 7.1 - Solids Fraction comparison at Low Ug, Low Ms Condition along the riser radius

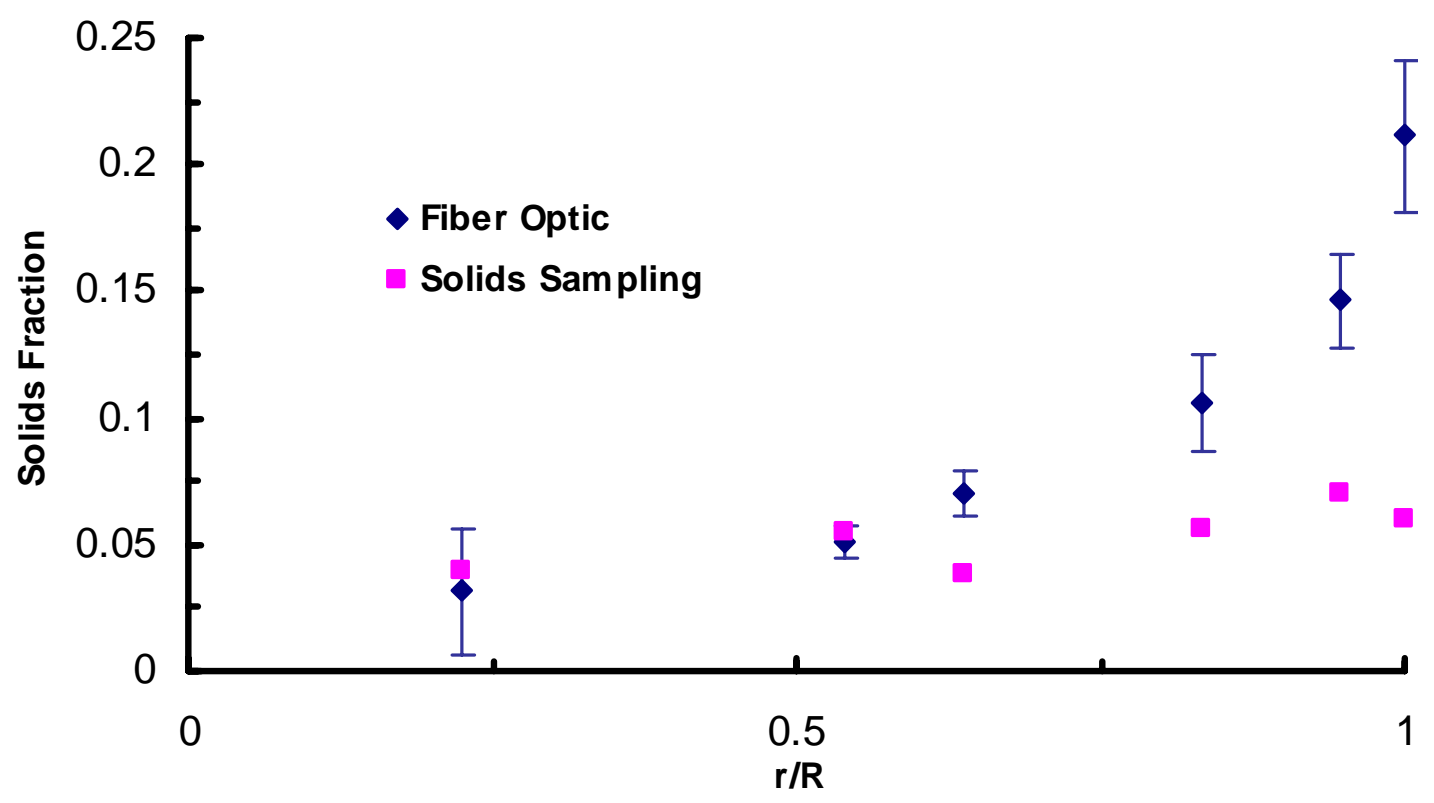

Figure 7.2 - Solids Fraction Comparison at Low Ug, High Ms Condition along the riser radius 
Figure 7.3 Illustrates the solids fraction profile at the centerpoint condition, defined where $\mathrm{U}_{\mathrm{g}}=6.4 \mathrm{~m} / \mathrm{s}$ and $\mathrm{M}_{\mathrm{s}}=51,000 \mathrm{~kg} / \mathrm{hr}$. The two probes once again agree quite well, with the solids sampling probe providing slightly lower values. This could once again be explained by the fact that the probe was undersampling for the reasons explained above, and the fiber optic probe once again shows a rapid increase in loading as $\mathrm{r} / \mathrm{R}$ approaches 1 .

The (high $\mathrm{U}_{\mathrm{g}}$, low $\mathrm{M}_{\mathrm{s}}$ ) condition is the next steady state condition illustrated in Figure 7.4. As expected, this was the lowest solids concentration of all of the conditions described, and both probes once again agree well, with the exception of the measurements taken near the wall.

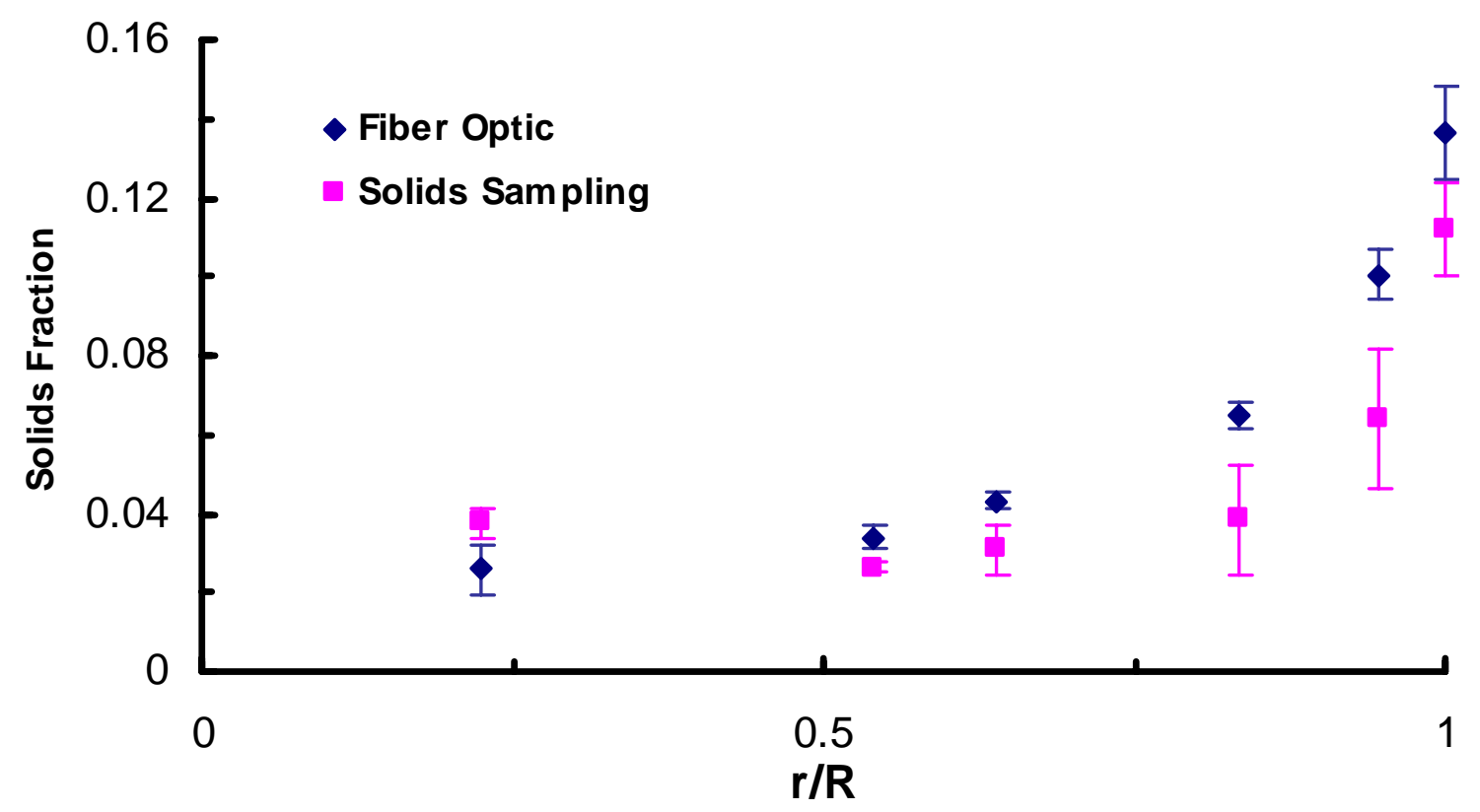

Figure 7.3 - Solids Fraction Comparison at "Centerpoint" Condition along the riser radius 
One $\mathrm{r} / \mathrm{R}$ value appears to be the only difference between the two probes for the (high $U_{g}$, high $M_{s}$ ) illustrated in Figure 7.5. This could once again be due to the solids sampling probe undersampling for the explanations mentioned above.

There exist other reasons that could explain the observed discrepancies between the solids sampling and fiber optic probe measurements, such as the solids sampling probe not accounting for the horizontal flow of particles. The probe was used to take a sample with the tip of the probe pointing down and then a sample with the tip pointing up. This is performed because the primary purpose of this probe was to measure upward and downward flowing solids fluxes. Additionally, it was proposed that the probe could have become partially clogged with solids during sampling at the higher solids loading conditions.

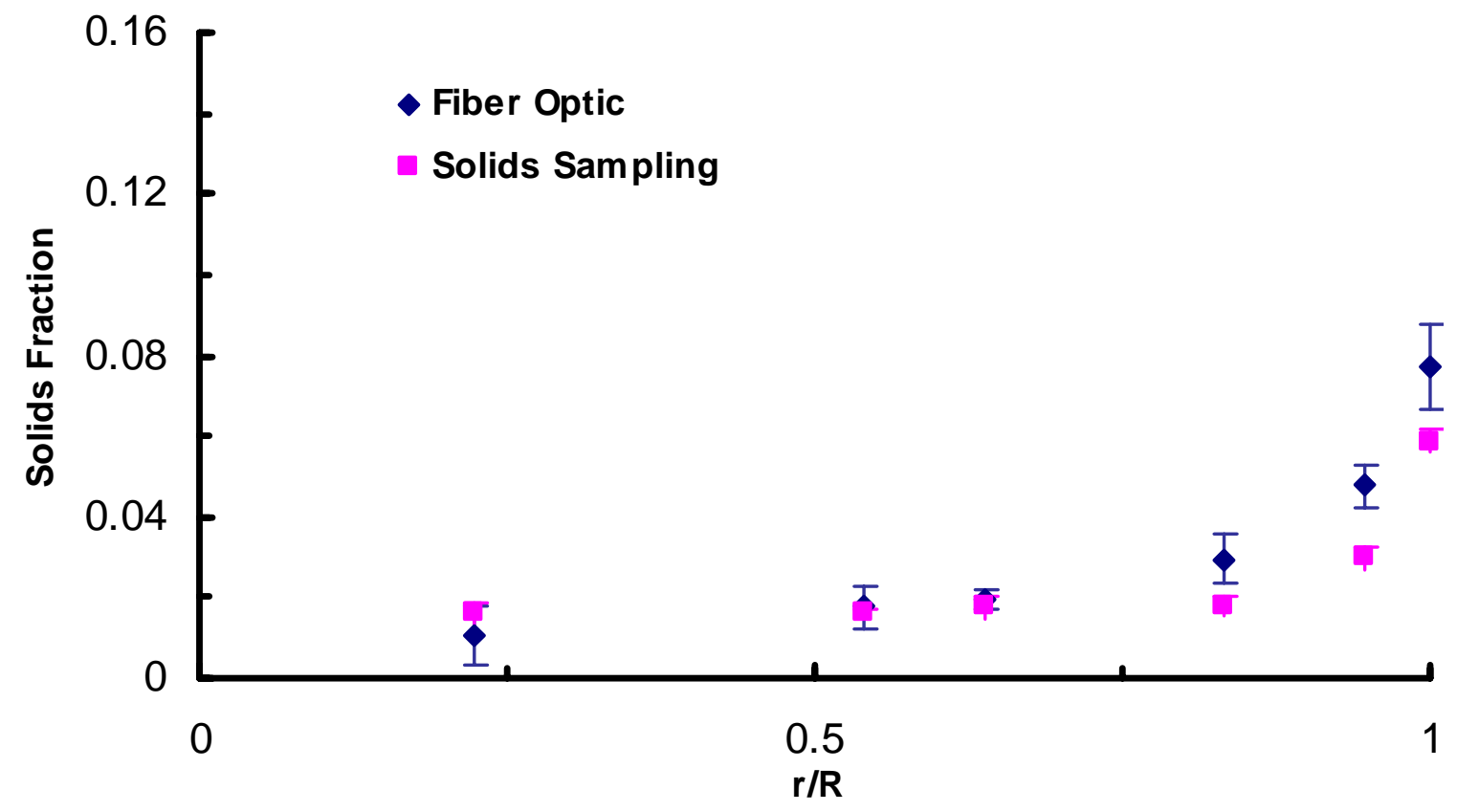

Figure 7.4 - Solids Fraction Comparison at High Ug, Low Ms Condition along the riser radius 


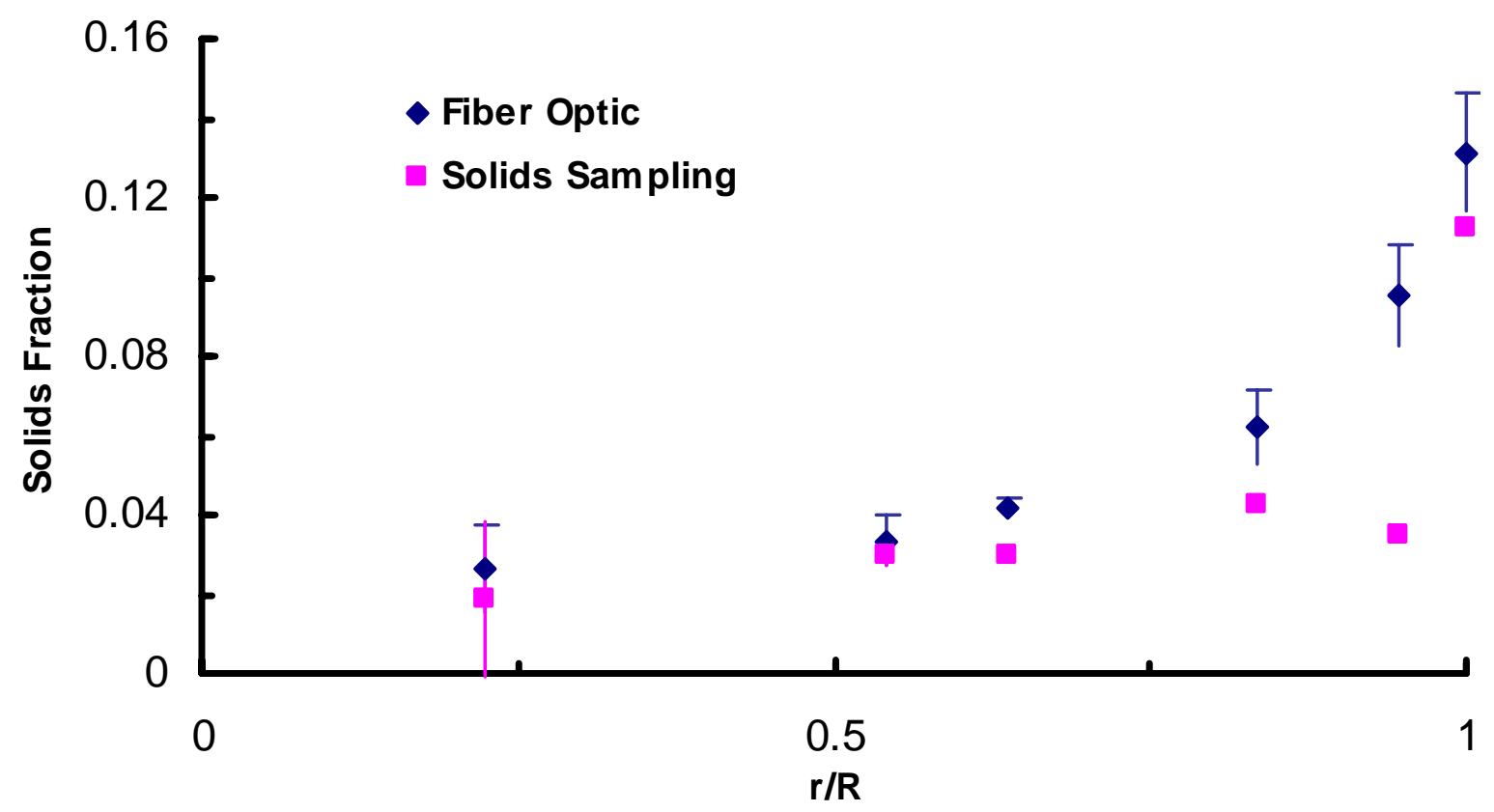

Figure 7.5 - Solids Fraction Comparison at High Ug, High Ms Condition along the riser radius

\subsubsection{Pressure Drop}

The solids fraction radial profiles from the data obtained at the $8.5 \mathrm{~m}$ elevation using the fiber optic probe and the solids sampling probe were then compared to the solids fractions calculated using equation 6.3.1 and the pressure drop in the riser. The values found with the fiber optic probe and pressure drop measurements were determined at the 95\% confidence interval and the results are shown in Figure 2.1, where the load ratio represents the ratio of solids mass flux and gas mass flux. The pressure drop measurements and fiber optic probe measurements agree well, with the confidence intervals of the two measurement methods intersecting in all conditions tested. However, the solids sampling probe results deviate from the other two measurement methods above 
a mass load ratio of 20; this is believed to be due to errors in this measurement method as described previously.

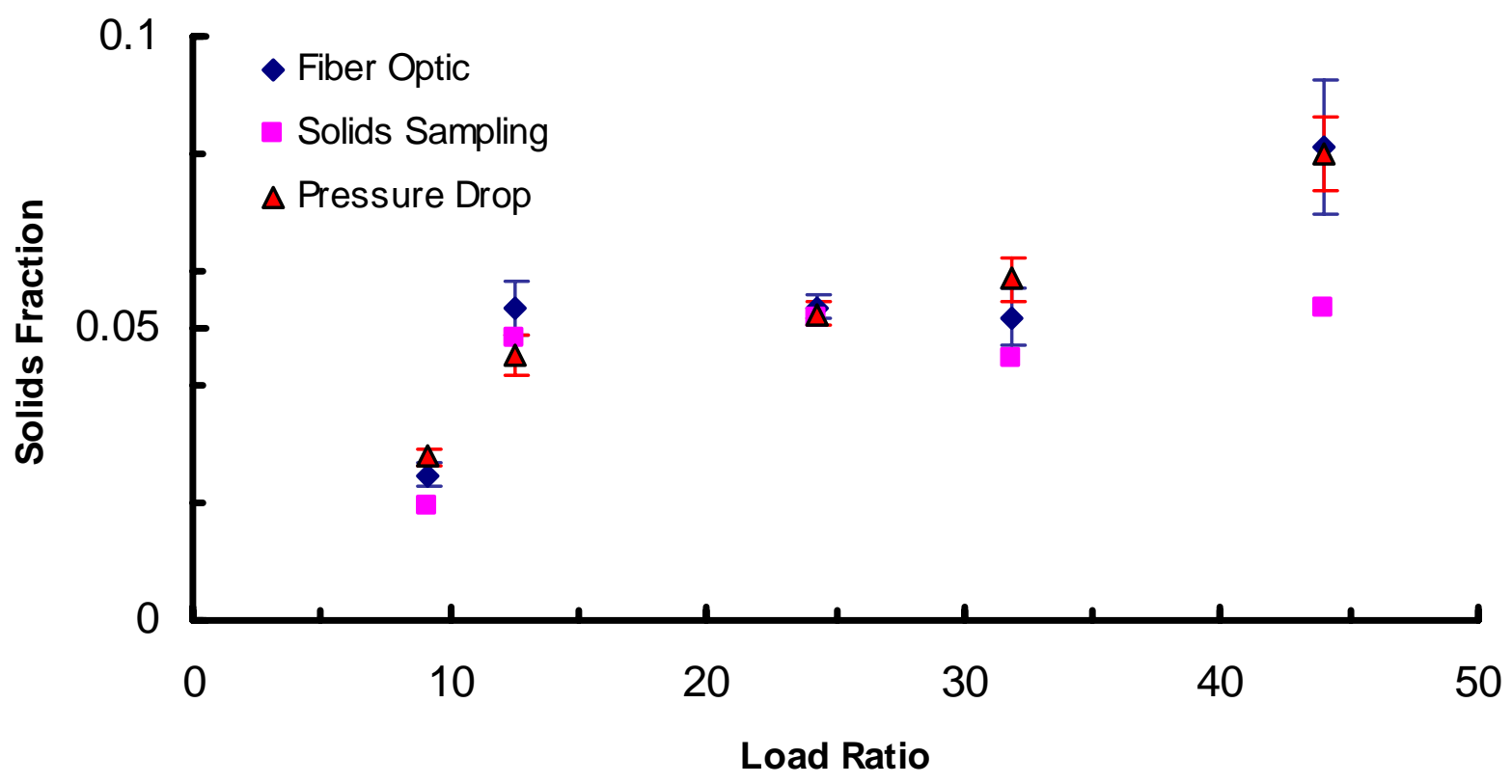

Figure 7.6 - Solids Fraction Comparisons at Different Load Ratios by three methods

\subsection{Azimuthal Dependency}

The next set of analyses involved using the solids fractions and solids velocities extracted from the voltage data obtained with the fiber optic probe to determine if there was any dependency on azimuthal location in the riser at several elevations. The probe was positioned in the riser after the solids inlet $(1.31 \mathrm{~m})$ at the 0 and 90 degree azimuthal locations and at the fully developed region (8.5m) at the 0,90 , and 270 degree locations for the tests conducted with smaller glass spheres as the bed material. For all ANOVAs, 
the independent variables were considered significant when the probability (p-value) was less than 0.05 . Therefore, the solids fractions or solids velocities were considered azimuthally dependent of the p-value for the “Angle” was less than 0.05.

The effects on solids concentrations at the $1.31 \mathrm{~m}$ level of the riser are shown in Table 7.1. As expected, the variability in solids fraction depends on the flow conditions, $\mathrm{U}_{\mathrm{g}}$ and $\mathrm{M}_{\mathrm{s}}$. Additionally, it was expected that the solids concentrations were different at different radial locations (r/R), which was demonstrated in the table. Due to the high amount of turbulence near the solids inlet, the solids fractions and solids velocities in the riser are considered azimuthally dependent at the $1.31 \mathrm{~m}$ elevation.

Table 7.1- ANOVA for 64-micron Particles, $1.3 \mathrm{~m}$ level

\begin{tabular}{|c|c|c|c|c|}
\cline { 2 - 5 } \multicolumn{1}{c|}{} & Source & $\begin{array}{c}\text { Degrees } \\
\text { of } \\
\text { Freedom }\end{array}$ & $\begin{array}{c}\text { Sum of } \\
\text { Squares }\end{array}$ & p-value \\
\hline \multirow{4}{*}{$\begin{array}{c}\text { Solids } \\
\text { Fraction }\end{array}$} & $\mathbf{U g}$ & 1 & 0.003 & 0.0041 \\
\cline { 2 - 5 } & $\mathbf{M s}$ & 1 & 0.017 & $<.0001$ \\
\cline { 2 - 5 } & Angle & $\mathbf{1}$ & $\mathbf{0 . 0 0 1 8}$ & $\mathbf{0 . 0 2 3 1}$ \\
\cline { 2 - 5 } & $\mathbf{r} / \mathbf{R}$ & 1 & 0.008 & $<.0001$ \\
\cline { 2 - 5 } & Error & 34 & 0.0003 & \\
\hline \multirow{3}{*}{$\begin{array}{c}\text { Solids } \\
\text { Velocity }\end{array}$} & $\mathbf{U g}$ & 1 & 17.72 & $<.0001$ \\
\cline { 2 - 5 } & Angle & 1 & 0.063 & 0.6907 \\
\cline { 2 - 5 } & r/R & 1 & 28.50 & $<.0001$ \\
\cline { 2 - 5 } & Error & 34 & 0.3946 & \\
\hline
\end{tabular}

ANOVAs were then performed for the data from the 8.5 meter level of the riser, which was essentially to confirm the location of the fully-developed region in the riser. It is shown in Table 7.2 that angle is not a significant factor to the variability of solids fractions or solids velocities the 8.5 meter elevation, confirming that this elevation was well-mixed and fully developed across the entire cross-section of the riser. 
Table 7.2 - ANOVA for 64-micron Particles, $8.5 \mathrm{~m}$ level

\begin{tabular}{|c|c|c|c|c|}
\cline { 2 - 5 } \multicolumn{1}{c|}{} & Source & $\begin{array}{c}\text { Degrees } \\
\text { of } \\
\text { Freedom }\end{array}$ & $\begin{array}{c}\text { Sum of } \\
\text { Squares }\end{array}$ & p-value \\
\hline \multirow{3}{*}{$\begin{array}{c}\text { Solids } \\
\text { Fraction }\end{array}$} & Ms & 1 & 0.04 & $<.0001$ \\
\cline { 2 - 5 } & Angle & 1 & 0.000034 & 0.61 \\
\cline { 2 - 5 } & r/R & 1 & 0.02 & $<.0001$ \\
\cline { 2 - 5 } & Error & 53 & 0.01 & \\
\hline \multirow{3}{*}{$\begin{array}{c}\text { Solids } \\
\text { Velocity }\end{array}$} & Ms & 1 & 2.17 & 0.0849 \\
\cline { 2 - 5 } & Angle & 1 & 0.64 & 0.3465 \\
\cline { 2 - 5 } & r/R & 1 & 456.01 & $<.0001$ \\
\cline { 2 - 5 } & Error & 65 & 45.97147 & \\
\hline
\end{tabular}

Fiber optic data obtained during the CFB tests with 180-micron glass spheres as the bed material were also observed using ANOVAs. This was executed on the data taken at 0.7 meters and 8.5 meters above the centerline the solids inlet at 0,90 , and 180 degrees, as well as in deceleration region of the riser (13 meters) at 45, 135, 225, and 315 degrees.

The values from the ANOVAs on the solids fraction and particle velocities from the 0.7 meter elevation are shown in Table 7.3. According to the analysis, azimuthal location is not a significant contribution to the measurement, which could be due to the longer sampling times resulting in uniform time-averaged solids concentrations..

However, there is significant turbulence at the inlet, causing considerable particle mixing. 


\begin{tabular}{|c|c|c|c|c|}
\hline & Source & $\begin{array}{c}\text { Degrees } \\
\text { of } \\
\text { Freedom }\end{array}$ & $\begin{array}{c}\text { Sum of } \\
\text { Squares }\end{array}$ & p-value \\
\hline \multirow{5}{*}{$\begin{array}{l}\text { Solids } \\
\text { Fraction }\end{array}$} & Ug & 1 & 0.024 & $<.0001$ \\
\hline & Ms & 1 & 0.242 & $<.0001$ \\
\hline & Angle & 1 & 1.19E-05 & 0.9206 \\
\hline & r/R & 1 & 5.03E-01 & $<.0001$ \\
\hline & Error & 126 & 0.15 & \\
\hline \multirow{5}{*}{$\begin{array}{l}\text { Solids } \\
\text { Velocity }\end{array}$} & Ug & 1 & 14.56 & 0.0009 \\
\hline & Ms & 1 & 12.00 & 0.0025 \\
\hline & Angle & 1 & 1.58 & 0.2663 \\
\hline & r/R & 1 & 917.82 & $<.0001$ \\
\hline & Error & 175 & 222.19 & \\
\hline
\end{tabular}

Results from the ANOVAs for the data obtained at the 8.5 meter elevation are displayed in Table 7.4. According to the analysis the solids fractions at this elevation were not azimuthally dependent, but azimuthal dependency existed in the particle velocities. This was cause for concern, because as mentioned above, this level had been considered fully-developed. In order to locate the problem, ANOVAs were performed for each flow condition at this elevation in order to determine the flow conditions in which the particle velocities were considered azimuthally dependent And the results are displayed in Table 7.5. There were insufficient data points in order to perform the ANOVA for the (low $\mathrm{U}_{\mathrm{g}}$, high $\mathrm{M}_{\mathrm{s}}$ ) condition due to improper sampling rates. Solids velocities were not considered azimuthally dependent for two of the four flow conditions analyzed, meaning the insufficient particle velocity data could have caused azimuthal dependency in the ANOVA. 
Table 7.4 - ANOVA for 180 -micron particles, $8.5 \mathrm{~m}$ level

\begin{tabular}{|c|c|c|c|c|}
\cline { 2 - 5 } \multicolumn{1}{c|}{} & Source & $\begin{array}{c}\text { Degrees } \\
\text { of } \\
\text { Freedom }\end{array}$ & $\begin{array}{c}\text { Sum of } \\
\text { Squares }\end{array}$ & p-value \\
\hline \multirow{4}{*}{$\begin{array}{c}\text { Solids } \\
\text { Fraction }\end{array}$} & $\mathbf{U g}$ & 1 & 0.042 & $<.0001$ \\
\cline { 2 - 5 } & $\mathbf{M s}$ & 1 & 0.038 & $<.0001$ \\
\cline { 2 - 5 } & Angle & 1 & 0.00027 & $\mathbf{0 . 3 6 5 8}$ \\
\cline { 2 - 5 } & $\mathbf{r / R}$ & 1 & 0.301 & $<.0001$ \\
\cline { 2 - 5 } & $\mathbf{E r r o r}$ & 200 & 0.066 & \\
\hline \multirow{4}{*}{ Solids } & $\mathbf{U g}$ & 1 & 10.66 & 0.0014 \\
\cline { 2 - 5 } Velocity & $\mathbf{M s}$ & 1 & 90.11 & $<.0001$ \\
\cline { 2 - 5 } & Angle & 1 & 15.22 & $\mathbf{0 . 0 0 0 2}$ \\
\cline { 2 - 5 } & $\mathbf{r / R}$ & 1 & 1994.75 & $<.0001$ \\
\cline { 2 - 5 } & Error & 103 & 101.23 & \\
\hline
\end{tabular}

Table 7.5 - ANOVA for Velocities at the $8.5 \mathrm{~m}$ level

\begin{tabular}{|c|c|c|c|c|}
\cline { 2 - 5 } \multicolumn{1}{c|}{} & Source & $\begin{array}{c}\text { Degrees } \\
\text { of } \\
\text { Freedom }\end{array}$ & $\begin{array}{c}\text { Sum of } \\
\text { Squares }\end{array}$ & p-value \\
\hline $\mathbf{6 . 4}$ & Angle & 1 & 3.6 & $\mathbf{0 . 0 5 5 7}$ \\
\cline { 2 - 5 } $\mathbf{5 1 0 0 0}$ & Error & 32 & 29.47 & \\
\hline $\mathbf{5 . 5 ,}$ & Angle & 1 & 6.2 & $\mathbf{0 . 0 0 8 3}$ \\
\cline { 2 - 5 } $\mathbf{2 2 7 0 0}$ & Error & 8 & 4.11 & \\
\hline $\mathbf{7 . 6 ,}$ & Angle & 1 & 4.31 & $\mathbf{0 . 2 0 0 2}$ \\
$\mathbf{7 9 4 0 0}$ & Error & 14 & 33.4 & \\
\hline $\mathbf{7 . 6 ,}$ & Angle & 1 & 6.31 & $\mathbf{0 . 0 0 3 9}$ \\
\hline $\mathbf{2 2 7 0 0}$ & Error & 8 & 3.14 & \\
\hline
\end{tabular}

Lastly, the ANOVAs were performed on the data from the 13-meter elevation of the riser where deceleration effects from the outlet of the riser were observed. The solids fractions are considered symmetric regardless of azimuthal location, although particle velocities did depend on azimuthal location, as shown in Table 7.6. 


\begin{tabular}{|c|c|c|c|c|}
\hline & Source & $\begin{array}{c}\text { Degrees } \\
\text { of } \\
\text { Freedom }\end{array}$ & $\begin{array}{l}\text { Sum of } \\
\text { Squares }\end{array}$ & p-value \\
\hline \multirow{5}{*}{$\begin{array}{l}\text { Solids } \\
\text { Fraction }\end{array}$} & Ug & 1 & 0.023 & $<.0001$ \\
\hline & Ms & 1 & 0.021 & $<.0001$ \\
\hline & Angle & 1 & 0.004 & 0.0553 \\
\hline & r/R & 1 & 0.13 & $<.0001$ \\
\hline & Error & 179 & 0.18 & \\
\hline \multirow{5}{*}{$\begin{array}{l}\text { Solids } \\
\text { Velocity }\end{array}$} & Ug & 1 & 2.07 & 0.0139 \\
\hline & Ms & 1 & 88.33 & $<.0001$ \\
\hline & Angle & 1 & 12.15 & $<.0001$ \\
\hline & r/R & 1 & 2092.06 & $<.0001$ \\
\hline & Error & 175 & 58.71 & \\
\hline
\end{tabular}

From the ANOVAs performed on the solids fraction data, there is speculation that the solids velocity inside the riser is more turbulent and less uniform than the solids fractions. The solids fractions appear to be relatively well mixed when a time representative sample of the flow is obtained. 


\section{Conclusions}

Using the present novel technique to measure solids fractions with a fiber optic probe is an important step in CFB flow dynamics modeling. As discussed in literature, while the majority of previous methods to measure solids fractions used a linear calibration to relate the reflected light to the solids concentration, this model better represents the relationship of light to particle concentration by using empirical calibration methods that have been developed with a theoretical basis in order to obtain solids concentration data.

All calibration constants were determined using proven literature or empirical methods. When using this method, calibration procedures must be performed on particle types identical to those used in the CFB. This new method compared well with older methods that are either too obtrusive to the flow, must remove particles from the system, or obtain global measurements., as well as provided a measuring device that simultaneously determined solids velocity and solids fractions in the CFB riser.

This method was used to conduct statistical analyses in order to learn additional information on the particle mixing in the riser of the CFB unit used for these experiments. Data obtained at additional azimuthal locations are due to the dependency of particle velocities on azimuthal location, which are more prevalent than those of solids fractions,. Further understanding of the flow structure inside the CFB riser was discovered through this novel method. 


\section{Future Plans}

The proposed model has brought about many possible opportunities with the fiber optic probe and the data acquired using this probe. Further verification of the accuracy of this probe will validate the model that was proposed in this work. Using this probe and the solids velocities and solids volume fractions it provides will be very useful to calculate localized solids fluxes and solids viscosities inside the CFB riser. Horizontal velocities could be measured in the CFB by turning the probe 90 degrees, which is another future study. Providing data for computational model validation is one of the main purposes of performing experimental measurements, which is one of the goals of developing this method. Additional measurements at more heights and azimuthal locations in the CFB will verify the location of the fully developed region of the riser, and show that the size and location of the fully developed region fluctuates with particle size and flow conditions. Details of the solids flow pattern and distribution in and near to the current inlet geometry, known as an L-valve, will be characterized using this probe. Determining where the entrance effects from the L-valve are no longer significant is an important application for this fiber optic probes measurements. Likewise, exit effects

will be determined using the method proposed and these fiber optic probes. Lastly, flow regime characterization is another important future study using this method. The riser flow regimes using the $180 \mu \mathrm{m}$ particle batch have not been characterized. Using the solids velocity and concentration data from these tests can assist with the characterization of these test conditions. 


\section{References}

[1] J. Grace, A. Avidan, and T. Knowlton (ed.). (1997). Circulating Fluidized Beds. New York: Blackie Academic and Professional, Chapman \& Hall.

[2] V. Alwayn. (2004) "Fiber optic Technologies: A Brief History of Fiber-Optic Communications.” Optical Network Design and Implementation. Cisco Press.

[3] J. Hecht. (2002). Understanding Fiber optics. Ed. Stephen Helba. New Jersey: Prentice Hall.

[4] E. Udd. (1991). Fiber optic Sensors: An Introduction for Engineers and Scientists. New York: Wiley-Interscience.

[5] H. Zhang, P. Johnston, J. Zhu, H. de Lasa, M. Bergougnou. (1998). A novel calibration procedure for a Fiber optic solids concentration probe. Powder Technology, 100, 260-272.

[6] U. Arena, A. Cammarota and L. Pistone, P, Basu ed. (1986). High Velocity Fluidization Behavior of Solids in a Laboratory Scale Circulating Bed. Proc. $1^{\text {st }}$ Int. Conf. Circulating Fluidized Bed Technology, Pergamon. 1986. pp. 119-126.

[7] B. Du, W. Warsito, and L-H Fan. (2005). ECT Studies of Gas-Solid Fluidized Beds of Different Diameters. Ind. Eng. Chem. Res., 44, 5020-5030.

[8] S. Morooka, K. Kawazuishi, and Y. Kato. (1980), Holdup and Flow Pattern of Solid Particles in Freeboard of Gas-Solid Fluidized Bed with Fine Particles. Powder Technology, 26, 75-82.

[9] D. Rensner and J. Werther. (1991). Modeling and application of a Fiber optical measuring system for higher concentrated multiphase flow, Proc. $4^{\text {th }}$ Int. Conf. Laser Anemometry, ASME, Cleveland, 1991, pp. 753-761.

[10] A. Miller and D. Gidaspow. (1992). Dense, Vertical Gas-Solid Flow in a Pipe. AIChE, 38(11), 1801-1815A.

[11] A. Magnusson, R. Rundqvist, A.E. Almstedt and F. Johnsson. (2005). Dual Fiber optical probe measurements of solids volume fraction in a circulating fluidized bed, Powder Technology, 151, 19-26.

[12] J.J. Nieuwland, R. Meijer, J.A.M Kuipers and W.P.M. van Swaij. (1996). Measurements of solids concentration and axial solids velocity in gas-solid twophase flows, Powder Technology, 8, 7127-139. 
[13] A. Yan, H. Zhu and J. Zhu. (2004). Comparison of FCC Particle Flow in a TwinRiser System. ECI Fluidization, 11.

[14] S. Seachman, P. Yue, E. Taylor and L. Shadle. (2005). Solids Fractions and Flow Characteristics in a CFB as Measured with a Fiber optic Probe. American Institute of Chemical Engineers. (Ohio)

[15] H. Hatano and M. Ishida. (1982). Kagaku Kogaku Ronbunshu. 8219.

[16] Y. Matsuno, H. Yamaguchi, T. Oka, H. Kage and K. Higashitani. (1983). The use of optical fiber probes for the measurement of dilute particle concentrations: calibration and application to gas fluidized bed carryover. Powder Technology, 36, 215-221.

[17] E. U. Hartge, D. Rensner and J. Werther. (1998). Solids concentration and velocity patterns in circulating fluidized beds, Circulating Fluidized Bed Technology II, P. Basu and J. F. Large, eds. Pergamon, New York, 165-180.

[18] E. U. Hartge and J. Werther (1986). Analysis of the local structure of two-phase flow in a fast fluidized bed. Proc. 1st Int. Conf. Circulating Fluidized Beds. (Halifax, N.S.) Pergamon Press, Canada, 153-160.

[19] M. Horio, K. Morishita, O. Tachibana and N. Murata, in P. Basu and J.P. Large (eds.), (1988), Solid Distribution and Movement in Circulating Fluidized Beds. Proc. $2^{\text {nd }}$ Int. Conf. Circulating Fluidized Bed Technology. Pergamon, Oxford. 147-154.

[20] W. Nowak, H. Mineo, R. Yamazaki, and K. Yoshida. (1991). Behavior of particles in a circulating "Fluidized bed of a mixture of two different sized particles. In P. Basu, M. Horio, \& M. Hasatani (Eds.), Circulating 6uidized bed technology III Oxford: Pergamon Press. 219-224.

[21] L. Reh and J. Li. (1991). Measurement of Voidage in Fluidized Beds by Optical Probes. Circulating Fluidized Bed Technology, 3, 163-170.

[22] D. Lischer and M. Louge. (1992). Optical fiber measurements of particle concentration in dense suspensions: calibration and simulation. Applied Optics, 31 (24), 5106-5113.

[23] H. Johnsson and F. Johnsson. (2001). Measurements of local solids volume-fraction in fluidized bed boilers. Powder Technology, 115, 13-26.

[24] R. Rundqvist, A. Magnusson, G. van Wachem and A. Almstedt. (2003). Dual optical fibre measurements of the particle concentration in gas/solid flows. Experiments in Fluids, 35, 572-579. 
[25] N. Samuel, K. Stefan and L. Hugo. (2004). Particle Velocity and Particle Clustering in Downflow Reactors: Measurements Using a CREC-GS-Optiprobe.

[26] J. Zhou, J. Grace, C. Lim and C. Brereton. (1995). Particle Velocity Profiles in a Circulating Fluidized Bed Riser of Square Cross-Section. Chemical Engineering Sciences, 50 (2), 237-244.

[27] Vector Scientific Instruments, Inc. (2000) Instruction Manual for VSI 1000/2000/3000 hardware and Vector V2 Software. Halifax, N.S.

[28] J. Zhu, G. Li, S. Qin, F. Li, H. Zhang and Y. Yang. (2001). Direct measurements of particle velocities in gas-solids suspension flow using a novel five-Fiber optical probe. Powder Technology, 115, 184-192.

[29] D. Lind, W. Marchal and R. Mason. (2002). Statistical Techniques in Business \& Economics. New York: McGraw-Hill Irwin. 413-449.

[30] H.C. van de Hulst. (1981). Light Scattering by Small Particles. New York: Dover. 401.

[31] J. Vincent. (1995). Aerosol Science for Industrial Hygienists. New York: Pergamon. 122-126.

[32] E. Monazam, L. Shadle, and L. Lawson (2001) A Method for Determining the Saturation Carrying Capacity of Gas in Circulating Fluid Beds, Powder Technology, 121, 205-212.

[33] E. Monazam, L. Shadle J. Mei and J. Spenik. (2005). Identification and Characteristics of Different Flow Regimes in a Circulating Fluidized Bed, Powder Technology, 155(1), 17-25.

[34] L. Shadle, E, Monazam, and J. Mei (2006). Transient Characterization of Type B particles in a Transport Riser.

[35] SAS Institute Inc. (2001). JMP User’s Guide, Version 4. Cary, NC. 


\section{Appendix I}

\section{Example Calculations}

\section{Calculating $\alpha$ and $\beta$ to determine $Q$ for the given particle sizes.}

For the $64 \mu \mathrm{m}$ particles:

$Q$ was determined by calculating the size parameter, $\alpha$, and the modified size parameter, $\beta$.

$$
\alpha=\frac{\pi d}{\lambda}
$$

In this equation, $d$ is the average particle diameter in meters, and $\lambda$ is the wavelength of the light source, in meters.

$$
\begin{aligned}
& d=6.4 * 10^{-5} \mathrm{~m} \\
& \lambda=6.6 * 10^{-7} \mathrm{~m}
\end{aligned}
$$

So the value of $\alpha$ becomes:

$$
\begin{aligned}
& \alpha=\frac{\pi^{*}\left(6.4 * 10^{-5}\right)}{6.6 * 10^{-7}} \\
& \alpha=3.05 * 10^{2} .
\end{aligned}
$$

Next, $\beta$ was solved for

$$
\beta=4 \alpha(m-1)
$$

where $m$ is the index of refraction. The index of refraction for glass was used because the particles tested were glass beads.

$$
m=1.5 \text { (for glass) }
$$




$$
\begin{aligned}
& \beta=4 *\left(3.05 * 10^{2}\right)(1.5-1) \\
& \beta=609.279 .
\end{aligned}
$$




\section{Calculating Sampling Frequency}

For Vector-S System:

$$
f=\frac{V_{p}}{d}\left(\frac{V_{p}}{E_{\max }}-1\right)
$$

In this equation, $f$ is the frequency in Hertz, $V_{p}$ is the maximum expected particle velocity in meters per second, $d$ is the space between the two fiber bundles in meters, and $E_{\max }$ is the maximum allowable error in the velocity measurement, in meters per second.

$$
\begin{gathered}
V_{p(\max )} \approx 10 \mathrm{~m} / \mathrm{s} \\
d=3.95 * 10^{-3} \mathrm{~m} \\
E_{\max }=0.5 \mathrm{~m} / \mathrm{s} .
\end{gathered}
$$

Note : $f$ is 4 times the clock frequency (two channels sampling twice the clock frequency). So, $f$ is:

$$
\begin{aligned}
& f=\frac{10}{3.95 * 10^{-3}}\left(\frac{10}{0.5}-1\right)=2531.65 * 19 \\
& f=48101.465 \mathrm{~Hz}=48.1 \mathrm{kHz}
\end{aligned}
$$

and the clock frequency $=12.5 \mathrm{kHz}$

$$
f=12.5 * 4=50 \mathrm{kHz} .
$$


Solving for $k_{1}$ and $k_{2}$ :

For VSI2000 system, $180 \mu \mathrm{m}$ particles, using $\mathrm{i}=0$ and $\mathrm{i}=1$ :

From equation 5.1.12

$$
I_{R_{\text {Measured }}}=k_{1} I_{0}\left[\sum_{n=0}^{i}\left(e^{-2 n\left(\frac{\pi d^{2}}{4}\right) Q k_{2}(1-\varepsilon) \ell}-e^{-(2 n+1)\left(\frac{\pi d^{2}}{4}\right) Q k_{2}(1-\varepsilon) \ell}\right)\right]
$$

For $I_{R 1_{\text {Measured }}}(\mathrm{i}=0)$ :

$$
I_{R 1_{\text {Measured }}}=k_{1}\left(I_{0}-I_{1}\right) e^{-\left(\frac{\pi d^{2}}{4}\right) Q k_{2}(1-\varepsilon) 0 * \ell}=k_{1} I_{0}\left(1-e^{-\frac{\pi d^{2}}{4} Q k_{2}(1-\varepsilon) \ell}\right)
$$

Solving for $k_{1}$ in terms of $k_{2}$ :

$$
k_{1}=\frac{I_{R 1_{\text {Measured }}}}{I_{0}\left(1-e^{-\left(\frac{\pi d^{2}}{4}\right) Q k_{2}(1-\varepsilon) \ell}\right)}
$$

Using $I_{R 2_{\text {Measured }}}$ and substituting for $k_{1}$ :

$$
I_{R 2_{\text {Mesurued }}}=I_{R 1} e^{-\left(\frac{\pi d^{2}}{4}\right) Q k_{2}(1-\varepsilon) 0 * \ell}+I_{R 2} e^{-\left(\frac{\pi d^{2}}{4}\right) Q k_{2}(1-\varepsilon) 1 * \ell}
$$




$$
\begin{gathered}
I_{R 2_{\text {Measured }}}=k_{1} I_{0}\left(1-e^{-\frac{\pi d^{2}}{4} Q k_{2}(1-\varepsilon) \ell}+e^{-\frac{\pi d^{2}}{4} Q k_{2}(1-\varepsilon) 2 \ell}-e^{-\frac{\pi d^{2}}{4} Q k_{2}(1-\varepsilon) 3 \ell}\right) \\
I_{R 2_{\text {Measured }}}=\frac{\left.I_{R 1_{\text {Messured }}}\right)}{I_{0}\left(1-e^{-\left(\frac{\pi d^{2}}{4}\right) Q k_{2}(1-\varepsilon) \ell}\right)} I_{0}\left(1-e^{-\frac{\pi d^{2}}{4} Q k_{2}(1-\varepsilon) \ell}+e^{-\frac{\pi d^{2}}{4} Q k_{2}(1-\varepsilon) 2 \ell}-e^{-\frac{\pi d^{2}}{4} Q k_{2}(1-\varepsilon) 3 \ell}\right) \\
I_{R 2_{\text {Mesurved }}}=\frac{I_{R 1_{\text {Mesurred }}}}{\left(1-e^{-\left(\frac{\pi d^{2}}{4}\right) Q k_{2}(1-\varepsilon) \ell}\right)} *\left(1-e^{-\frac{\pi d^{2}}{4} Q k_{2}(1-\varepsilon) \ell}+e^{-\frac{\pi d^{2}}{4} Q k_{2}(1-\varepsilon) 2 \ell}-e^{-\frac{\pi d^{2}}{4} Q k_{2}(1-\varepsilon) 3 \ell}\right)
\end{gathered}
$$

where

$$
\begin{gathered}
Q=2 \\
d=\ell=0.180 \mathrm{~mm} \\
(1-\varepsilon)=0.5866 \\
I_{R 1_{\text {Measured }}}=0.2446 \mathrm{~V} \\
I_{R 2_{\text {Measured }}}=0.4604 \mathrm{~V}
\end{gathered}
$$

Multiply the exponential term

$$
-\left(\frac{\pi d^{2}}{4}\right) Q k_{2}(1-\varepsilon) \ell=-\left(\frac{\pi * 0.180^{2}}{4}\right) 2 * k_{2} * 0.5866 * 0.180=-0.00537 * k_{2}
$$

Substitute

$$
0.4604=\frac{0.2446}{\left(1-e^{-0.00537 k_{2}}\right)} *\left(1-e^{-0.00537 k_{2}}+e^{-2^{*} 0.00537 k_{2}}-e^{-3^{*} 0.00537 k_{2}}\right)
$$

Due to the complexity of this equation, it was plotted on a graphing calculator, with 0.4606 as Y1 and the right hand side as Y2 (with $k_{2}$ being denoted as $x$ ). The intercept program was then used to determine $k_{2}$. 
Substitute $k_{2}$ value into equation A1.3.3 to solve for $k_{l}$ :

$$
k_{1}=\frac{I_{R 1_{\text {Measured }}}}{I_{0}\left(1-e^{-\left(\frac{\pi d^{2}}{4}\right) Q k_{2}(1-\varepsilon) \ell}\right)}
$$

where

$$
\begin{gathered}
I_{0}=9.4294 \mathrm{~V} \\
k_{1}=\frac{0.2446}{9.4294\left(1-e^{-0.00537^{* 11.6195}}\right)} \\
k_{1}=0.4288 .
\end{gathered}
$$




\section{Solids Fraction Calculation}

As mentioned before, a program was written by David Casleton in order to solve for the solids fractions using the above equations. Since many of the values were held constant, and the amount of particle layers needed in order to give a representative reflected voltage was known, the equation was simplified in order to place it into the program:

$$
I_{R_{\text {Measured }}}=k_{1} I_{0}\left[\sum_{n=0}^{i}\left(e^{-2 n\left(\frac{\pi d^{2}}{4}\right) Q k_{2}(1-\varepsilon) \ell}-e^{-(2 n+1)\left(\frac{\pi d^{2}}{4}\right) Q k_{2}(1-\varepsilon) \ell}\right)\right]
$$

Combining constant terms:

$$
\begin{gathered}
\omega=Q * k_{2} * \ell \\
(1-\varepsilon)=x \\
r=e^{x} \\
S=\frac{I_{R}}{k_{1} I_{0}}
\end{gathered}
$$

For 6 particle layers:

$$
\begin{array}{r}
S=\left(1-r^{\omega}\right)+\left(r^{2 \omega}-r^{3 \omega}\right)+\ldots+\left(r^{12 \omega}-r^{13 \omega}\right) \\
r^{\omega} S=\left(1-r^{\omega}\right)+\left(r^{2 \omega}-r^{3 \omega}\right)+\ldots+\left(r^{13 \omega}-r^{14 \omega}\right)
\end{array}
$$

Canceling out terms and taking out a $\left(1+r^{\omega}\right)$ term:

$$
\left(1+r^{\omega}\right) S=1-r^{14 \omega}
$$


So,

$$
S=\frac{1-r^{14 \omega}}{\left(1+r^{\omega}\right)}
$$

Back Substitution:

$$
\frac{I_{R_{\text {Measured }}}}{k_{1}^{*} I_{o}}=\frac{1-e^{-14^{*} Q^{*} k_{2}(1-\varepsilon)^{* \ell}}}{\left(1+e^{-Q^{*} k_{2}(1-\varepsilon)^{* \ell}}\right)}
$$

This was then put into the program with all constants user defined, depending on the probe and material. The number of layers was generalized for each type of particle layer thickness needed to represent the light intensity reflected back into the probe for different materials. The program generates a list that finds the reflected voltage needed in order to find solids fractions from 0 to 1 up to 6 decimal places (i.e. 0.000000 to 1.000000 and all points in between). After generating this list, the voltages are read into the program and "matched" to their respective solids fraction values on the generated list. This is done on an individual level, and then averaged into series and radial position levels. All of these values are given in output files after the program is completed. The values only need to be calculated once, instead of hundreds of thousands to millions of times, which dramatically improves process times. 


\section{To calculate 95\% Confidence Interval}

Centerpoint solids fraction data, $180 \mu \mathrm{m}$ particles, VSI2000 system, $8.5 \mathrm{~m}$ level, $\mathrm{r} / \mathrm{R}=0.224(\mathrm{P} 0):$

The solids fraction values describe above are gathered into Table A1. 1. Since solids fractions were found to be azimuthally independent at this level, 12 samples were taken that were duplicates.

Table A1. 1- Solids Fraction Values From Centerpoint Condition, $8.5 \mathrm{~m}$ elevation, r/R $=0.224$

\begin{tabular}{|l|c|}
\hline & Solids Fraction \\
\hline RPN41_P0 & 0.0219 \\
\hline RPN42_P0 & 0.0259 \\
\hline RPN86_P0 & 0.0320 \\
\hline RPN91_P0 & 0.0330 \\
\hline RPN47_P0 & 0.0057 \\
\hline RPN92_P0 & 0.0074 \\
\hline RPN52_P0 & 0.0336 \\
\hline RPN54_P0 & 0.0333 \\
\hline RPN56_P0 & 0.0328 \\
\hline RPN67_P0 & 0.0291 \\
\hline RPN68_P0 & 0.0288 \\
\hline RPN72_P0 & 0.0274 \\
\hline
\end{tabular}

To find error bars for the $95 \%$ confidence interval, the equation is as follows

$$
95 \% C I=\frac{t_{0.025} * s t d e v}{\sqrt{n}}
$$

Where $t$ is dependent on the amount of samples (n-1) and found through t plots (or excel).

$\mathrm{n}$ is the sample size. These values are shown in Table A1. 2

Table A1. 2 - Confidence Interval Values

\begin{tabular}{|l|r|}
\hline $\mathrm{n}$ & 12 \\
\hline $\mathrm{t}$-value & 2.200985 \\
\hline stdev & 0.009715 \\
\hline
\end{tabular}

So solving for the $95 \% \mathrm{CI}$

$$
95 \% C I=\frac{2.200985 * .009715}{\sqrt{12}}=0.006173
$$




\section{Appendix II \\ Solids Fraction Test Matrices}

The test matrix for the $64 \mu \mathrm{m}$ glass beads is represented in Table A2. 1. The $\mathrm{U}_{\mathrm{g}}$ was fixed at $5.17 \mathrm{~m} / \mathrm{s}$ and the solids circulation rate was varied between 5,400 and 33,500 $\mathrm{kg} / \mathrm{hr}$ for these test runs. The five equal area radial positions mentioned previously were taken for these tests. Each complete set of radial positions taken is denoted by an "x."

Table A2. 1 - Solids Fraction Test Matrix for $64 \mu \mathrm{m}$ Glass Beads

\begin{tabular}{|c|c|c|c|c|c|c|}
\hline & & \multicolumn{4}{|c|}{ Angle } & \\
\hline $\operatorname{Ug}(\mathrm{m} / \mathrm{s})$ & Ms (kg/hr) & 0 & 90 & 180 & 270 & Elevation (m) \\
\hline 5.17 & 33,500 & $x$ & $x$ & & $x x$ & \multirow{2}{*}{8.5} \\
\hline 5.17 & 5,400 & $x$ & $x$ & & $x x$ & \\
\hline 5.17 & 33,500 & & $x$ & $\mathbf{x}$ & & \multirow{2}{*}{1.3} \\
\hline 5.17 & 5,400 & & $x$ & $x$ & & \\
\hline
\end{tabular}

The test matrix for the $180 \mu \mathrm{m}$ material is found in Table A2. 2. More time was allowed for these test conditions. Additionally, five different flow conditions were used. The “centerpoint” condition was repeated each time testing was performed, which explains the higher amount of duplicates for that flow condition. The five equal area radial positions as well as a wall measurement were taken for all of these tests. The reason for not having complete sets for some conditions (i.e., $5.5 \mathrm{~m} / \mathrm{s}, 79,400 \mathrm{~kg} / \mathrm{hr}, 0.7$ m, 0 deg) was due to the fact that there was not enough solids inventory in the CFB system to perform that test. 
Table A2. 2- Solids Fraction Test Matrix for $180 \mu \mathrm{m}$ Glass Beads

\begin{tabular}{|c|c|c|c|c|c|c|c|c|c|}
\hline & & & & & Angl & & & & \\
\hline $\operatorname{Ug}(\mathrm{m} / \mathrm{s})$ & Ms (kg/hr) & 0 & 45 & 90 & 135 & 180 & 225 & 315 & Elevation (m) \\
\hline 5.5 & 79,400 & & $\bar{x}$ & & $\bar{x}$ & & $\bar{x}$ & $\bar{x}$ & \\
\hline 7.6 & 79,400 & & $\bar{x}$ & & $\mathbf{x x}$ & & $x$ & $\mathbf{x x}$ & \\
\hline 6.4 & 51,000 & & $\mathbf{x x}$ & & $\mathbf{x x x}$ & & $\mathbf{x x x}$ & Xxxx & 13 \\
\hline 5.5 & 22,700 & & $x$ & & $\mathbf{x}$ & & $\mathbf{x}$ & $\mathbf{x}$ & \\
\hline 7.6 & 22,700 & & $\mathbf{x}$ & & $\mathbf{x}$ & & $x x$ & $x$ & \\
\hline 5.5 & 79,400 & $\mathbf{x x}$ & & $x$ & & $x \mathbf{x}$ & & & \\
\hline 7.6 & 79,400 & $x x x$ & & $x x$ & & $\mathbf{x}$ & & & \\
\hline 6.4 & 51,000 & $\operatorname{XXXXXX}$ & & $\mathbf{X X X X}$ & & $\mathbf{x X}$ & & & 8.5 \\
\hline 5.5 & 22,700 & $\mathbf{x x}$ & & $\mathbf{x x}$ & & $\mathbf{x x}$ & & & \\
\hline 7.6 & 22,700 & $\mathbf{x x}$ & & $x x$ & & $\mathbf{x x}$ & & & \\
\hline 5.5 & 79,400 & & & $\bar{x}$ & & $x x x$ & & & \\
\hline 7.6 & 79,400 & $\mathbf{x}$ & & $\mathbf{x}$ & & $x \mathbf{X X}$ & & & \\
\hline 6.4 & 51,000 & $x x$ & & $\mathbf{x x}$ & & $x x x$ & & & 0.7 \\
\hline 5.5 & 22,700 & $\mathbf{x}$ & & $x$ & & $\mathbf{x x}$ & & & \\
\hline 7.6 & 22,700 & $\mathbf{x}$ & & $\mathbf{x}$ & & $\mathbf{X X}$ & & & \\
\hline
\end{tabular}




\section{Appendix III \\ Solids Fraction Radial Profiles}

\section{For 64 $\mu \mathrm{m}$ Particles:}

Figures A3.1 and A3.2 illustrate the solids fraction profiles from the $64 \mu \mathrm{m}$

particle test runs at the 1.3 m elevation. Data was somewhat limited for these situations.

All experiments that were performed with the $64 \mu \mathrm{m}$ particles used the Vector-S system.

The profile is much more uniform with dilute case than is with the dense case.

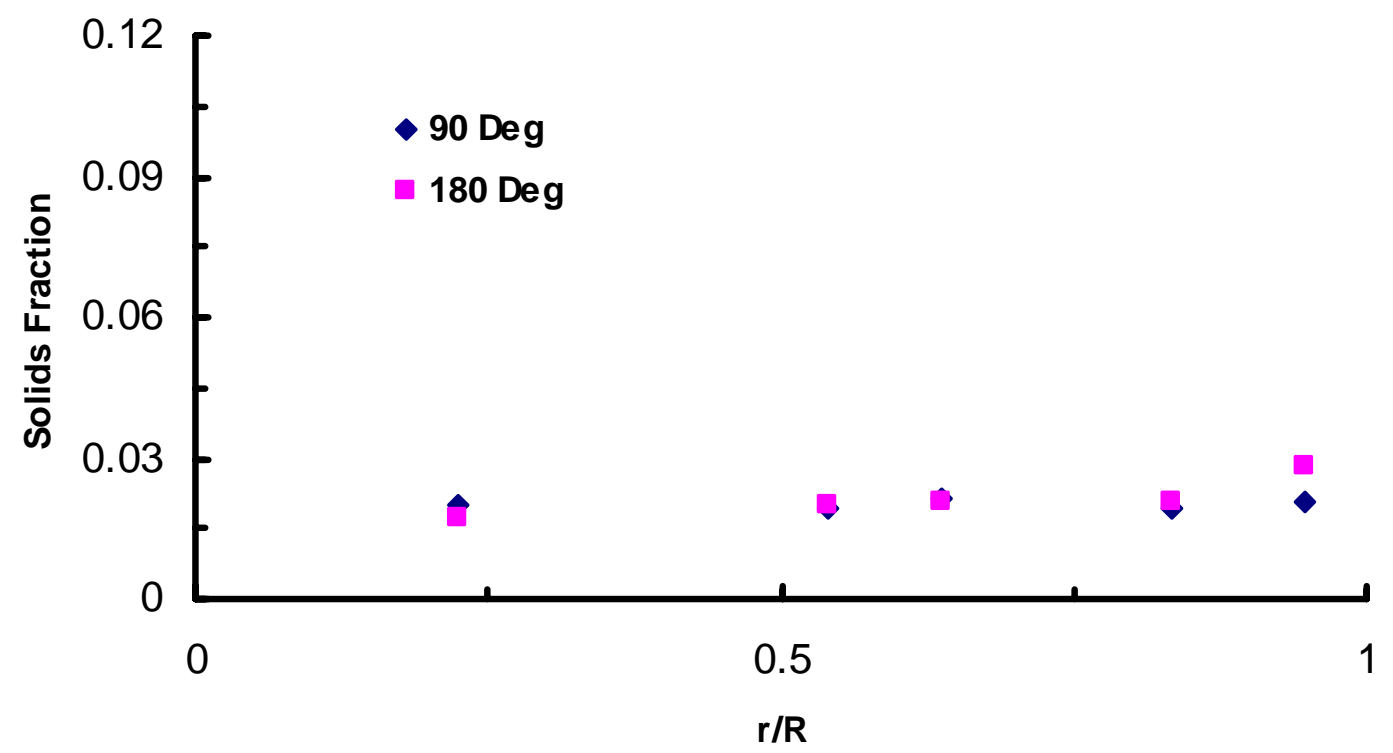

Figure A3. 1 - Ug = $5.17 \mathrm{~m} / \mathrm{s}, \mathrm{Ms}=5,400 \mathrm{~kg} / \mathrm{hr}, 1.3 \mathrm{~m}$ elevation 


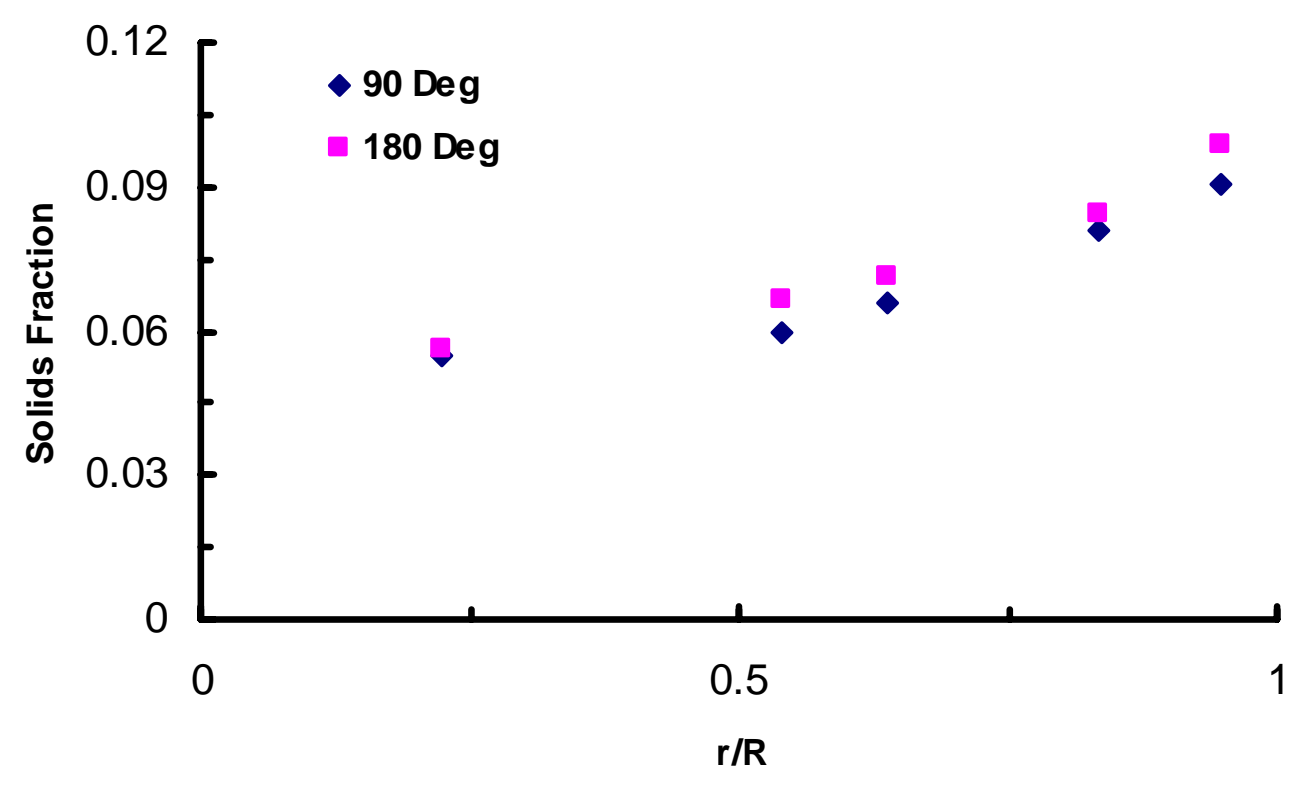

Figure A3. 2 - Ug = $5.17 \mathrm{~m} / \mathrm{s}, \mathrm{Ms}=33,500 \mathrm{~kg} / \mathrm{hr}, 1.3 \mathrm{~m}$ elevation

The $64 \mu \mathrm{m}$ tests at the $8.5 \mathrm{~m}$ elevation are depicted in Figure A3. 3 and A3.4.

More tests were performed at this level to check for azimuthal dependency at this elevation. The profiles were extremely similar as was shown by the ANOVAs. Once again, the dilute flow situation shown in Figure A3. 3 is much more uniform across the riser cross section. 


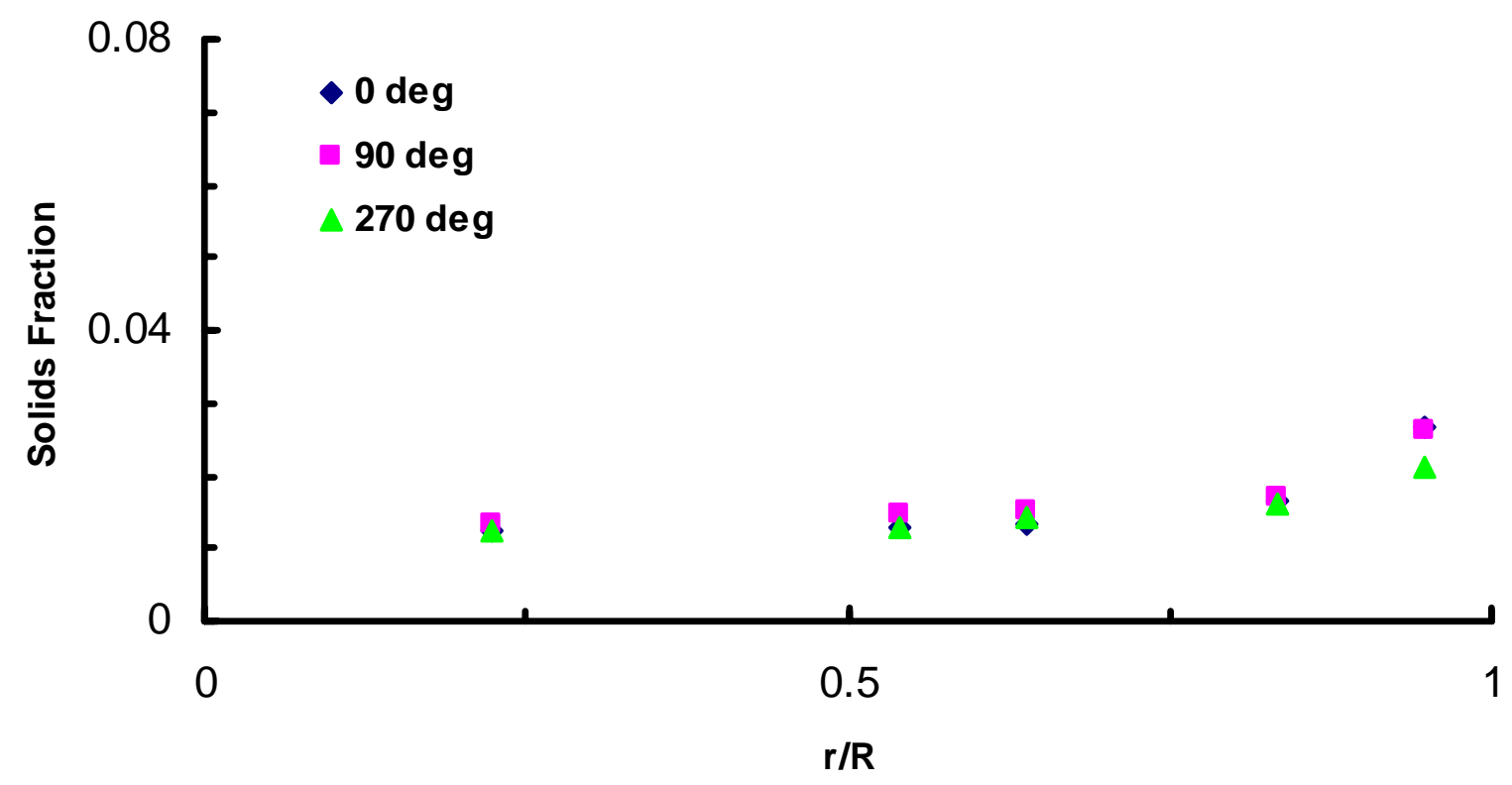

Figure A3. 3 - Ug= $5.17 \mathrm{~m} / \mathrm{s}, \mathrm{Ms}=5,400 \mathrm{~kg} / \mathrm{hr}, 8.5 \mathrm{~m}$ elevation

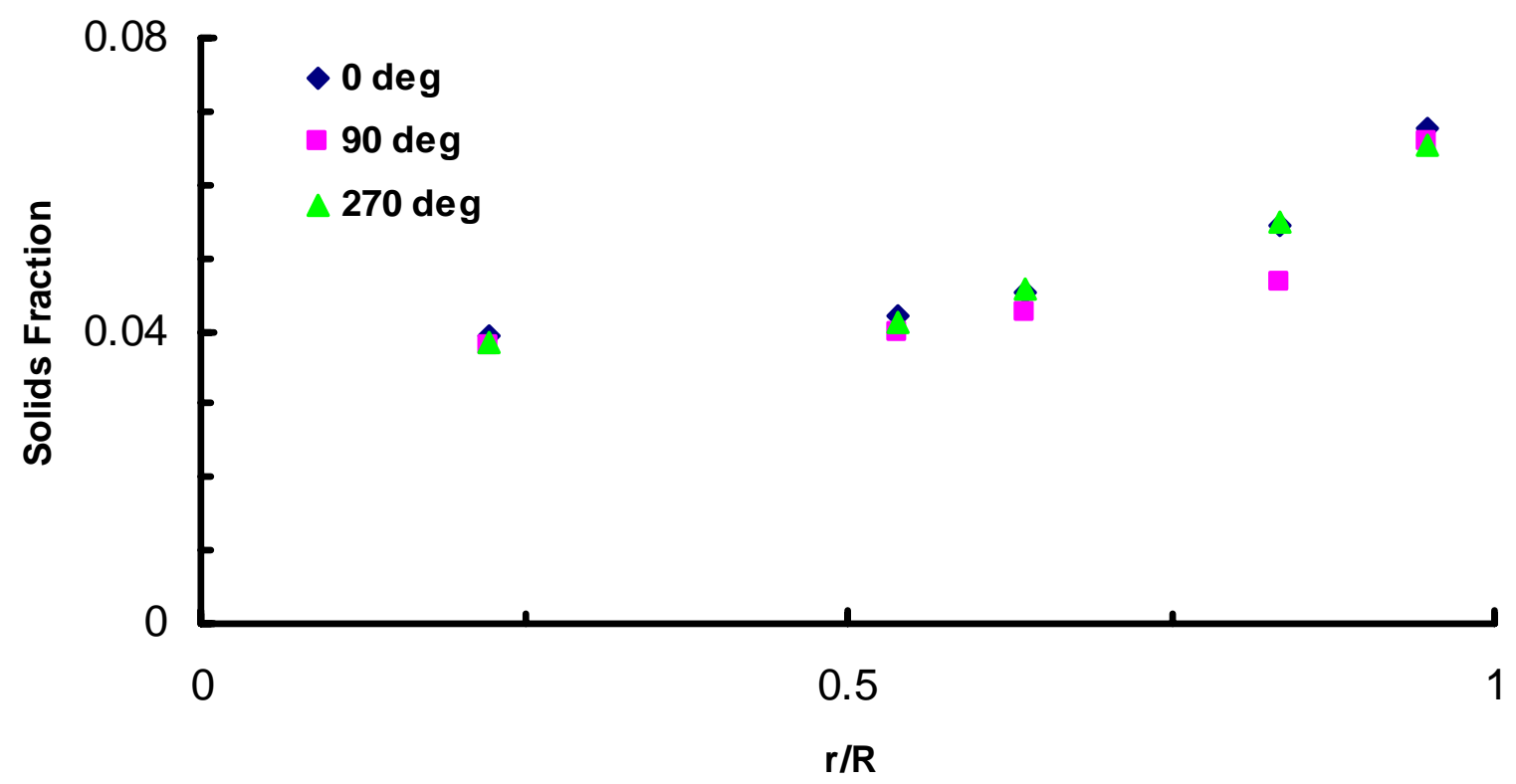

Figure A3. $4-\mathrm{Ug}=5.17 \mathrm{~m} / \mathrm{s}, \mathrm{Ms}=33,500 \mathrm{~kg} / \mathrm{hr}, 8.5 \mathrm{~m}$ elevation 


\section{For $180 \mu \mathrm{m}$ particles:}

Data taken with the Vector-S system at the $0.7 \mathrm{~m}$ elevation for the larger particle size is shown in Figure A3. 5- A3.9 in order of descending load ratios. The azimuthal distributions in these situations are reasonably uniform with the exception of the (high $\mathrm{U}_{\mathrm{g}}$, high $\mathrm{M}_{\mathrm{s}}$ ) condition illustrated in Figure A3. 6 .

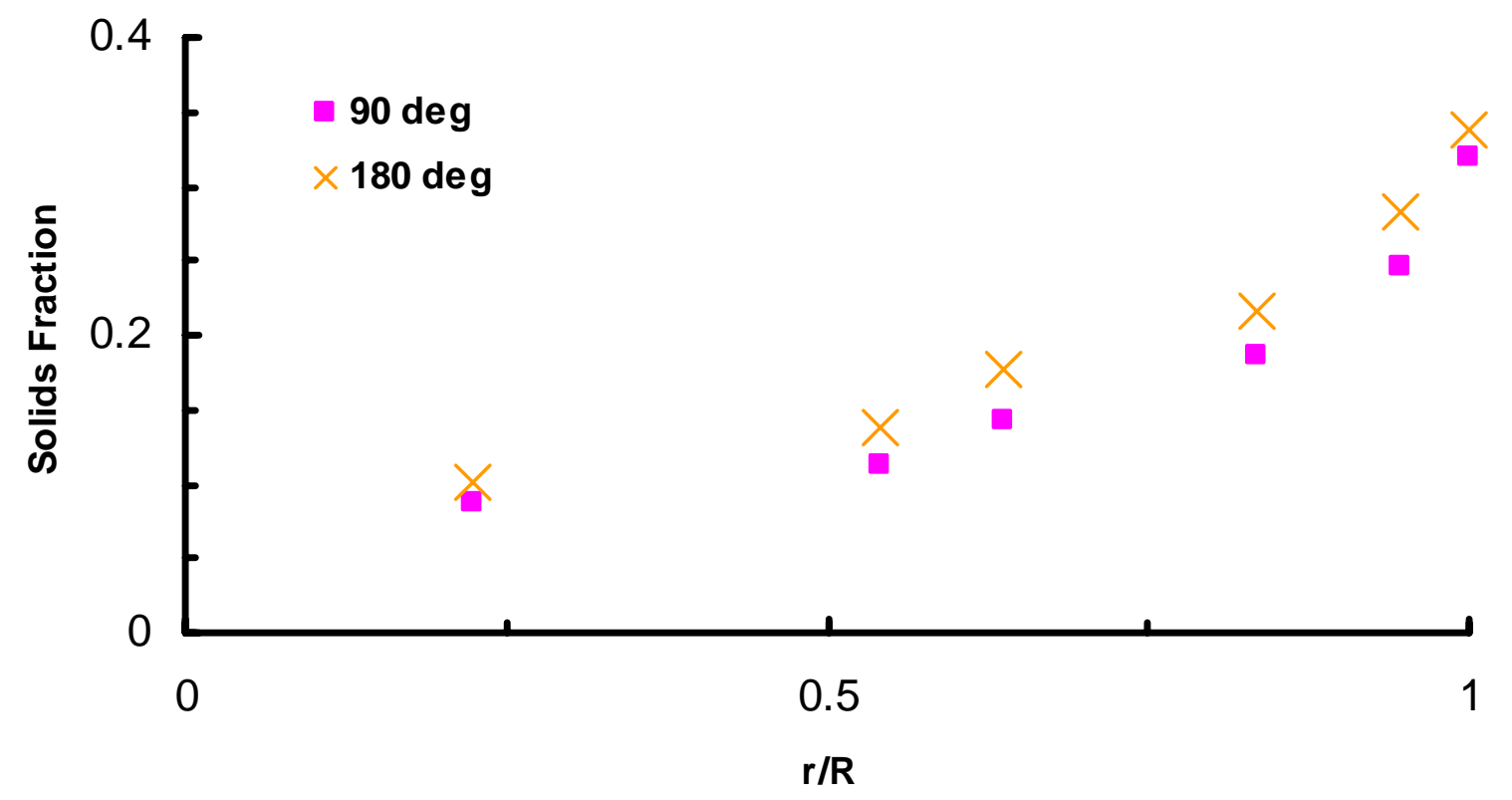

Figure A3. 5 - Ug $=5.5 \mathrm{~m} / \mathrm{s}, \mathrm{Ms}=79,400 \mathrm{~kg} / \mathrm{hr}, 0.7 \mathrm{~m}$ elevation 


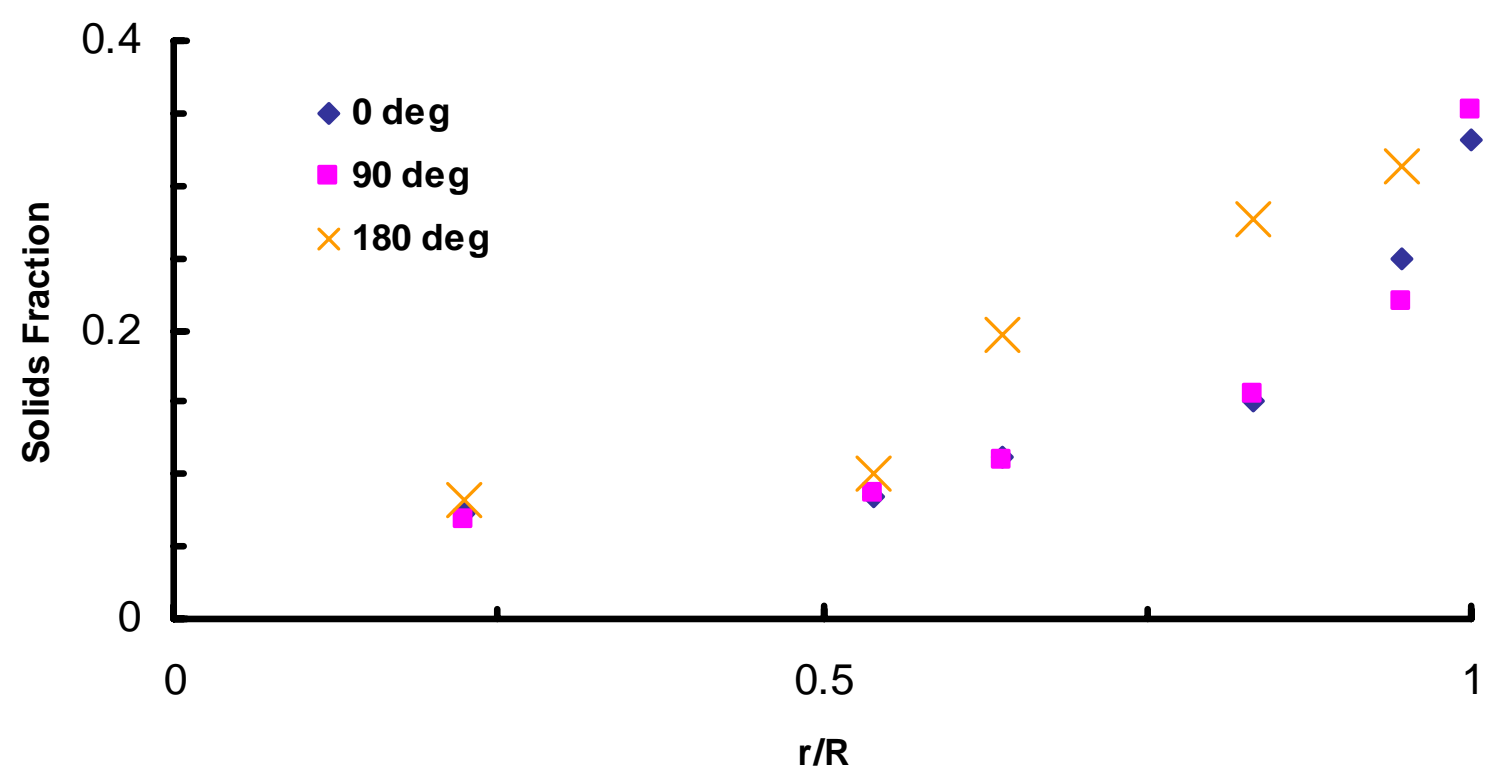

Figure A3. 6 - Ug = $7.6 \mathrm{~m} / \mathrm{s}, \mathrm{Ms}=79,400 \mathrm{~kg} / \mathrm{hr}, 0.7 \mathrm{~m}$ elevation

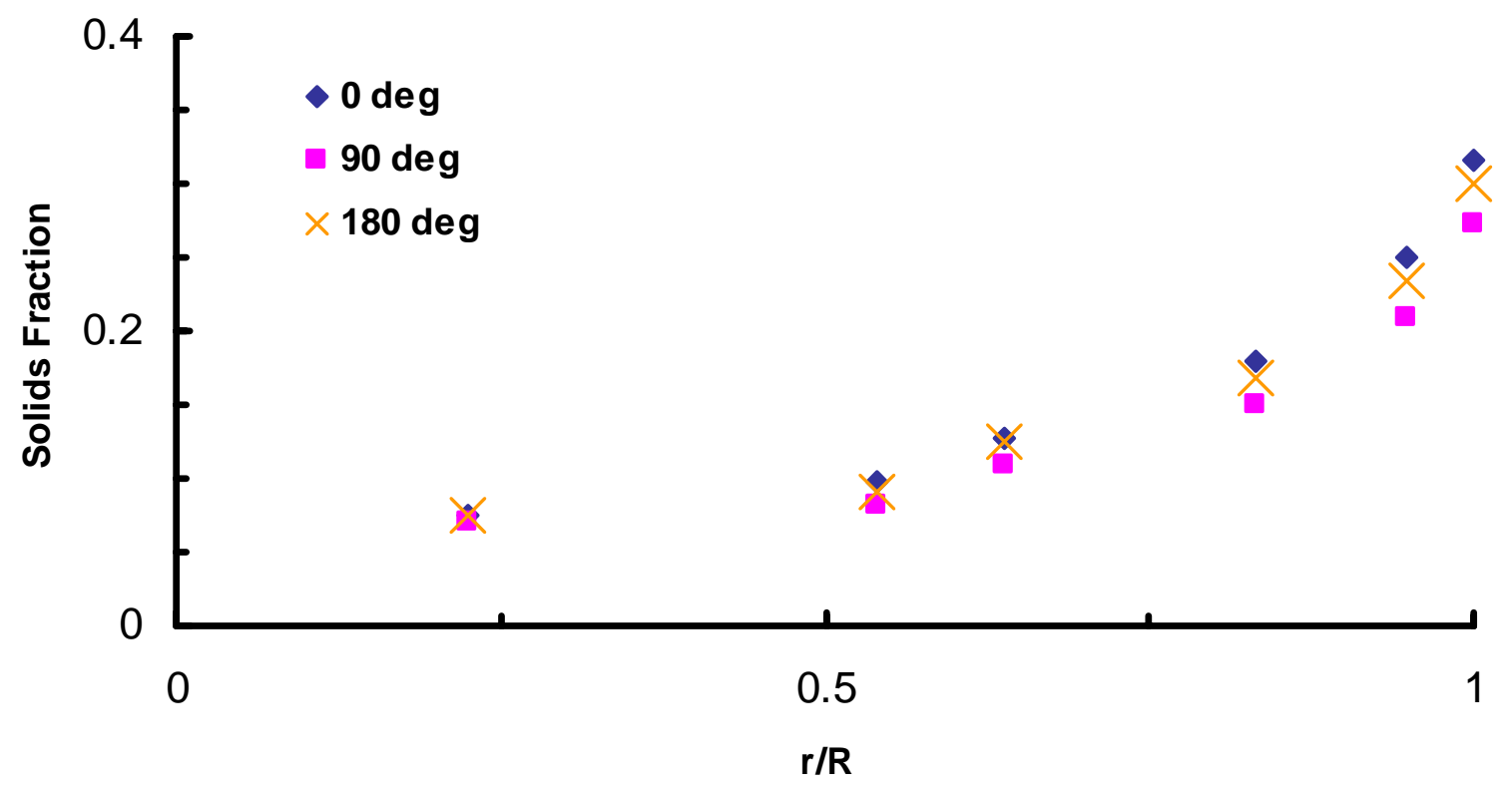

Figure A3. 7 - Ug = $6.4 \mathrm{~m} / \mathrm{s}, \mathrm{Ms}=51,000 \mathrm{~kg} / \mathrm{hr}, 0.7 \mathrm{~m}$ elevation 


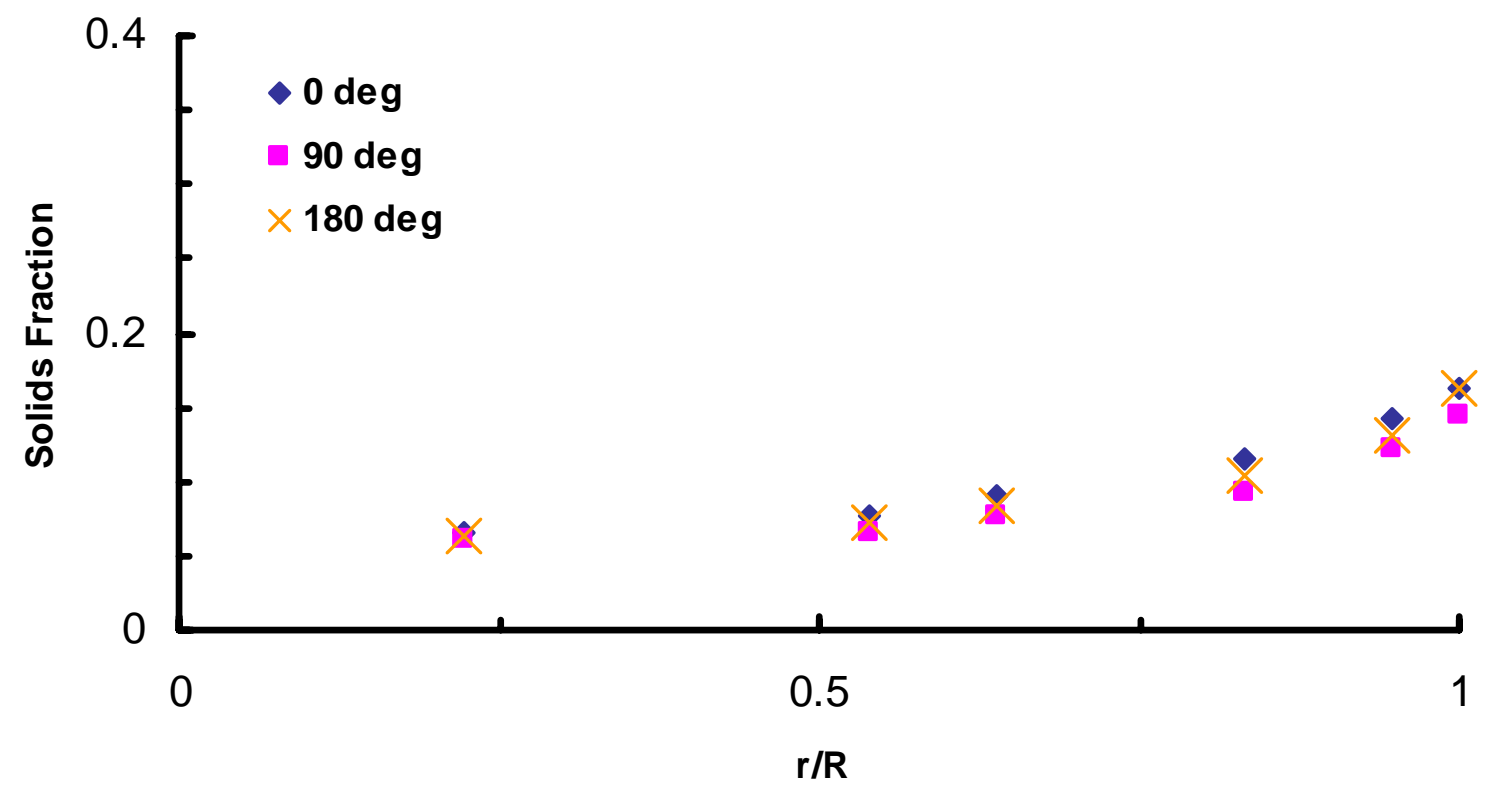

Figure A3. 8 - Ug = $5.5 \mathrm{~m} / \mathrm{s}, \mathrm{Ms}=22,700 \mathrm{~kg} / \mathrm{hr}, 0.7 \mathrm{~m}$ elevation

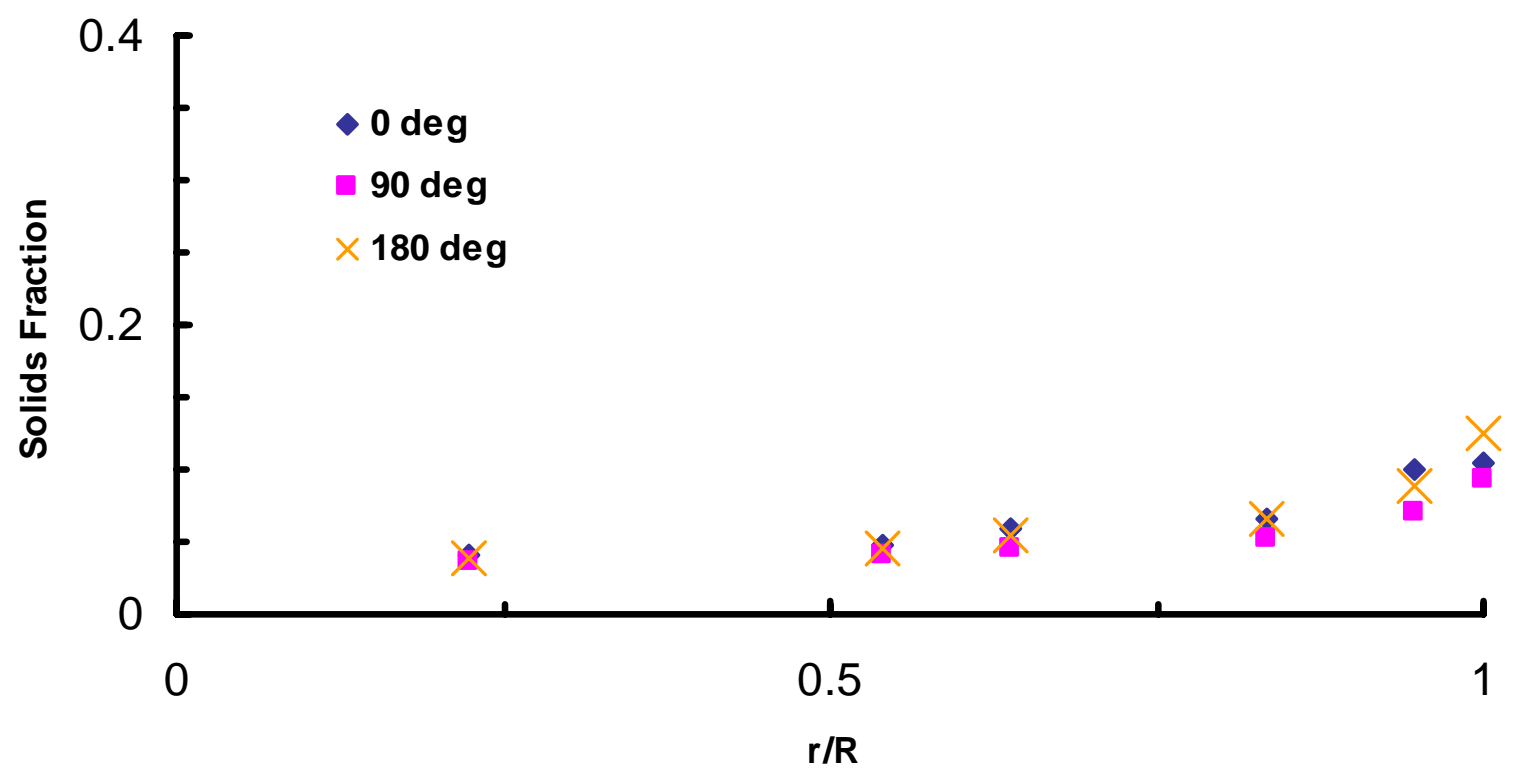

Figure A3. 9 - Ug $=7.6 \mathrm{~m} / \mathrm{s}, \mathrm{Ms}=22,700 \mathrm{~kg} / \mathrm{hr}, 0.7 \mathrm{~m}$ elevation 
The data from the $8.5 \mathrm{~m}$ elevation was taken with the VSI2000 system and are depicted in Figure A3. 10-A3.14. Like the previous set of figures, these are also in order by descending load ratios. The profile is once again remarkably uniform across the cross section of the riser, as shown previously with the ANOVAs performed on the data.

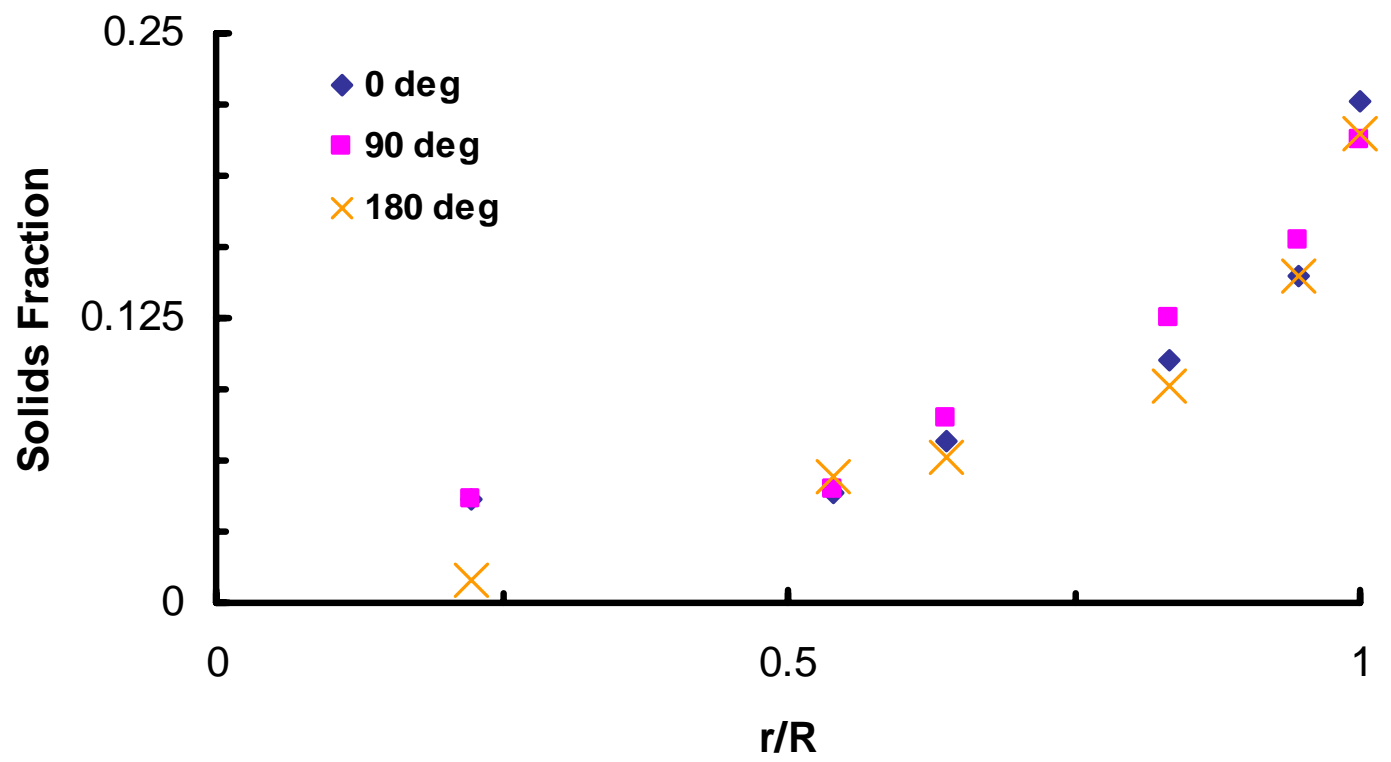

Figure A3. 10 - Ug = $5.5 \mathrm{~m} / \mathrm{s}, \mathrm{Ms}=$ 79,400 kg/hr, $8.5 \mathrm{~m}$ elevation

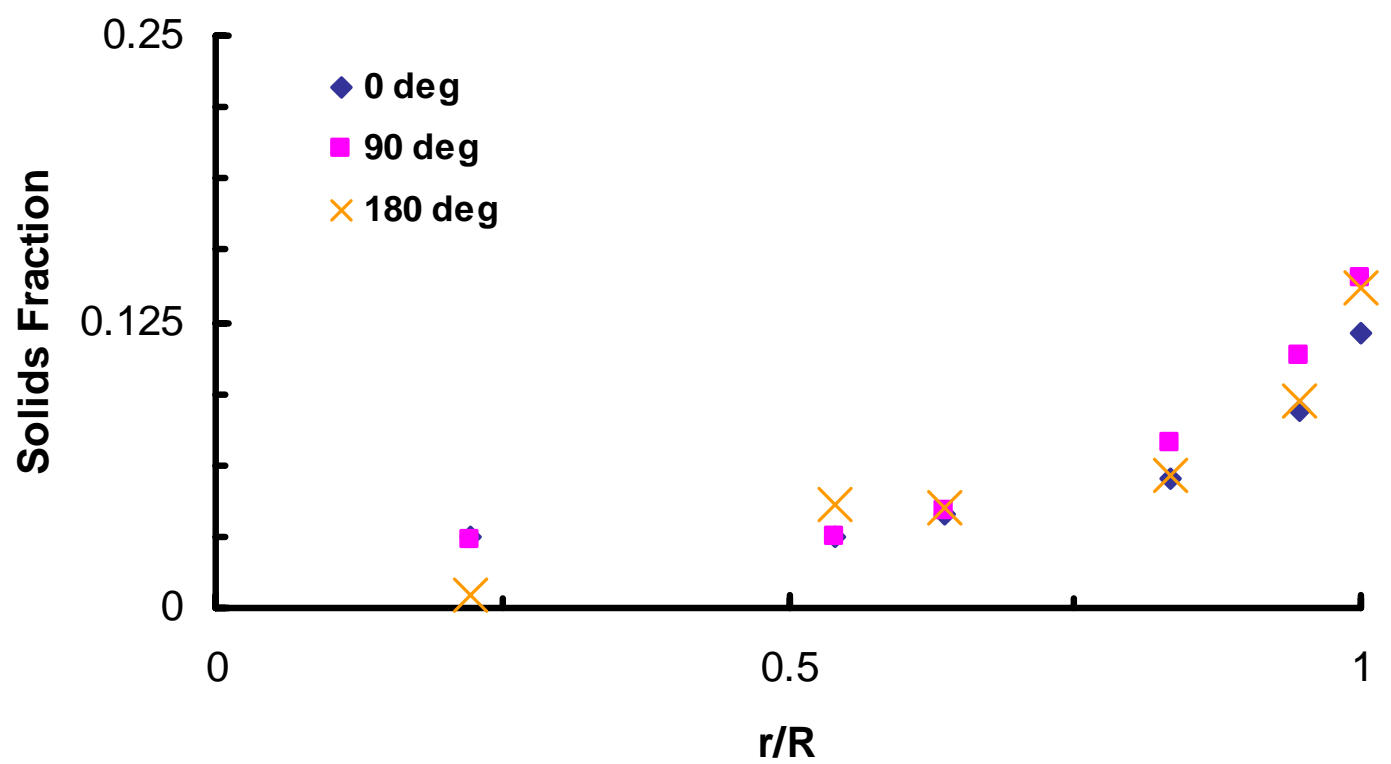

Figure A3. 11 - Ug = 7.6 m/s, Ms = 79,400 kg/hr, $8.5 \mathrm{~m}$ elevation 


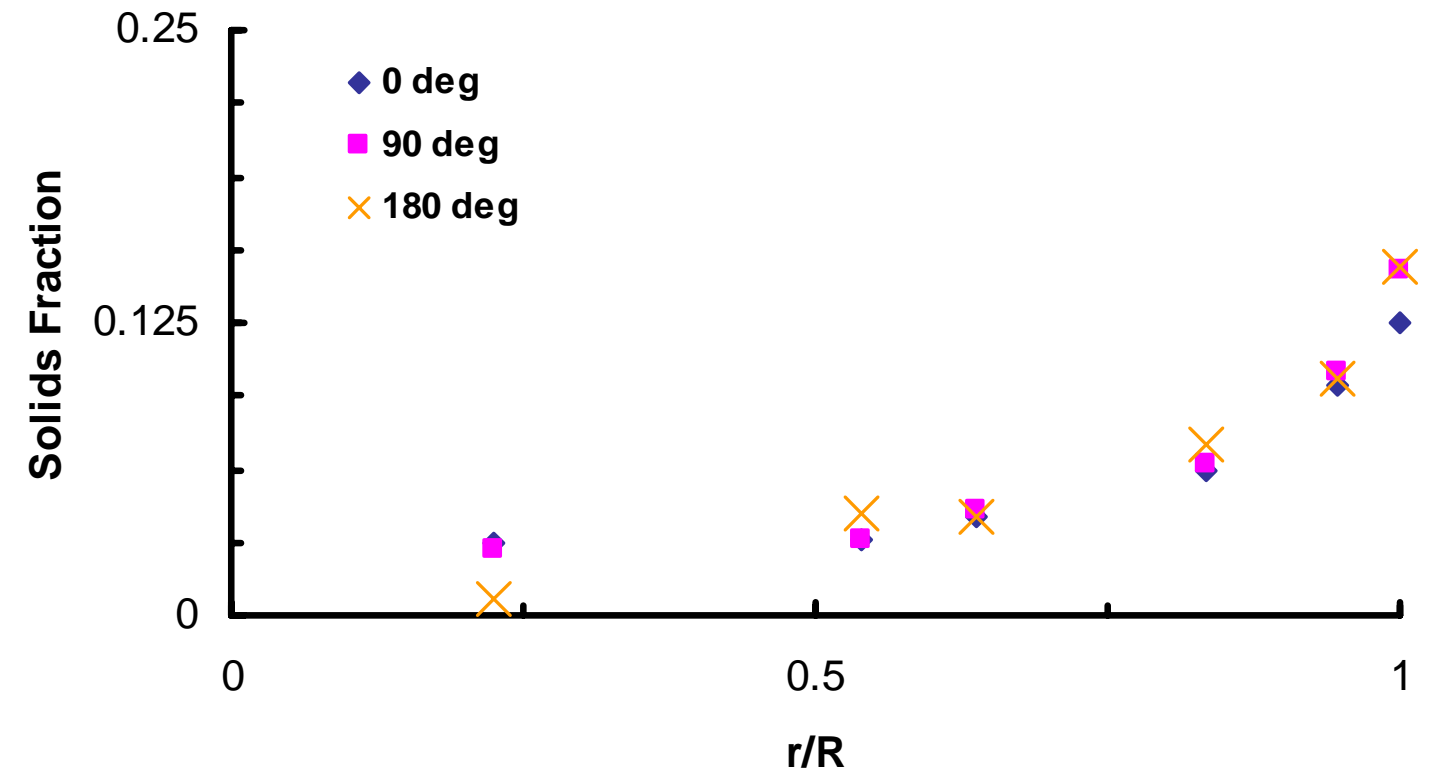

Figure A3. 12 - Ug = $6.4 \mathrm{~m} / \mathrm{s}, \mathrm{Ms}=51,000 \mathrm{~kg} / \mathrm{hr}, 8.5 \mathrm{~m}$ elevation

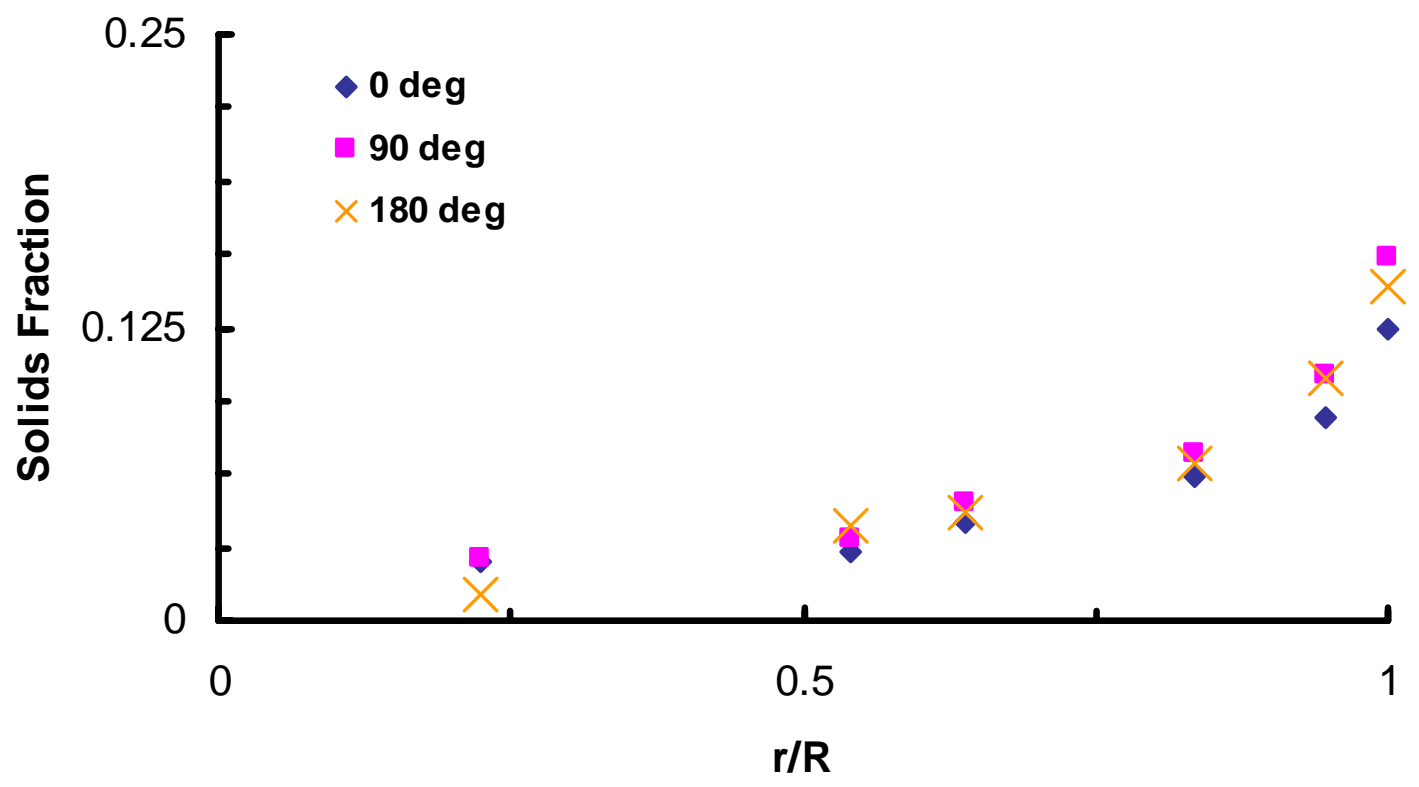

Figure A3. $13-\mathrm{Ug}=5.5 \mathrm{~m} / \mathrm{s}, \mathrm{Ms}=22,700 \mathrm{~kg} / \mathrm{hr}, 8.5 \mathrm{~m}$ elevation 


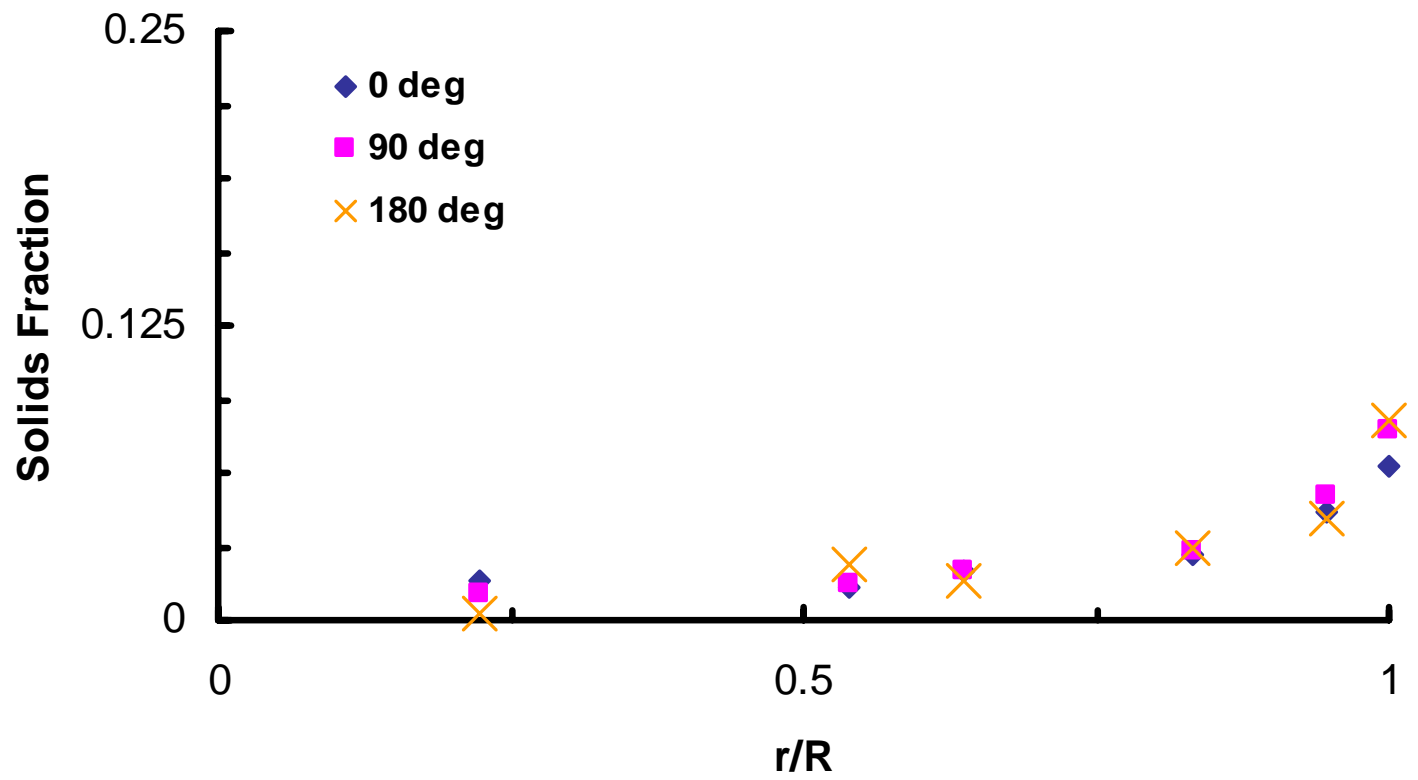

Figure A3. 14 - Ug = 7.6 m/s, Ms = 22,700 kg/hr, $8.5 \mathrm{~m}$ elevation

The data from the $13 \mathrm{~m}$ elevation was taken with the Vector-S system and is shown in Figure A3. 15-A3.19. These profiles are also remarkably similar with the exception of the 135 degree position, which seems to be consistently higher than the others in all tests. 


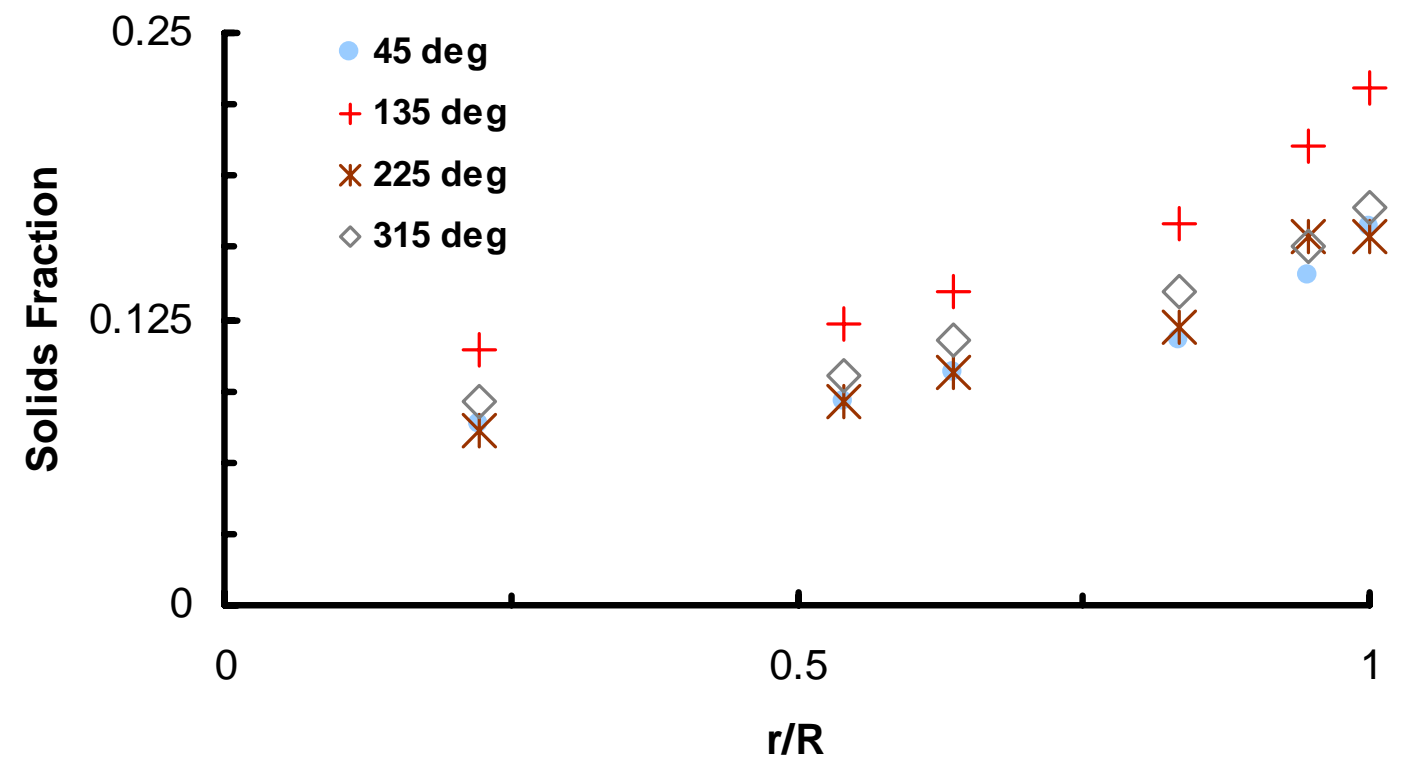

Figure A3. $15-\mathrm{Ug}=5.5 \mathrm{~m} / \mathrm{s}, \mathrm{Ms}=79,400 \mathrm{~kg} / \mathrm{hr}, 13 \mathrm{~m}$ elevation

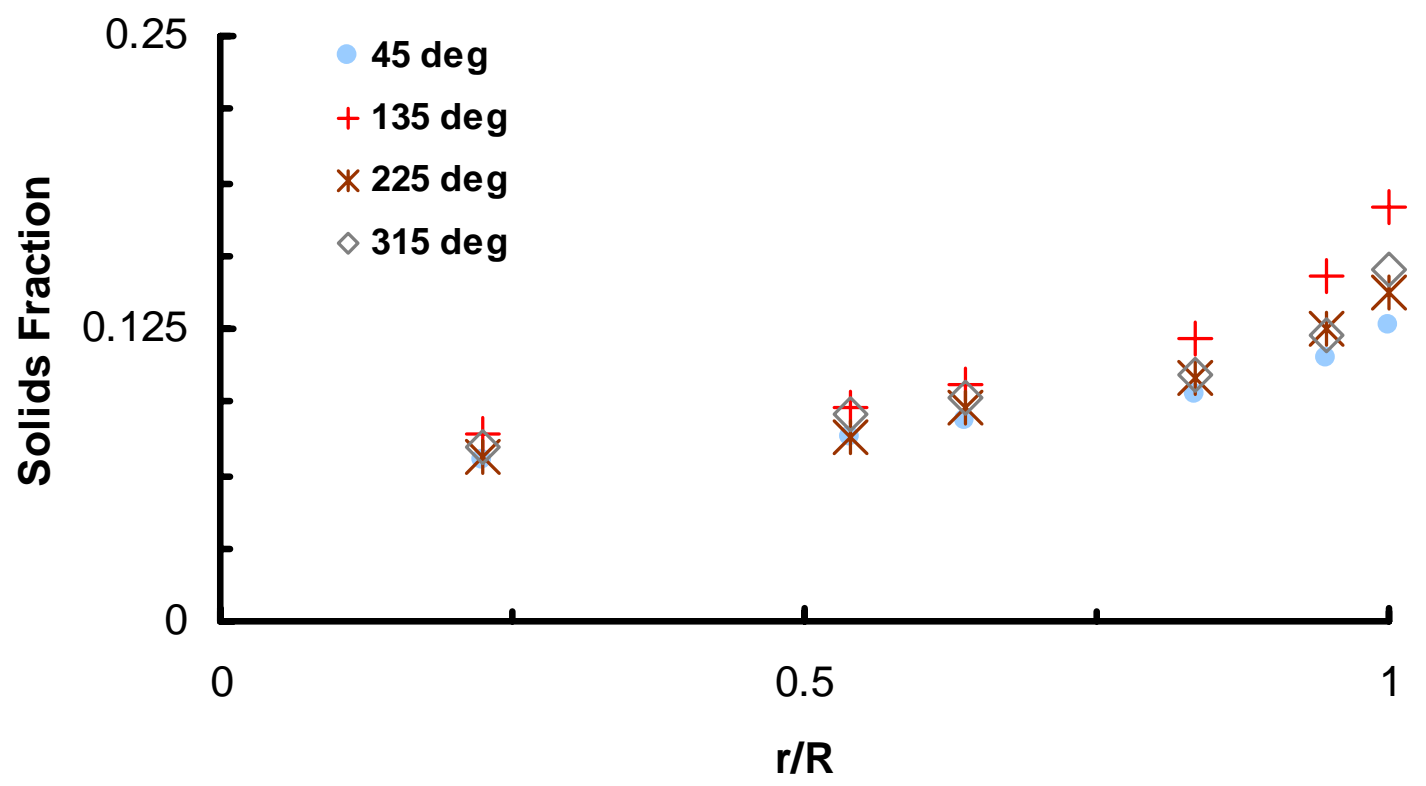

Figure A3. $16-\mathrm{Ug}=7.6 \mathrm{~m} / \mathrm{s}, \mathrm{Ms}=79,400 \mathrm{~kg} / \mathrm{hr}, 13 \mathrm{~m}$ elevation 


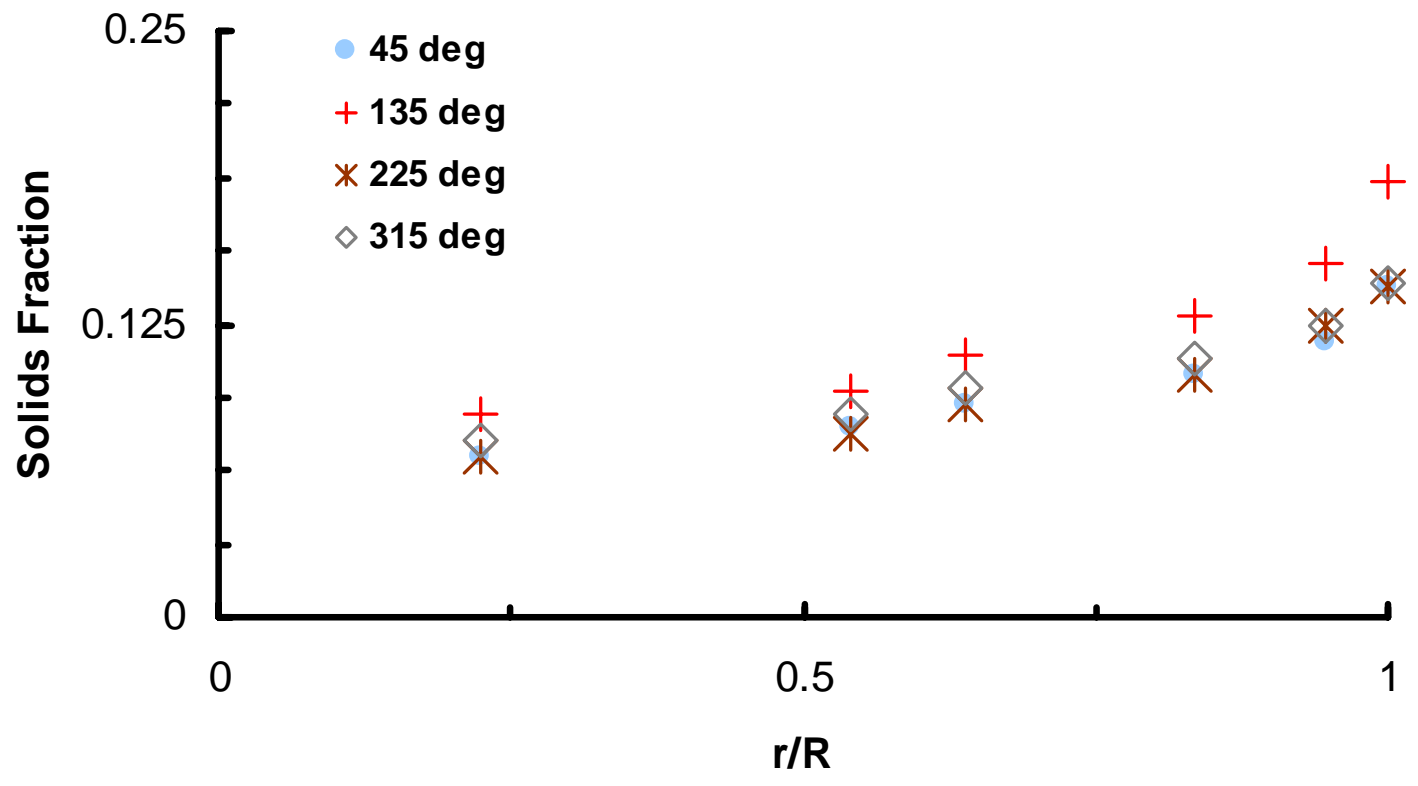

Figure A3. $17-\mathrm{Ug}=6.4 \mathrm{~m} / \mathrm{s}, \mathrm{Ms}=51,000 \mathrm{~kg} / \mathrm{hr}, 13 \mathrm{~m}$ elevation

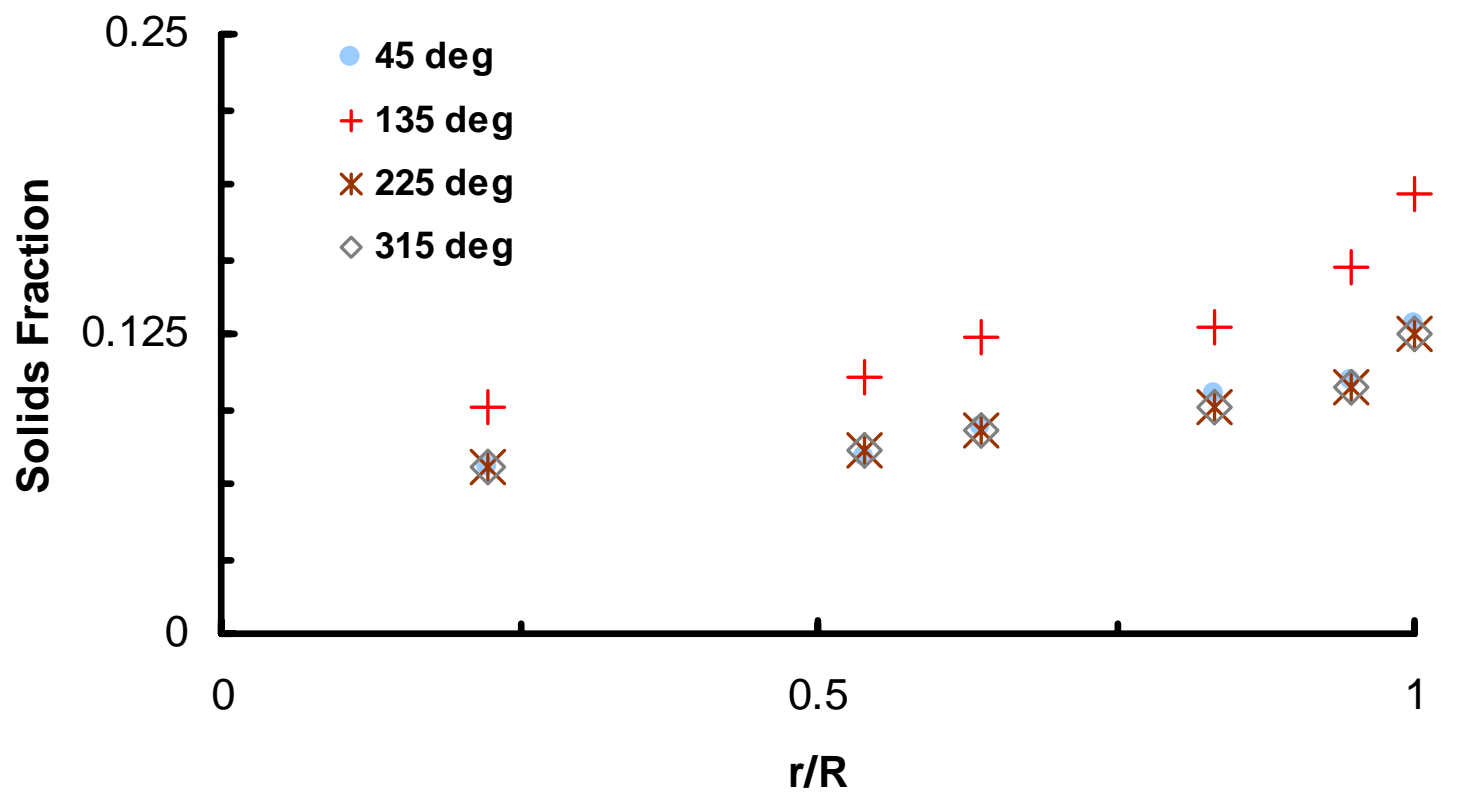

Figure A3. $18-\mathrm{Ug}=7.6 \mathrm{~m} / \mathrm{s}, \mathrm{Ms}=22,700 \mathrm{~kg} / \mathrm{hr}, 13 \mathrm{~m}$ elevation 


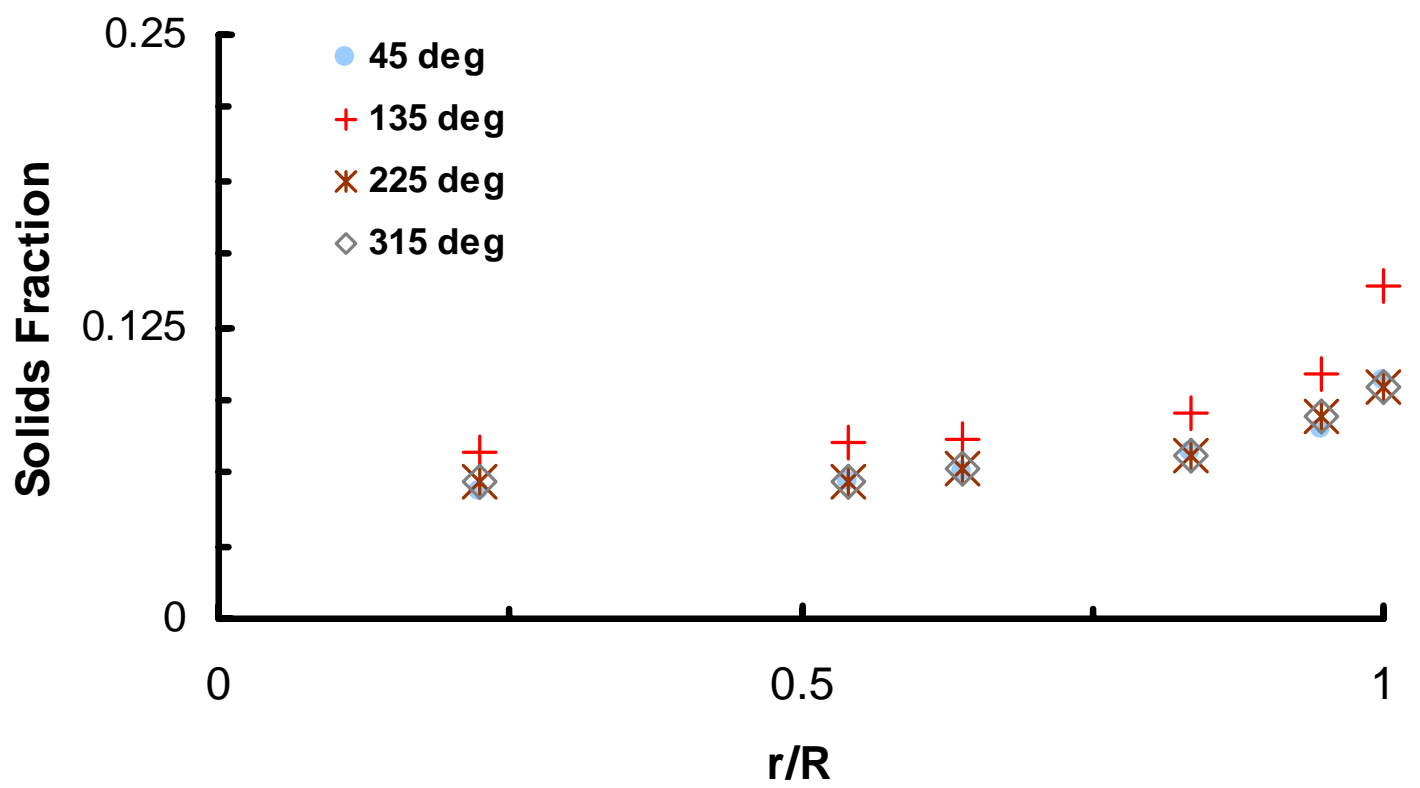

Figure A3. $19-\mathrm{Ug}=7.6 \mathrm{~m} / \mathrm{s}, \mathrm{Ms}=22,700 \mathrm{~kg} / \mathrm{hr}, 13 \mathrm{~m}$ elevation 